2011-03-17

\title{
Strength and Deformation Characteristics of a Cement-Treated Reclaimed Pavement with a Chip Seal
}

Bryan T. Wilson

Brigham Young University - Provo

Follow this and additional works at: https://scholarsarchive.byu.edu/etd

Part of the Civil and Environmental Engineering Commons

\section{BYU ScholarsArchive Citation}

Wilson, Bryan T., "Strength and Deformation Characteristics of a Cement-Treated Reclaimed Pavement with a Chip Seal" (2011). Theses and Dissertations. 2612.

https://scholarsarchive.byu.edu/etd/2612

This Thesis is brought to you for free and open access by BYU ScholarsArchive. It has been accepted for inclusion in Theses and Dissertations by an authorized administrator of BYU ScholarsArchive. For more information, please contact scholarsarchive@byu.edu, ellen_amatangelo@byu.edu. 
Strength and Deformation Characteristics of a Cement-Treated

Reclaimed Pavement with a Chip Seal

Bryan T. Wilson

A thesis submitted to the faculty of

Brigham Young University

in partial fulfillment of the requirements for the degree of

Master of Science

W. Spencer Guthrie, Chair

Mitsuru Saito

Grant G. Schultz

Department of Civil and Environmental Engineering

Brigham Young University

April 2011

Copyright (c) 2011 Bryan T. Wilson

All Rights Reserved 



\begin{abstract}
Strength and Deformation Characteristics of a Cement-Treated

Reclaimed Pavement with a Chip Seal
\end{abstract}

\author{
Bryan T. Wilson \\ Department of Civil and Environmental Engineering \\ Master of Science
}

The objective of this research was to analyze the strength and deformation characteristics of a cement-treated base (CTB) constructed using full-depth reclamation, microcracked, and then surfaced with a single chip seal. In this field study, strength characteristics of the CTB layer were determined at the time of construction, and then both strength and deformation characteristics were evaluated after 9 months of low-volume, heavy truck traffic. After 9 months, observed distresses included transverse cracking, rutting, and chip seal joint failure. The loss of the chip seal was caused by poor chip seal construction practices and not a deficiency in the CTB layer. The importance of the role of the chip seal as a wearing course was made evident by these failures since the exposed CTB often exhibited material loss. The average ride qualities in and out of the wheel path were in the fair ride category; the roughness was not likely caused by trafficking but probably resulted from construction or climatic factors. Structural testing performed after 9 months of service indicated that the CTB stiffness and modulus were greater than the values measured after microcracking at the time of construction, indicating continued strength gain. However, trafficking over the 9-month period had caused significantly lower stiffnesses measured in the wheel paths than between the wheel paths. The average unconfined compressive strength (UCS) of the cores tested at 9 months was not significantly different than the average UCS of the field-compacted specimens tested at 6 weeks. Based on the observed performance of the CTB and chip seal evaluated in this research, recommendations for improved CTB performance include the use of a thicker and/or stiffer CTB layer, ensuring a smooth CTB surface during construction, and application of a double chip seal or equivalent.

Key words: cement stabilization, cement-treated base, chip seal, distress, full-depth reclamation, microcracking, modulus, stiffness, roughness, rutting 



\section{ACKNOWLEDGMENTS}

This research was supported by JFC Engineers and Surveyors and Oftedal Construction, Inc. Brigham Young University (BYU) students Mark Butler, Jeremy Dye, and Maile Rogers and BYU laboratory manager David Anderson assisted with field testing. I appreciate Dr. Grant G. Schultz and Dr. Mitsuru Saito for participating on my graduate advisory committee. I thank Dr. W. Spencer Guthrie, my mentor and friend, for his selfless dedication to my learning and personal development. His attention to detail and persistent goal of excellence has elevated the quality of this research. Most importantly, I thank my wife, Aisling, for her untiring love and support throughout my degree. All my hard work and accomplishments are for her and my son Carter. 



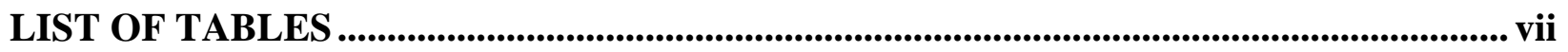

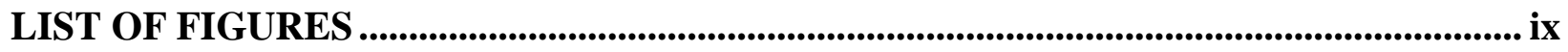

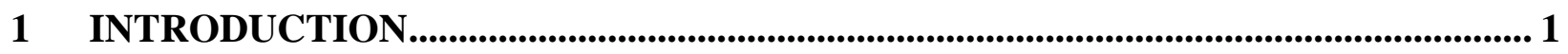

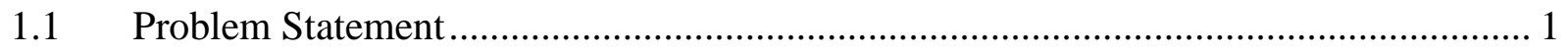

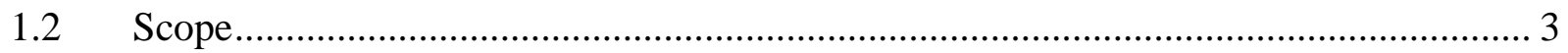

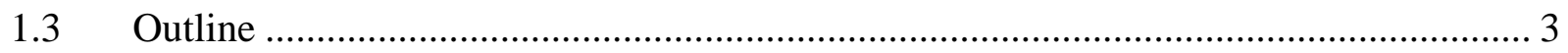

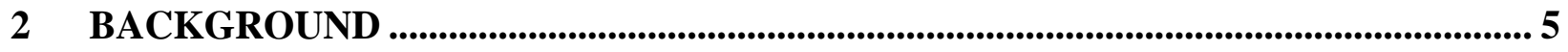

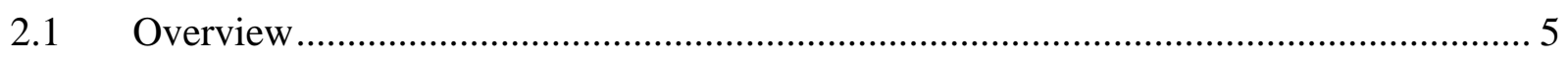

2.2 Performance Characteristics of Reclaimed Base Materials ...................................... 5

2.3 Failure Mechanisms of Cement-Treated Base Layers .......................................... 6

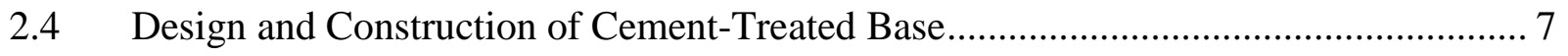

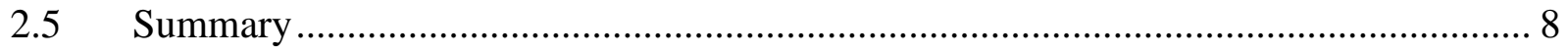

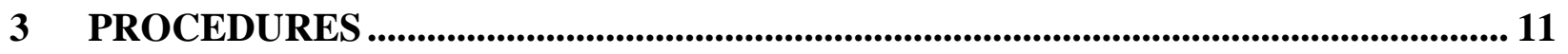

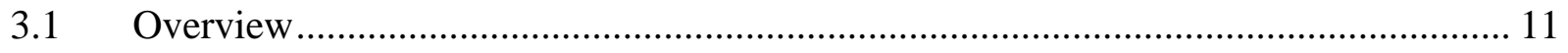

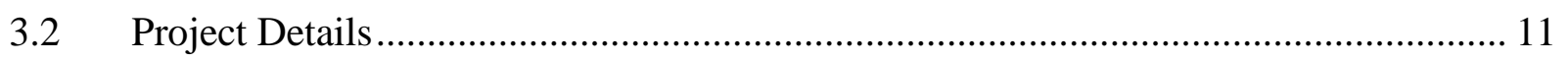

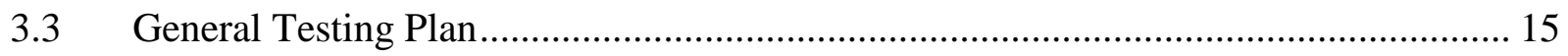

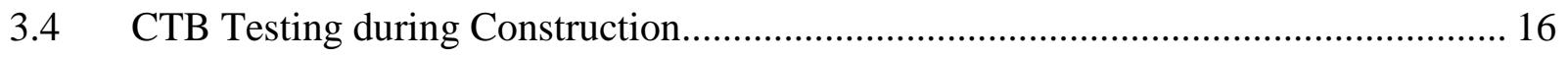

3.5 CTB Testing after 9 Months of Service .......................................................... 19

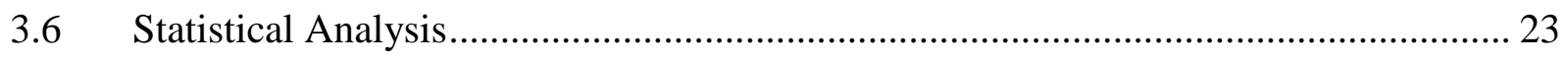

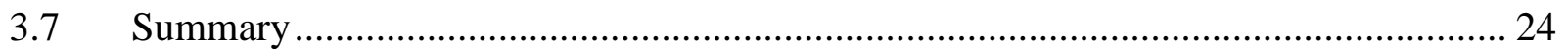

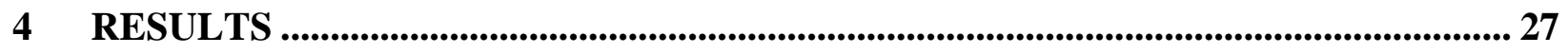




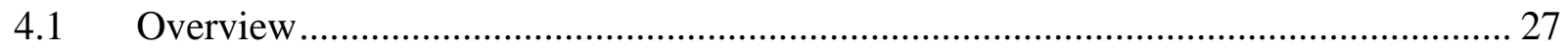

4.2 CTB Performance during Construction ........................................................... 27

4.3 CTB Performance after 9 Months of Service ................................................... 29

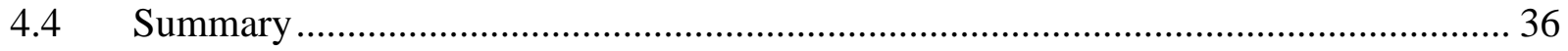

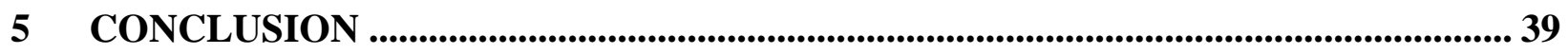

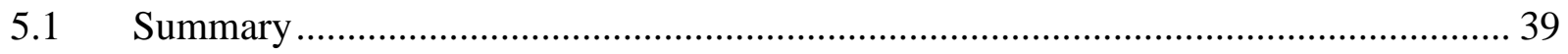

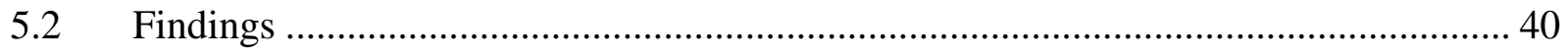

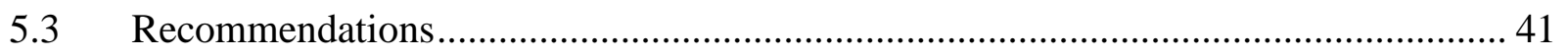

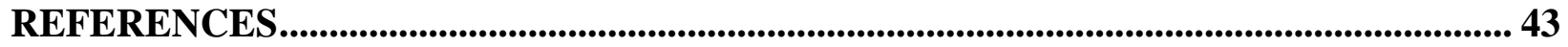

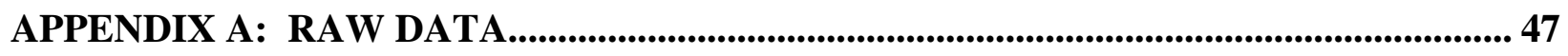

APPENDIX B: DISTRESS SURVEYS ................................................................................ 57 


\section{LIST OF TABLES}

Table 4.1 Summary of 3-Day CTB Stiffness (SSG) and Modulus (PFWD) ............................. 29

Table 4.2 Summary of UCS of Field-Compacted CTB Specimens.......................................... 29

Table 4.3 Nine-Month Distress Summary .................................................................... 30 


\section{LIST OF FIGURES}

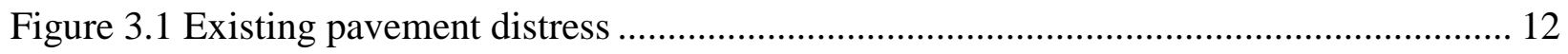

Figure 3.2 Distribution of the cement with a cement spreader truck..................................... 13

Figure 3.3 In-situ mixing of the base, RAP, and cement with a reclaimer .............................. 13

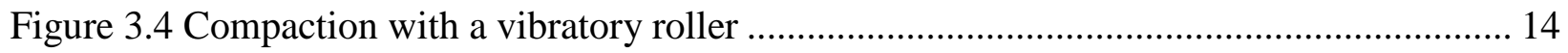

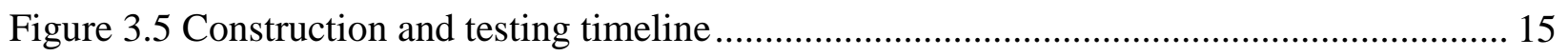

Figure 3.6 Section layout for testing during construction................................................... 16

Figure 3.7 Example station layout for testing during construction....................................... 17

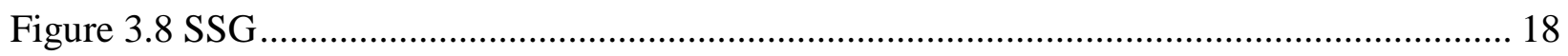

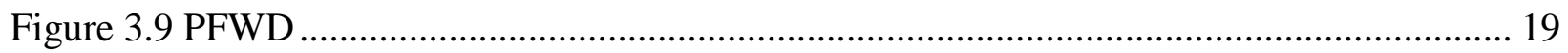

Figure 3.10 Station layout for testing after 9 months of service......................................... 20

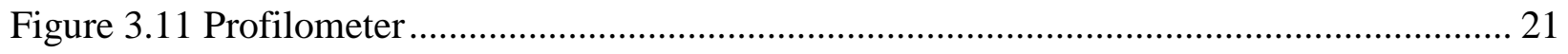

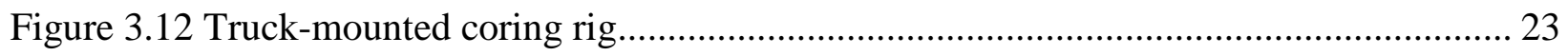

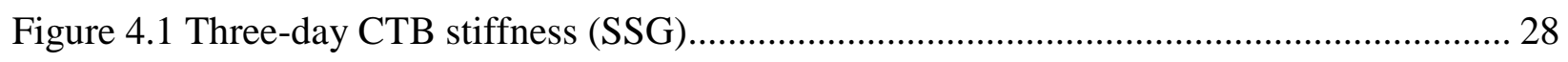

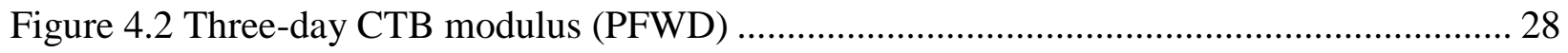

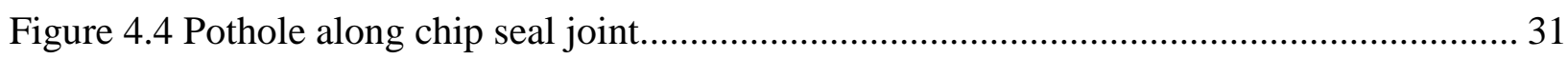

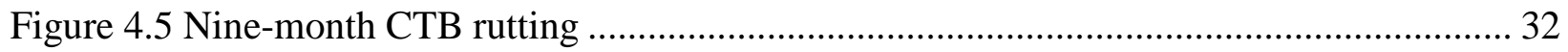

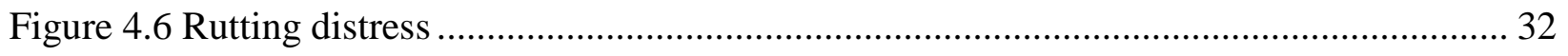

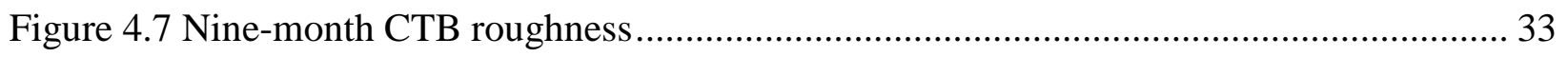

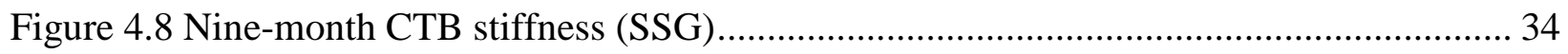

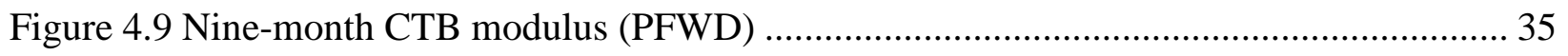

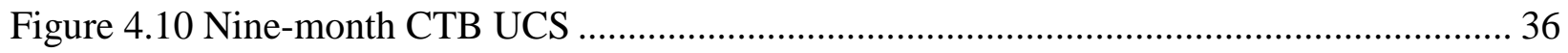




\section{INTRODUCTION}

\subsection{Problem Statement}

Because of rising construction costs and environmental pressures, full-depth reclamation (FDR) with cement stabilization is becoming a more common practice for flexible pavement rehabilitation (1). FDR is the in-situ pulverization and mixing of the asphalt layer and a portion of the underlying base or subgrade followed by compaction to produce a new road base. When the in-situ aggregates exhibit poor strength and durability, stabilization should be implemented. Research and experience have shown that, with a small addition of portland cement, many inferior aggregates can be used to construct a strong, durable pavement layer called cementtreated base (CTB) (2). FDR with cement stabilization has many economic benefits since the existing materials can be reused and the costs of aggregate transportation and disposal are minimized. This practice is also environmentally friendly because it uses materials that may otherwise be discarded.

Following CTB construction, the base is frequently surfaced by hot-mix asphalt (HMA) to protect the base from direct traffic loads and water ingress. Since the asphalt layer is expensive, agencies sometimes choose to place a low-cost chip seal instead. A standard chip seal consists of a thin emulsion layer covered with a one-stone-thick layer of uniformly graded gravel. The application can be repeated with smaller gravel to create a double chip seal. The emulsion keeps moisture out of the base and holds the gravel in place, and the gravel provides 
skid resistance and protects the emulsion. Since the structural benefits of a chip seal are negligible, all traffic loads would be effectively carried by the underlying layers in this case.

Pavements consisting of CTB as the primary structural layer, though common to some locations, have been the focus of only a limited number of studies. Field and laboratory studies from South Africa and Texas have addressed the performance of CTB layers surfaced with a double chip seal or thin asphalt overlay, usually 1.0 to 1.5 in. thick.

One study in South Africa analyzed the effects of simulated traffic loading on rehabilitated CTB pavements with a double chip seal (3). Pavement performance was evaluated using measurements of backcalculated elastic modulus, surface crack length, and permanent deformation. Another study conducted in South Africa addressed the failure mechanisms of deep and shallow CTB pavements with thin asphalt surfaces under simulated traffic loading (4). Failure was assessed primarily by the measurement of permanent deformation at variable depths. While both of these studies examined CTB as the primary structural layer, neither considered CTB constructed through the FDR process. A base created through FDR, which incorporates reclaimed asphalt pavement (RAP), can have different structural properties than standard CTB $(1,5)$. In addition, the traffic loading in both of these studies was simulated, which may not be representative of service conditions, and the results are applicable only to climates and materials similar to those found in South Africa.

Unlike the research performed in South Africa, the studies conducted in Texas were focused on cementitious stabilization in conjunction with $\operatorname{FDR}(6,7,8)$. A total of 57 FDR projects were evaluated in six districts within the Texas Department of Transportation, with experimental factors including different base materials, subgrades, stabilizers, stabilizer concentrations, surfacing treatments, construction practices, and traffic and climate conditions. 
Of these projects, 39 were cementitiously stabilized bases with a thin surface treatment, most commonly a double chip seal; however, only two were stabilized specifically with portland cement. The other 37 projects incorporated lime, fly ash, lime-fly ash, or cement-fly ash. Pavement performance was evaluated using measurements of backcalculated elastic modulus and visual distress. Pavements that performed well were on non-plastic and low-plasticity subgrades, had low traffic volumes, were not overly stabilized, and had well-sealed surfaces. These studies support the concept of using a stabilized base as the primary structural layer; however, the results are applicable only to climates and materials similar to those found in Texas.

\subsection{Scope}

Based on the lack of information on this topic in the literature, the objective of this research was to analyze the performance of CTB as the primary structural layer of a pavement constructed through the FDR process and subjected to low-volume truck traffic in an extreme freeze-thaw climate. Performance was evaluated in terms of both strength and deformation characteristics at the time of construction and at 9 months. The results of this research address the viability of recommending such a pavement for construction, which would be a low-cost alternative to standard flexible pavements.

\subsection{Outline}

This report contains five chapters. Chapter 1 describes the problem statement and scope, while Chapter 2 provides background information on FDR and CTB layers. Chapter 3 describes the research site and details the procedures followed for this research. Chapter 4 presents the results of the study, and, finally, Chapter 5 summarizes the research, presents the conclusions, and offers recommendations. 


\section{BACKGROUND}

\subsection{Overview}

This chapter provides the results of a literature review on the performance characteristics of reclaimed pavements, failure mechanisms of CTB layers, and CTB design and construction considerations.

\subsection{Performance Characteristics of Reclaimed Base Materials}

Although the FDR process has several economic and environmental benefits over new construction, reclaimed pavement base layers may have inferior material properties. Base materials constructed through the FDR process may have lower strengths and densities and greater spatial variability.

Reclaimed base layers are often weaker than layers constructed with virgin materials in large part due to the presence of RAP. Because of this undesirable trend, cement stabilization is frequently applied to improve the structural properties of the in-situ RAP-base material. Average RAP contents generally range between 30 and 70 percent by weight of the total reclaimed material, depending on the thickness of the HMA and depth of pulverization (9). As RAP contents increase, the compressive strength $(1,5,10)$, modulus $(10)$, and tensile strength $(10)$ of the reclaimed material generally decrease. These decreases may be attributable to reduced interparticle friction and reduced bond strength between the cement paste and the aggregate surfaces 
caused by the presence of the asphalt coating on RAP particles (1). The trend of decreasing strength with RAP content might also be partially attributed to decreased density; the maximum dry density of RAP-base blends also decreases as RAP content increases $(1,5,10)$.

Spatial variability in material properties is greater in reclaimed pavement layers than in newly constructed layers due primarily to variability in the properties of the in-situ materials. If the in-situ layer thicknesses, gradations, and moisture contents are variable, which is often the case, the resulting reclaimed layer properties will also vary $(6,9,11)$. Spatial variability can also occur due to non-uniformity in the spreading and mixing of the cement $(9,11)$. For these reasons, FDR projects may require special design and construction considerations to achieve adequate CTB performance.

\subsection{Failure Mechanisms of Cement-Treated Base Layers}

During active cement hydration in the days following compaction, CTB layers are prone to transverse shrinkage cracking, which is often later manifest as reflective cracking in the wearing course. These cracks are initially a cosmetic problem but, if wide enough, may allow water to infiltrate and weaken the pavement. Autogenous shrinkage occurs in the CTB due to self-desiccation during cement hydration, and drying shrinkage occurs as a result of water evaporation into the surrounding environment. High-severity shrinkage has been linked to many factors, including high fines content $(12,13)$, poor compaction $(12,13)$, excessive compaction moisture (12), inadequate moist curing (14), and high cement content $(12,14,15,16)$. Depending on the shrinkage severity and layer tensile strength, shrinkage cracks may be spaced between 3 and $60 \mathrm{ft}$ apart (17).

After cement hydration is substantially complete and the layer is in service, the governing CTB failure mechanisms are dependent on the layer stiffness. Bases with a higher cement 
content, and therefore higher stiffness, behave as rigid systems, capable of bearing traffic loads and evenly distributing these loads to the subgrade. The primary failure in these cases is the widening of shrinkage cracks due to thermal cycling and load-induced degradation around these cracks (16). Load-induced fatigue cracking may also occur if the layer is too thin $(3,16)$. As the cement content and stiffness decrease, the base begins to behave more as a flexible system. Though transverse and fatigue cracking are still a concern, other failure types begin to govern performance. Rutting may occur if the CTB does not adequately protect the subgrade from traffic loads or if internal shear failures occur in the CTB. Crushing of the upper CTB surface can also occur in pavements in which a CTB is the primary structural layer $(3,4)$.

Once the CTB is significantly distressed, further deterioration associated with water infiltration can occur. Under trafficking, fines can be pumped out of the layer, leaving only coarser aggregate in the base. The removal of fines results in decreased aggregate interlock, causing poor load transfer and additional structural deterioration $(3,12)$. The end result of CTB failure is increased pavement roughness and unacceptable ride quality.

\subsection{Design and Construction of Cement-Treated Base}

Proper design of CTB is a balance between achieving suitable strength and durability and minimizing the risks of shrinkage cracking. In the past, the mindset "stronger is better" often governed design, so cement contents around 6 to 8 percent were frequently used $(14,17,18)$. However, as previously discussed, these high cement contents can lead to excessive shrinkage cracking and poor pavement performance. Many researchers therefore recommend limiting the cement content or design strength to minimize shrinkage $(12,14,17,19)$. To achieve a balance of strength and durability, the Portland Cement Association (PCA) recommends a moderatelystabilized CTB with a cement content yielding a 7-day unconfined compressive strength (UCS) 
between 300 and $400 \mathrm{psi}$ (20). Some agencies have introduced additional testing procedures in the design process to further ensure that the resulting CTB is shrinkage resistant, durable, nonmoisture-susceptible, and non-frost-susceptible (19). These practices generally yield cement contents between 2 and 5 percent for base stabilization.

Once a design has been selected, adherence to sound construction practices can further reduce risks of shrinkage cracking. These practices include adequate compaction, adequate moist curing, and an emerging practice called microcracking. In microcracking, a vibratory roller is used to create a network of fine cracks in the CTB after 2 or 3 days of curing. Introducing these cracks relieves most of the early shrinkage stress, and subsequent shrinkage is then distributed over many smaller cracks instead of being concentrated at a few larger cracks. In addition, the cement will continue to hydrate and "heal" the hairline cracks, restoring the CTB stiffness to near or above the pre-microcracked state within a few days. Researchers have found microcracking to be an effective means of reducing reflective cracking without compromising the integrity of the CTB $(12,14,15,21)$. Other proposed construction techniques to reduce reflective cracking include jointing of the CTB (21), delayed HMA surfacing $(12,15)$, and installation of a stress-relieving interlayer between the CTB and the HMA (12).

\subsection{Summary}

Base layers constructed through the FDR process may have lower strengths and densities and greater spatial variability than newly constructed layers. These trends are primarily due to the presence of RAP and variability in the properties of the in-situ materials. For these reasons, FDR projects are frequently performed in conjunction with cement stabilization and may require special design and construction considerations to achieve adequate performance. 
During active cement hydration in the days following compaction, CTB layers are prone to transverse shrinkage cracking. After cement hydration is substantially complete and the layer is in service, the governing CTB failure mechanisms are dependent on the layer stiffness. The primary failure mechanisms in CTB with high stiffness are the widening of shrinkage cracks, degradation around these cracks, and fatigue cracking if the layer is too thin. For CTB with low stiffness, the primary failure mechanisms are rutting and, when CTB is the primary structural layer, crushing of the upper CTB surface. Once the CTB is significantly distressed, fines can be pumped out of the layer, resulting in decreased aggregate interlock and overall structural deterioration.

Proper design of CTB is a balance between achieving suitable strength and durability and minimizing the risks of shrinkage cracking. PCA recommends a moderately-stabilized CTB with a cement content yielding a 7-day UCS between 300 and 400 psi. Once a design has been selected, adherence to sound construction practices, such as microcracking, can further reduce risks of shrinkage cracking. 


\section{PROCEDURES}

\subsection{Overview}

The following sections provide project details, describe the general testing plan, detail CTB testing during construction and after 9 months of service, and explain the statistical analysis applied to the data collected in this research.

\subsection{Project Details}

The subject of this research is a coal mine access road in Wyoming. The traffic on the access road is low-volume with a moderate percentage of heavy trucks. The heavy traffic generally consists of fuel and equipment-delivery trucks. Average annual daily traffic was estimated at 100 vehicles, with 19 percent trucks. This area of Wyoming receives an average of 8.4 in. of precipitation per year and experiences an average of 135 freeze-thaw cycles per year (22). The 20-year air-freezing index, a measure of the severity and duration of freezing, is about $1,530^{\circ} \mathrm{F}$-days (23).

Through previous field and laboratory testing performed by Brigham Young University researchers, thicknesses and soil classifications of the existing pavement layers were determined. The existing asphalt and base were 10.5 and 10.8 in. thick, respectively. The American Association of State Highway and Transportation Officials (AASHTO) classifications for the base and subgrade were determined to be A-2-4 (0) and A-7-6 (29), respectively. The 
corresponding classifications in the Unified Soil Classification System (USCS) were determined to be silty sand with gravel (SM) and fat clay (CH).

Due to the development of high-severity transverse and fatigue cracking and excessive roughness, the original pavement, depicted in Figure 3.1,was reconstructed in August 2009. Because of the low quality of existing pavement materials and the economic benefits inherent in the process, FDR in conjunction with cement stabilization was implemented. The pavement design specified a 9-in.-thick CTB with 4.0 percent Type II cement and a RAP-base ratio of 50:50 by weight. Therefore, the upper 6 in. of HMA was removed by milling, and the remaining approximately $4.5 \mathrm{in}$. of asphalt and an equal depth of base were then pulverized together with a reclaimer. The required cement, in powder form, was then spread with a distributor truck and mixed with the base material through another pass of the reclaimer as shown in Figures 3.2 and 3.3, respectively. Water was introduced in the pulverizing chamber to bring the material to the optimum moisture content of 9.0 percent. Immediately following mixing, the treated

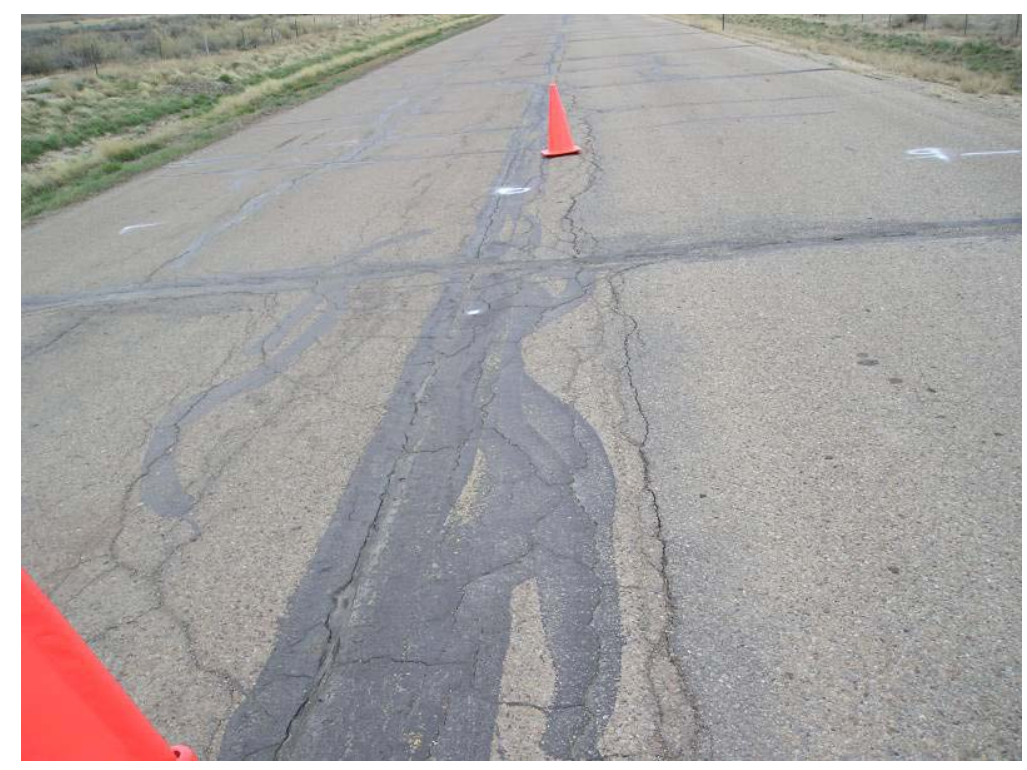

Figure 3.1 Existing pavement distress. 


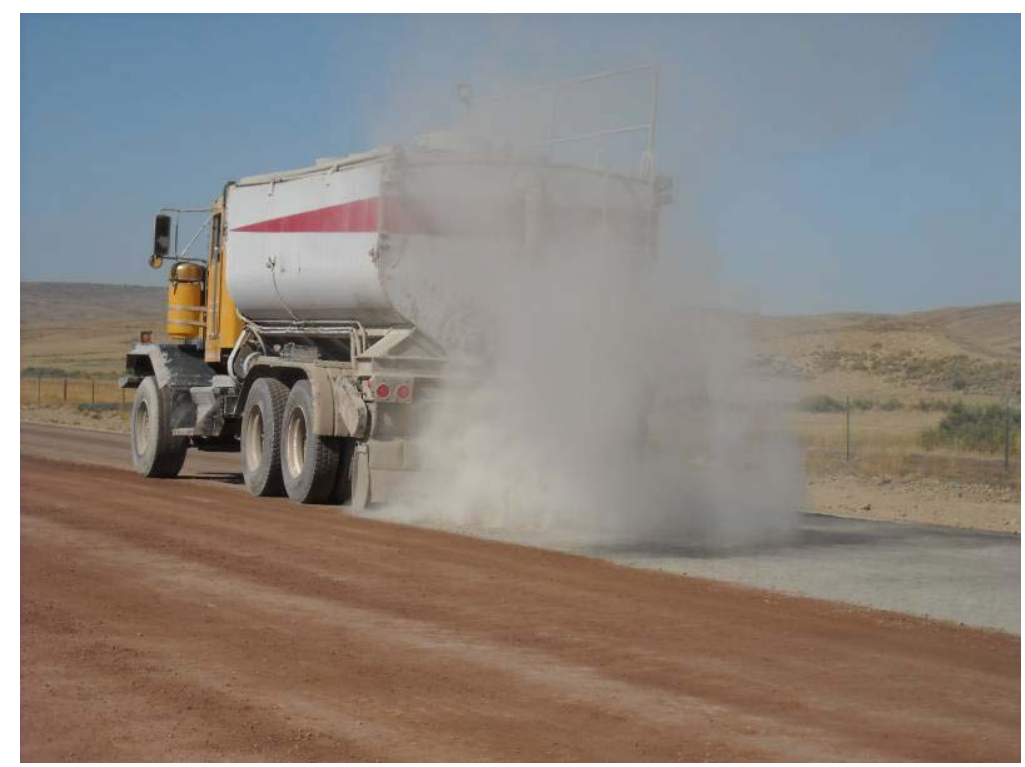

Figure 3.2 Distribution of the cement with a cement spreader truck.

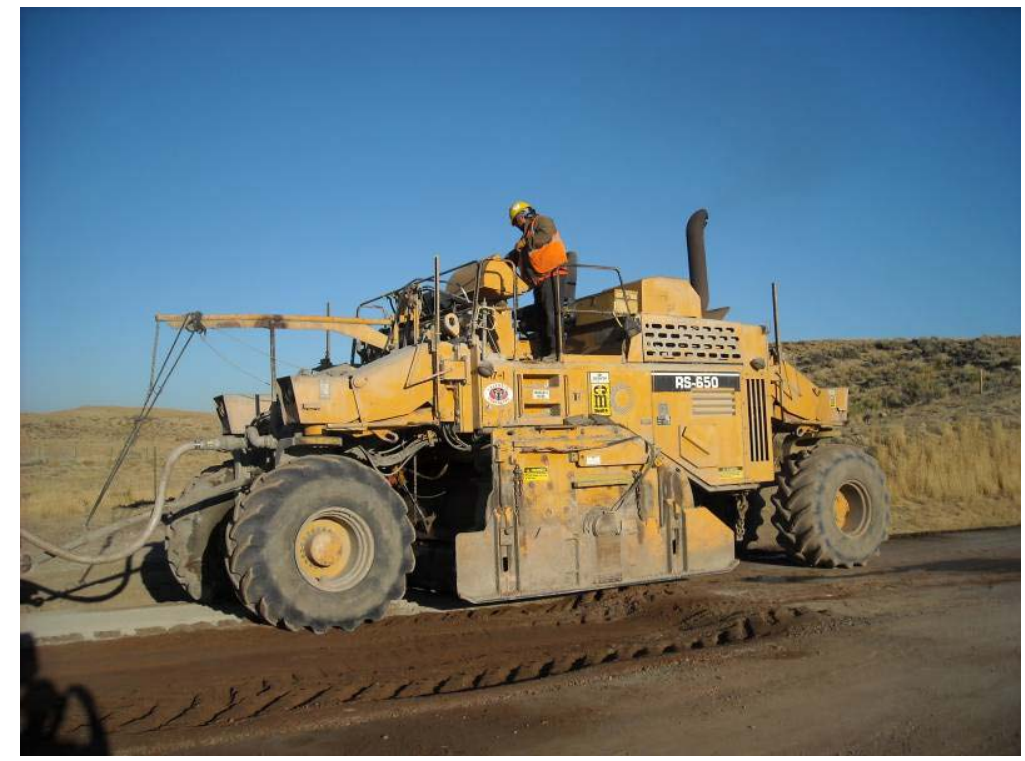

Figure 3.3 In-situ mixing of the base, RAP, and cement with a reclaimer. 
material was compacted to a minimum relative density of 95 percent of the maximum dry density of $118.6 \mathrm{lb} / \mathrm{ft}^{3}$ with a single-drum, 12-ton vibratory roller as depicted in Figure 3.4. After three days of moist curing, the CTB was microcracked with the same vibratory roller used for compaction. A stiffness reduction in the CTB between 30 and 40 percent was desired for this project, which corresponded to a measured reduction between 20 and 30 percent for the composite pavement structure including the CTB and subgrade. While a normal strength reduction of 40 to 60 percent is recommended, heavy truck trafficking over the CTB and the likelihood of an insufficiently thick wearing course justified use of a lower strength reduction range. The rolling pattern applied to most of the project consisted of two passes over the fullwidth of the CTB, followed by one pass along each wheel path. For reference, one pass is defined as down, not down and back.

The original pavement design required 4.0 in. of HMA, but, due to budget restrictions, placement of an HMA surfacing was postponed for a projected period of 1 year, and a single

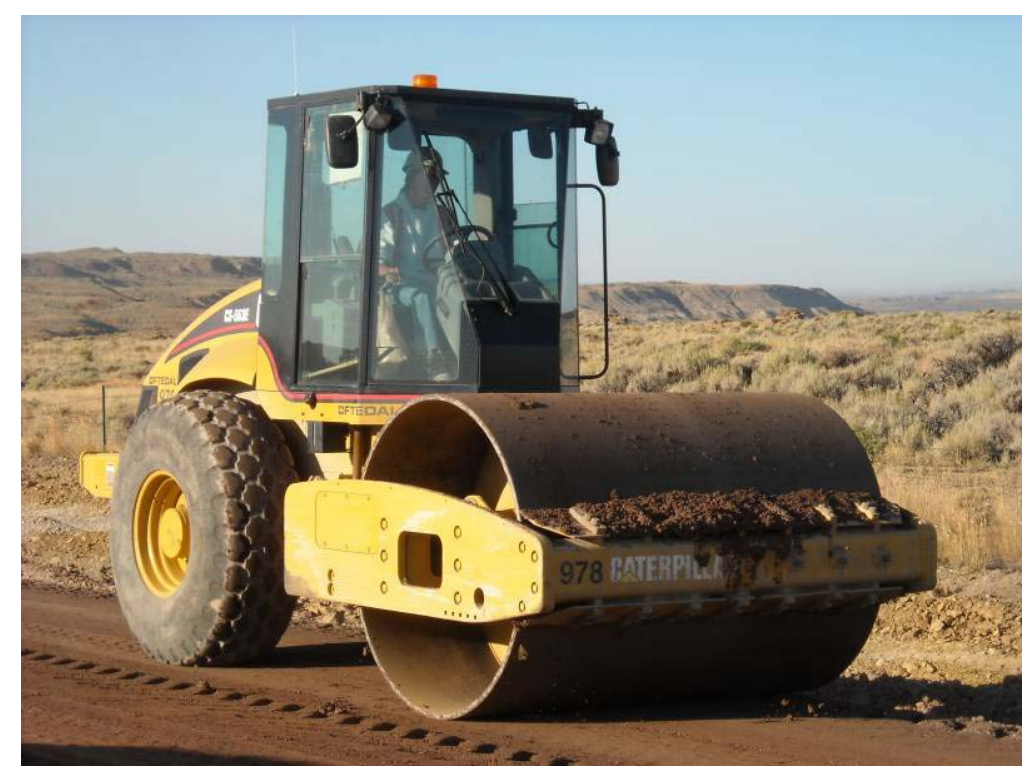

Figure 3.4 Compaction with a vibratory roller. 
chip seal was constructed in its place in early September 2009. While a chip seal inhibits water ingress and provides skid resistance, the structural benefits of a chip seal are negligible. The CTB may therefore have been inadequately protected from traffic loads and prone to premature structural failure in this condition.

\subsection{General Testing Plan}

In this research, performance of the CTB was assessed at the time of construction and then after 9 months of service. A timeline relating construction and testing is given in Figure 3.5. Initial testing, which was performed 3 days after CTB compaction in August, was performed on the same day as microcracking for a given section; tests were performed immediately before and after microcracking. At the beginning of September, the CTB was surfaced with a chip seal, and the road continued in service through the fall, winter, and spring. Subsequent testing was performed in May during the spring-thaw period.

The testing plan developed for this research involved evaluating both strength and deformation characteristics of the CTB layer. At the time of construction, strength characteristics were assessed in terms of stiffness, modulus, and compressive strength. After 9

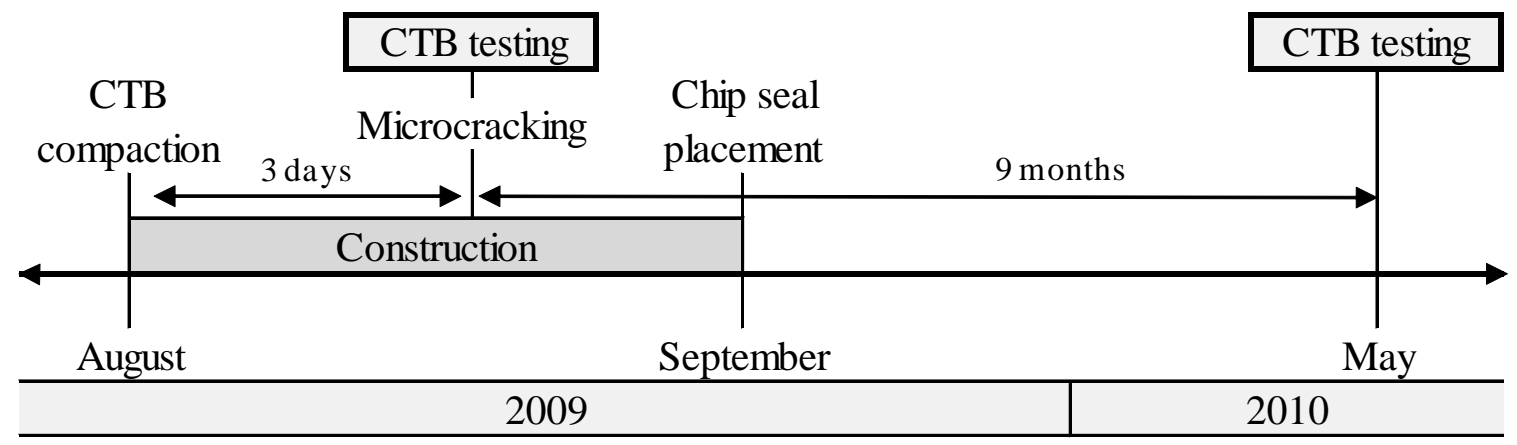

Figure 3.5 Construction and testing timeline. 
months of service, the same strength characteristics were assessed, and deformation characteristics were also assessed in terms of surface distress and roughness.

\subsection{CTB Testing during Construction}

Structural testing accomplished during construction was performed on the CTB after 3 days of constant moist curing. The first set of tests was performed to establish a nonmicrocracked baseline stiffness. Following microcracking, a second set of tests was performed. A total of 61 randomly selected sites were monitored; these sites were distributed among construction sections A through F, as shown in Figure 3.6. As depicted in Figure 3.7, 10 stations were randomly located within each section, except for section E, which had 11 stations.

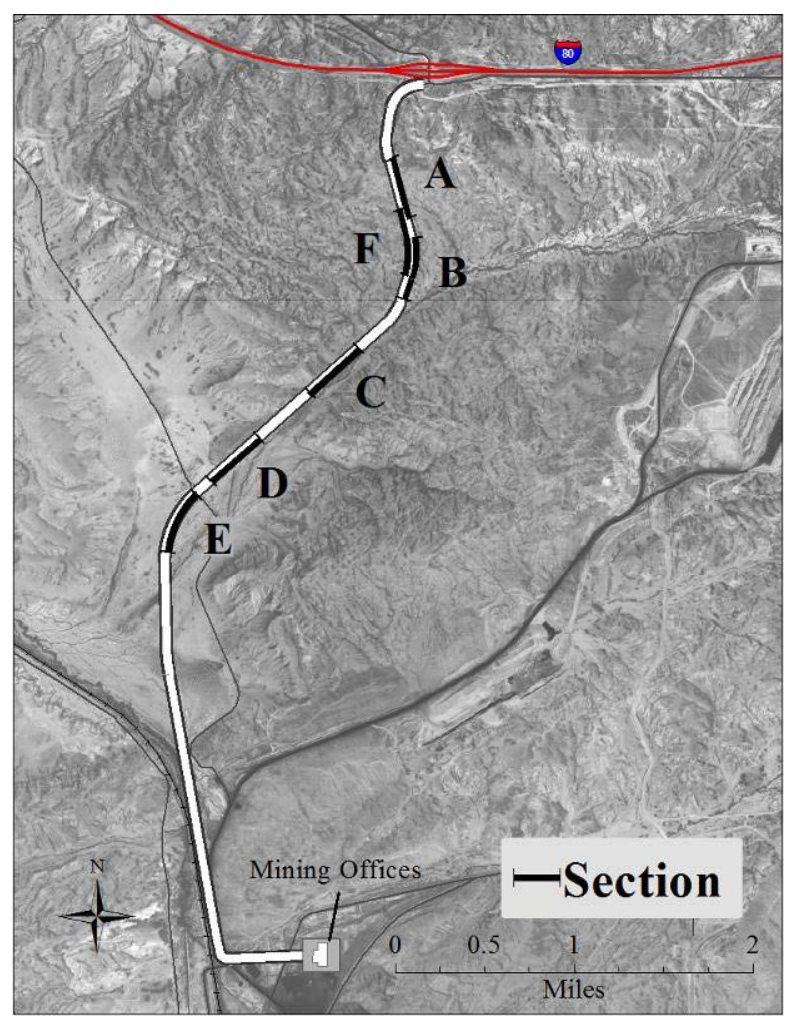

Figure 3.6 Section layout for testing during construction. 


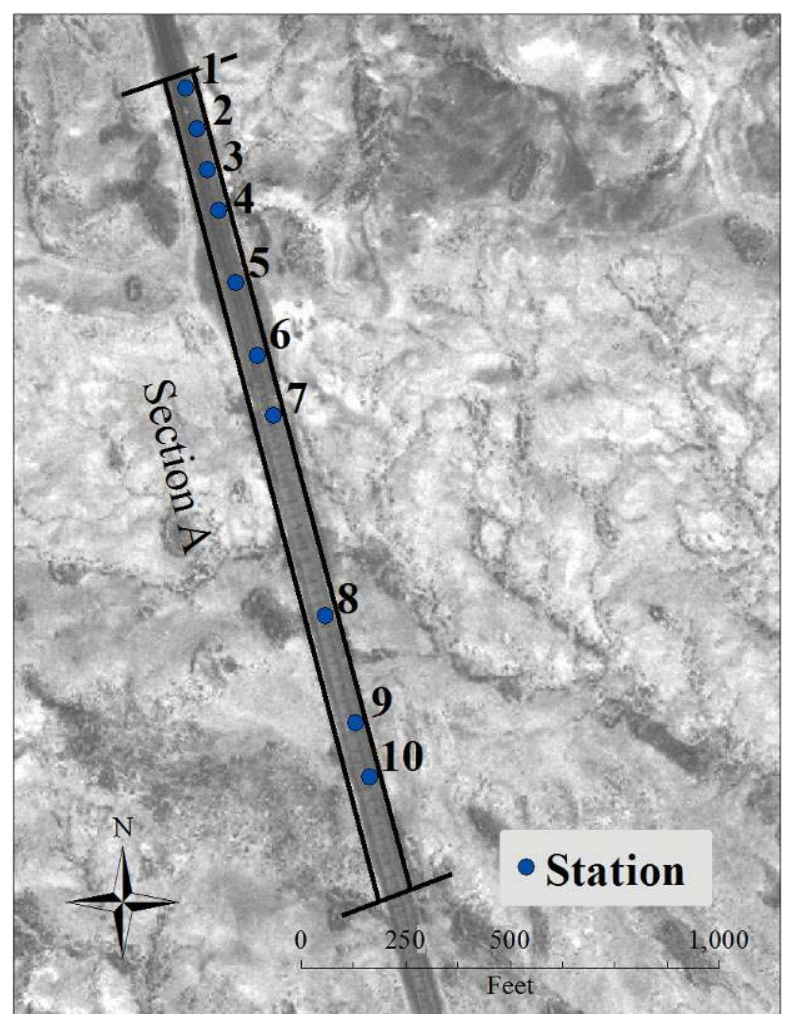

Figure 3.7 Example station layout for testing during construction.

The CTB stiffness testing was performed with a soil stiffness gauge (SSG) and a portable falling-weight deflectometer (PFWD) as shown in Figures 3.8 and 3.9, respectively. The SSG measures the stiffness of a soil by imparting vibrations to the surface while measuring the resulting displacement. The stiffness is determined as the ratio of the force to the displacement. The PFWD evaluates the elastic modulus of pavement layers by imparting a concentrated load of about $4000 \mathrm{lbf}$ and measuring the vertical deflections at specified distances from the center of the load plate. The modulus of each pavement layer can then be estimated from the measured PFWD deflections using backcalculation software. The SSG and PFWD tests were performed in general accordance with American Society for Testing and Materials (ASTM) D6758 (Standard Test Method for Measuring Stiffness and Apparent Modulus of Soil and Soil-Aggregate In-Place by Electro-Mechanical Method) and ASTM E2583 (Standard Test Method for Measuring 


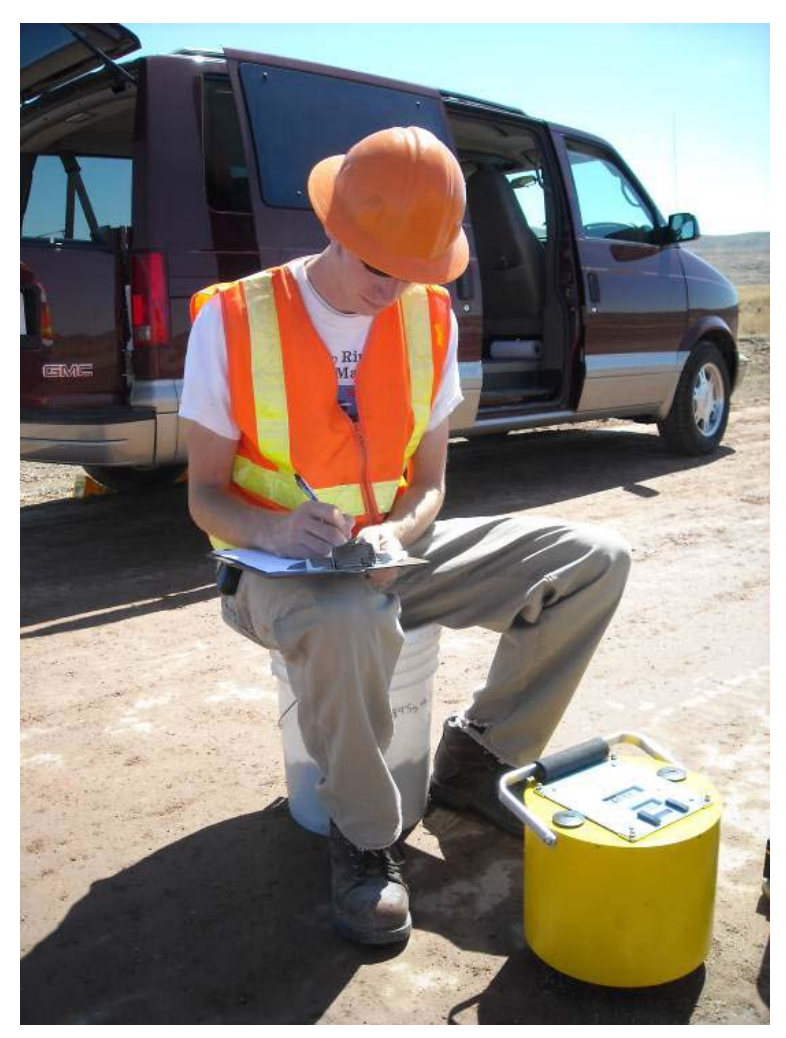

Figure 3.8 SSG.

Deflections with a Light Weight Deflectometer), respectively. The deflections measured by the PFWD were input into BAKFAA to estimate the modulus of the CTB (24). The pavement was assumed to be a two-layer system consisting of CTB and subgrade. Values for the individual inputs used in backcalculation are provided in Appendix A. Three readings from each device were recorded at each site and later averaged.

In addition to in-place stiffness testing of the CTB layer, field-mixed CTB specimens were compacted and later tested for UCS. A total of 14 specimens with a diameter of 4 in. and height of approximately 4.6 in. were manually compacted using the modified Proctor procedure in general accordance with ASTM D1557 (Standard Test Methods for Laboratory Compaction Characteristics of Soil Using Modified Effort $\left.\left(56,000 \mathrm{ft}-\mathrm{lbf} / \mathrm{ft}^{3}\left(2,700 \mathrm{kN}-\mathrm{m} / \mathrm{m}^{3}\right)\right)\right)$. The treated materials used to prepare these specimens were collected from two locations on two different 


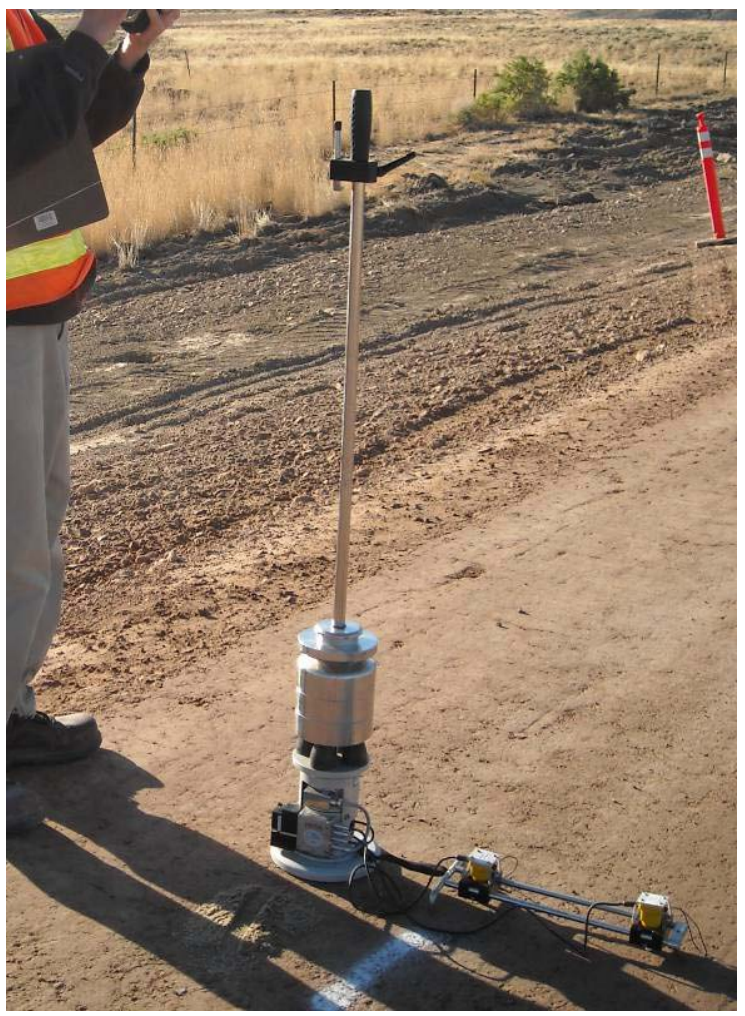

Figure 3.9 PFWD.

days of construction and immediately compacted in the field. After 7 days and after 6 weeks of curing in the laboratory, subsets of these specimens were capped and subjected to UCS testing in general accordance with ASTM D1633 (Standard Test Methods for Compressive Strength of Molded Soil-Cement Cylinders).

\subsection{CTB Testing after 9 Months of Service}

In May 2010, after the CTB had been in service for 9 months, researchers evaluated the surface condition and structural capacity of the pavement. The pavement at that time consisted of the chip seal and CTB. While previous testing was limited to areas under construction on days on which the researchers were available, the 9-month testing locations were distributed throughout the length of the project. A total of 15 stations were randomly selected for evaluation 
as shown in Figure 3.10. A distress survey was performed at each station, and structural and roughness tests were performed in alternating inbound and outbound lanes, with tests performed in the outer wheel path and between the wheel paths at each station.

Detailed distress surveys were conducted to quantify the extent and severity of surface defects, including cracking, potholing, and rutting. Each survey involved an edge-to-edge distress map for a 100-ft longitudinal section, centered at the station marker, and rut depth measurements for all inbound and outbound wheel paths. The distresses were rated in general accordance with the Long Term Pavement Performance (LTPP) Program guidelines. An additional distress was considered where aggregate loss and CTB exposure along the chip seal joint occurred and was labeled as chip seal joint failure.

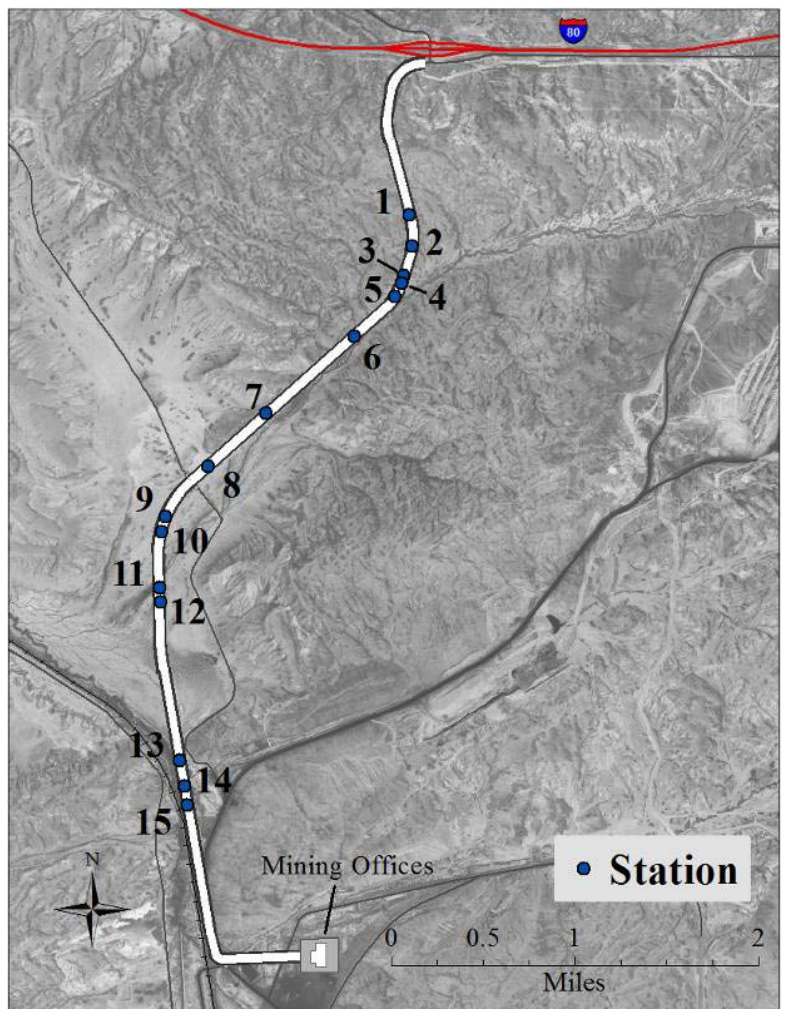

Figure 3.10 Station layout for testing after 9 months of service. 
Roughness tests were performed with a profilometer as shown in Figure 3.11 to calculate the international roughness index (IRI) of the pavement in and between the wheel paths at each station. The base of the instrument contains a precision inclinometer that measures the height difference between two surface points spaced $1 \mathrm{ft}$ apart; after a given reading is obtained, the instrument is then manually rotated to the next position. When testing of a given profile is completed, an onboard computer calculates the IRI from the collected data. This test was performed in each case along a 100-ft line centered longitudinally at each station. By testing in and out of the wheel paths, the effect of trafficking on pavement roughness could be captured. Testing was accomplished in general accordance with ASTM E1274 (Standard Test Method for Measuring Pavement Roughness Using a Profilograph).

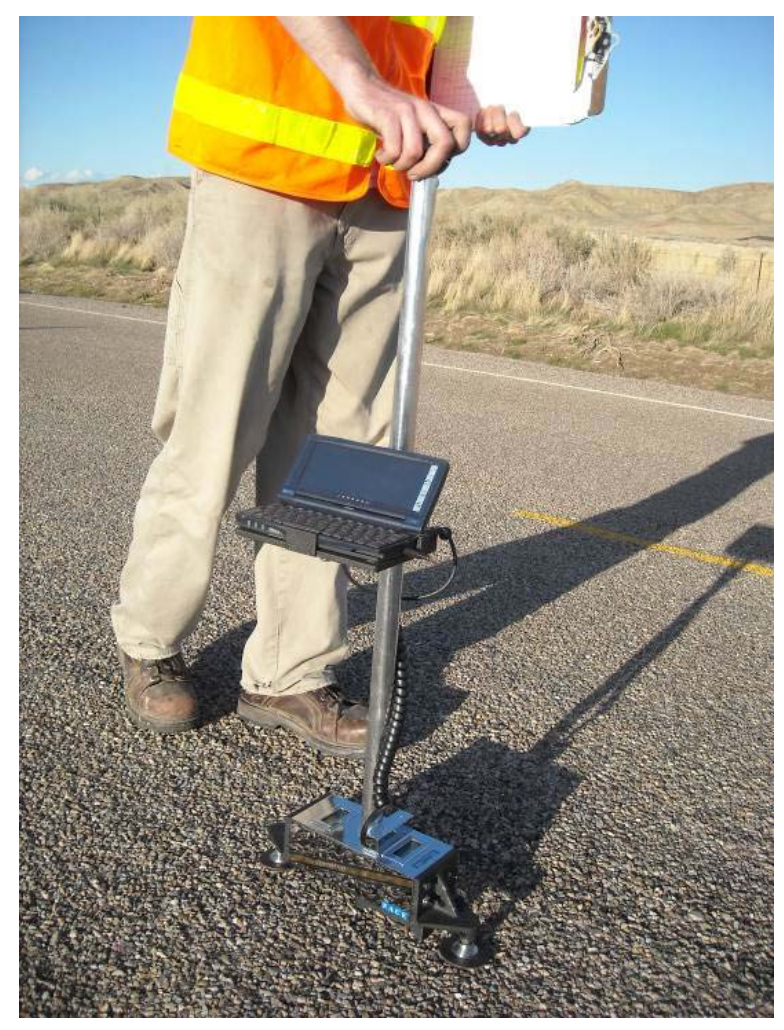

Figure 3.11 Profilometer. 
To facilitate accurate assessment of the CTB structural properties at designated test locations in the outer wheel path and between the wheel paths at each station, the chip seal needed to be removed before testing could proceed. The emulsion was quickly softened with a propane blow torch, and the aggregate was removed with a handheld metal scraper. PFWD testing on the bare CTB surface was performed first, followed by testing with the SSG. Readings were collected both in and out of the wheel paths to capture the effect of trafficking on the in-situ structural properties of the CTB. The deflections recorded by the PFWD were again used to backcalculate the CTB modulus with BAKFAA. As with the initial testing, three readings for each test were recorded and later averaged.

Cores of the CTB were extracted from each test station and subjected to laboratory UCS testing to provide another measure of CTB structural condition. A truck-mounted coring rig, as shown in Figure 3.12, was used to extract 4-in.-diameter cores from both in and between the wheel paths at the same locations of PFWD and SSG testing. When a full core could not be extracted due to cracking or degradation of the material during cutting, the CTB pieces were still collected. After being returned to the laboratory, intact cores were used to estimate the UCS of the CTB. The cores were saw-cut to a height of 4.6 in. to achieve the same aspect ratio as the previously prepared modified Proctor specimens. To minimize damage that might occur during saw-cutting, the cores were first frozen. After being cut, the specimens were thawed for 24 hours at room temperature, soaked underwater for 4 hours according to PCA protocols, and then tested. 


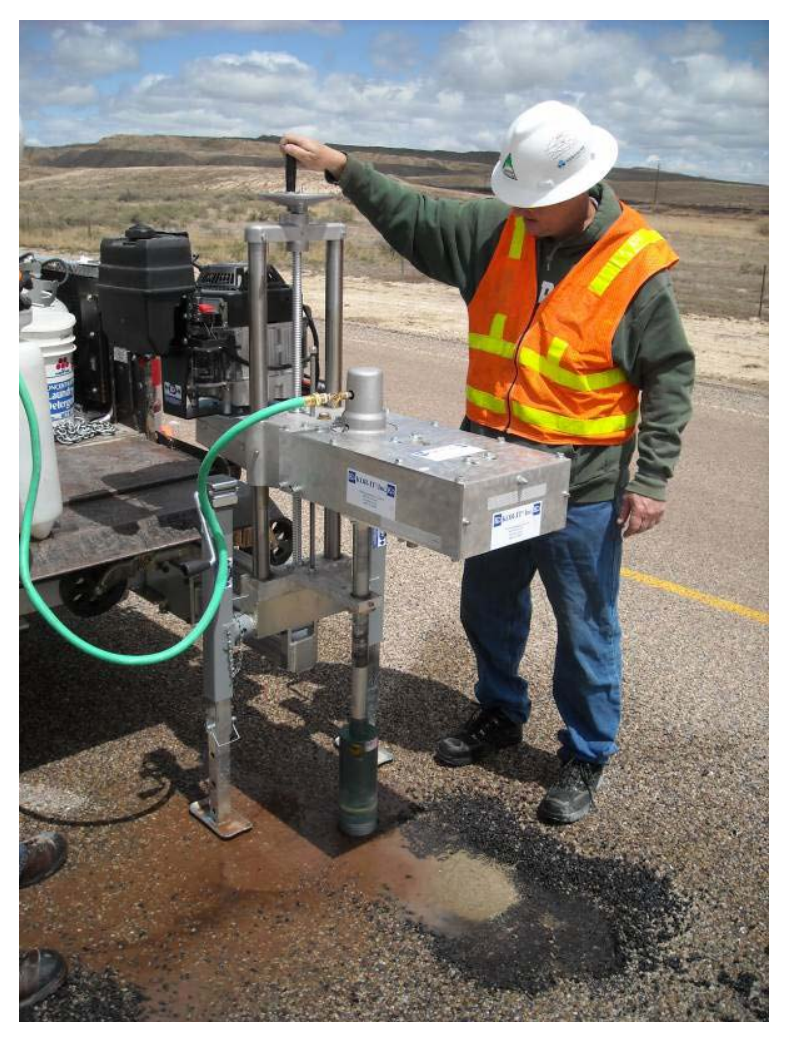

Figure 3.12 Truck-mounted coring rig.

\subsection{Statistical Analysis}

In the 9-month CTB testing, many of the tests were performed both in the wheel path and between the wheel paths at each station to capture the effects of trafficking on different CTB performance indicators. The performance within the wheel path was expected to be poorer due to the effect of heavy vehicle trafficking. To determine whether the results obtained in the wheel path for a given test were significantly worse than those obtained between the wheel paths, a one-tailed, paired $t$-test was conducted. An $\alpha$-value of 0.05 , corresponding to a 95 percent confidence level, was used to establish statistical significance. If the $p$-value resulting from the $t$-test was less than or equal to 0.05 , then the difference between properties measured in the wheel paths and those measured between the wheel paths was considered to be statistically significant. 


\subsection{Summary}

The subject of this research is a coal mine access road in Wyoming. The road has lowvolume traffic with a moderate percentage of heavy trucks, receives little precipitation per year, and experiences freeze-thaw cycling and prolonged freezing during winter. The existing asphalt and base were $10.5 \mathrm{in}$. and $10.8 \mathrm{in}$. thick, respectively. The AASHTO classifications for the base and subgrade were A-2-4 (0) and A-7-6 (29), respectively. The corresponding classifications in the USCS were silty sand with gravel (SM) and fat clay (CH).

Due to the development of high-severity transverse and fatigue cracking and excessive roughness, the original pavement was reconstructed through FDR in conjunction with cement stabilization and was microcracked after 3 days of moist curing. The original pavement design required 4 in. of HMA, but, due to budget restrictions, placement of an HMA surfacing was postponed, and a single chip seal was constructed in its place.

Strength characteristics of the CTB layer were evaluated during construction with various tests. After 3 days of curing, the first set of tests was performed to establish a non-microcracked baseline stiffness with an SSG and PFWD. Following microcracking, a second set of tests was performed. Additionally, field-mixed CTB specimens were compacted and later tested for UCS. Researchers evaluated the CTB again after it had been in service for 9 months.

Deformation characteristics were assessed through detailed distress surveys and roughness tests. Strength characteristics were again evaluated with the SSG and PFWD, and cores of the CTB were extracted and subjected to laboratory UCS testing.

In the 9-month CTB testing, many of the tests were performed both in the wheel path and between the wheel paths to capture the effects of trafficking on different CTB performance indicators. To determine whether the results obtained in the wheel path for a given test were 
significantly worse than those obtained between the wheel paths, a one-tailed, paired $t$-test was conducted in each case. 


\section{RESULTS}

\subsection{Overview}

The following sections describe the performance of the CTB during construction and after 9 months of service. At the time of construction, performance was evaluated in terms of strength characteristics. The 9-month performance was evaluated in terms of both strength and deformation characteristics.

\subsection{CTB Performance during Construction}

The average SSG stiffness and PFWD modulus results for each testing section at the time of construction are shown in Figures 4.1 and 4.2, respectively, and are summarized in Table 4.1. Unfortunately, the contact interface between the SSG and the CTB surface was unsatisfactory when measuring the CTB stiffness before microcracking for sections A and B; those values have therefore been omitted. Based on the available SSG and PFWD measurements, the average decreases in stiffness and modulus were computed to be 22 and 37 percent, respectively. The large standard deviations observed in the modulus data are likely attributable to the spatial variability inherent in FDR. The details for both data sets are presented in Appendix A.

The average UCS values of the field-compacted specimens are shown in Table 4.2. Each value is the average of three specimens, except the 6-week UCS value for location 2, where only 


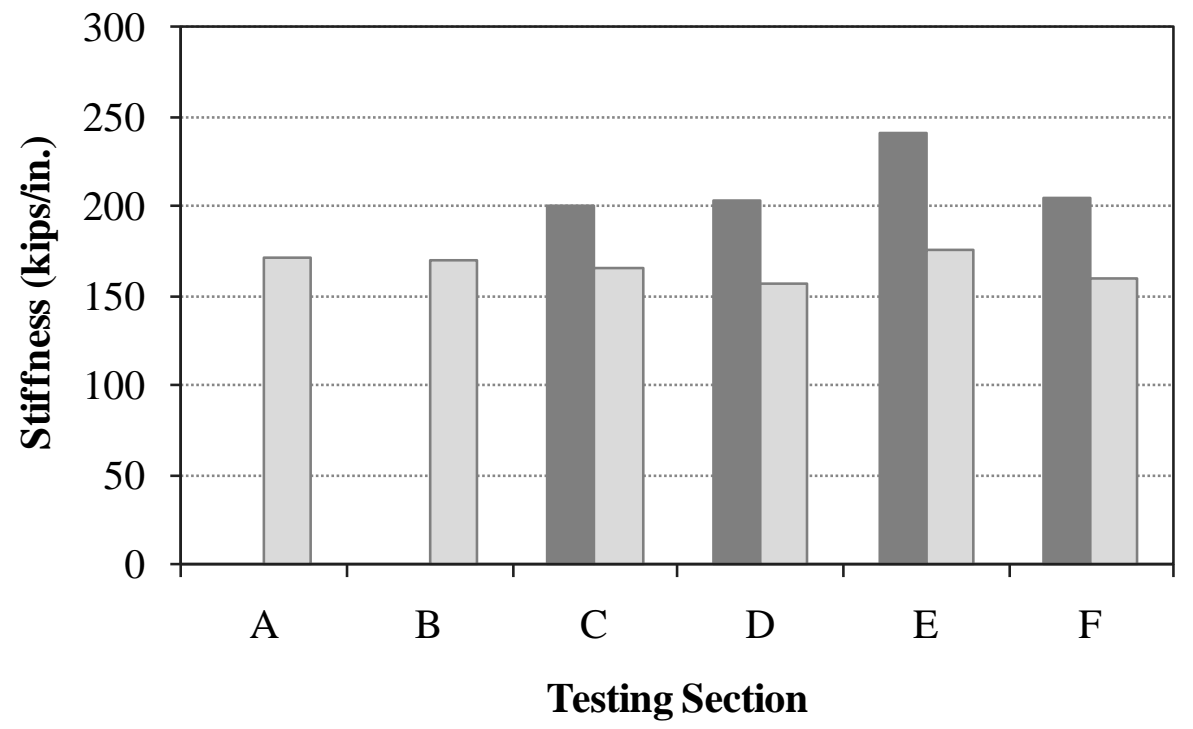

Before Microcracking $\square$ After Microcracking

Figure 4.1 Three-day CTB stiffness (SSG).

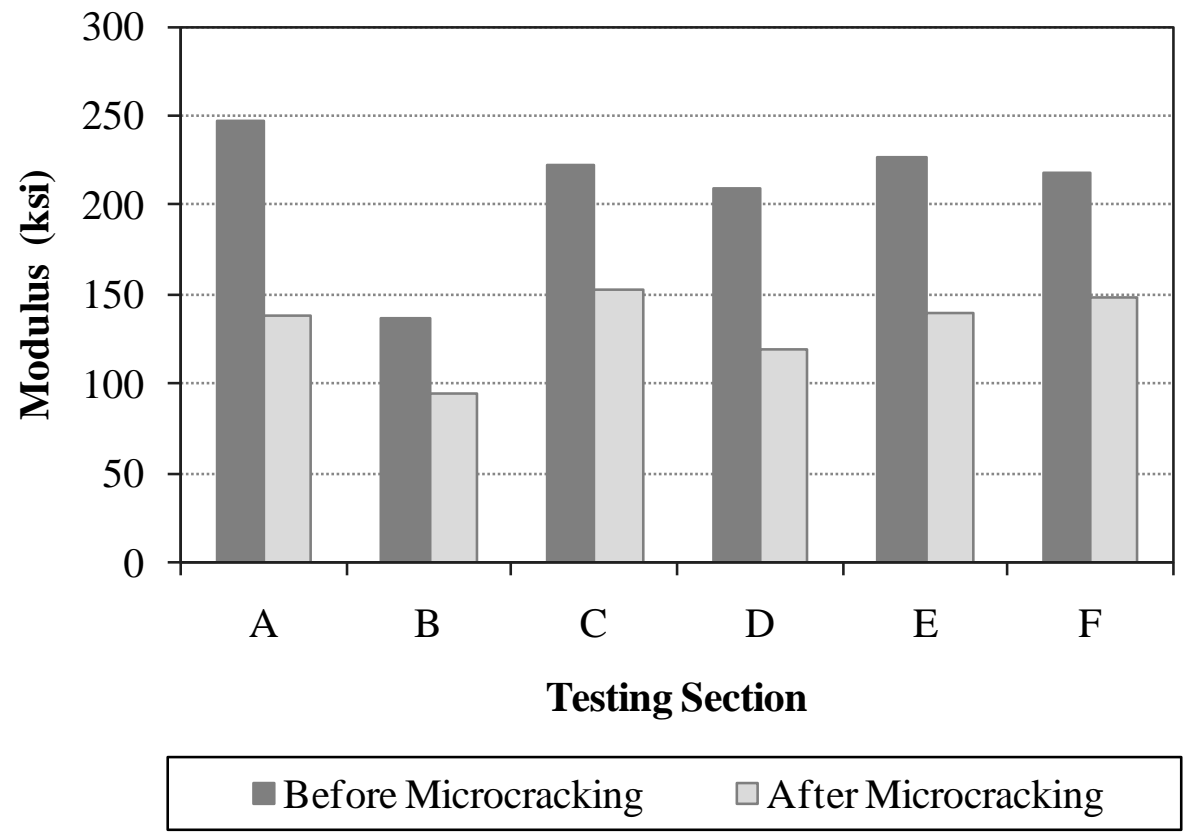

Figure 4.2 Three-day CTB modulus (PFWD). 
Table 4.1 Summary of 3-Day CTB Stiffness (SSG) and Modulus (PFWD)

\begin{tabular}{lccccc}
\hline & \multicolumn{2}{c}{ Stiffness (kips/in.) } & & \multicolumn{2}{c}{ Modulus (ksi) } \\
\cline { 2 - 3 } \cline { 5 - 6 } Period of Testing & Average & St. Dev. & & Average & St. Dev. \\
\hline Before Microcracking & 212 & 41 & & 211 & 131 \\
After Microcracking & 166 & 34 & & 133 & 77 \\
\hline
\end{tabular}

Table 4.2 Summary of UCS of Field-Compacted CTB Specimens

\begin{tabular}{|c|c|c|c|c|c|}
\hline \multirow[b]{2}{*}{ Location } & \multicolumn{2}{|c|}{ 7-Day UCS (psi) } & \multicolumn{2}{|c|}{ 6-Week UCS (psi) } & \multirow{2}{*}{$\begin{array}{l}\text { Average RAP } \\
\text { Content (\%) }\end{array}$} \\
\hline & Average & St. Dev. & Average & St. Dev. & \\
\hline 1 & 343 & 16 & 427 & 32 & 68 \\
\hline 2 & 486 & 44 & 860 & 42 & 53 \\
\hline
\end{tabular}

two specimens were averaged. These values represent a hypothetical situation in which the CTB was never microcracked. The first set of specimens had a higher RAP content, and the average 7-day UCS value for the two sites was nearly 400 psi. The average 6-week UCS value was nearly 600 psi. These strengths are typical of values at the upper end of the acceptable range for CTB layers (20). More detailed UCS data are presented in Appendix A.

\subsection{CTB Performance after 9 Months of Service}

After 9 months of service, the inbound and outbound lanes of the reconstructed pavement had each experienced an estimated 2,600 heavy vehicle passes. The pavement had also been subjected to a high number of freeze-thaw cycles, as described previously.

Table 4.3 summarizes the distresses present in the pavement at the time of the 9-month testing. On average, 2.7 low-severity transverse cracks were observed in every $100 \mathrm{ft}$ of pavement. In CTB, transverse cracks are generally evidence of shrinkage. Since the CTB in 
Table 4.3 Nine-Month Distress Summary

\begin{tabular}{|c|c|c|c|c|c|c|c|}
\hline \multirow[b]{2}{*}{ Station } & \multicolumn{2}{|c|}{ Transverse Cracking } & \multicolumn{2}{|c|}{ Chip Seal Joint Failure } & \multicolumn{2}{|c|}{ Longitudinal Cracking } & \multirow{2}{*}{$\begin{array}{l}\text { Potholes } \\
\text { Area }\left(\mathrm{ft}^{2}\right)\end{array}$} \\
\hline & Length (ft) & Count & Length (ft) & $\begin{array}{l}\text { Average } \\
\text { Width (in.) }\end{array}$ & $\begin{array}{l}\text { Non-Wheel-Path } \\
\text { Length (ft) }\end{array}$ & $\frac{\text { Wheel-Path }}{\text { Length (ft) }}$ & \\
\hline 1 & 17 & 2 & 50 & 2.8 & 70 & 0 & 13 \\
\hline 2 & 59 & 3 & 74 & 2.9 & 100 & 0 & 0 \\
\hline 3 & 55 & 4 & 36 & 2.0 & 85 & 52 & 9 \\
\hline 4 & 28 & 2 & 88 & 3.4 & 0 & 0 & 0 \\
\hline 5 & 6 & 1 & 0 & - & 100 & 0 & 0 \\
\hline 6 & 41 & 3 & 0 & - & 100 & 0 & 0 \\
\hline 7 & 4 & 1 & 68 & 2.0 & 100 & 0 & 0 \\
\hline 8 & 41 & 3 & 0 & - & 10 & 0 & 0 \\
\hline 9 & 76 & 5 & 0 & - & 100 & 0 & 0 \\
\hline 10 & 63 & 3 & 60 & 2.5 & 62 & 0 & 0 \\
\hline 11 & 60 & 5 & 26 & 2.5 & 0 & 0 & 0 \\
\hline 12 & 98 & 5 & 64 & 2.5 & 2 & 0 & 0 \\
\hline 13 & 28 & 2 & 0 & - & 0 & 0 & 0 \\
\hline 14 & 14 & 1 & 0 & - & 0 & 28 & 0 \\
\hline 15 & 17 & 1 & 0 & - & 100 & 32 & 0 \\
\hline Average & 40.5 & 2.7 & 31.1 & 2.6 & 55.3 & 7.5 & 1.4 \\
\hline
\end{tabular}

*Values represent distress per 100 linear feet of pavement $\left(2800 \mathrm{ft}^{2}\right)$

each lane of this project was constructed independently, the occurrence of shrinkage cracks was often lane-specific. The average crack spacing within a lane was roughly $50 \mathrm{ft}$, a comparatively low frequency of shrinkage cracking. However, significant joint failure of the chip seal, characterized by the loss of chips and asphalt emulsion, was evident at over half of the test stations. These failures were caused by poor chip seal construction practices and are not indicative of poor CTB performance. Nonetheless, the importance of the role of the chip seal as a wearing course is made evident by these failures since the exposed CTB often exhibited material loss. Likely, surface water ponded in these joints and facilitated comparatively rapid CTB erosion under traffic loads and freeze-thaw cycling. At stations 1 and 3, the degradation was so severe that long 1-in.-deep potholes had developed as shown in Figure 4.3. Further chip loss would likely lead to continued degradation of the CTB. Longitudinal cracking was evident 


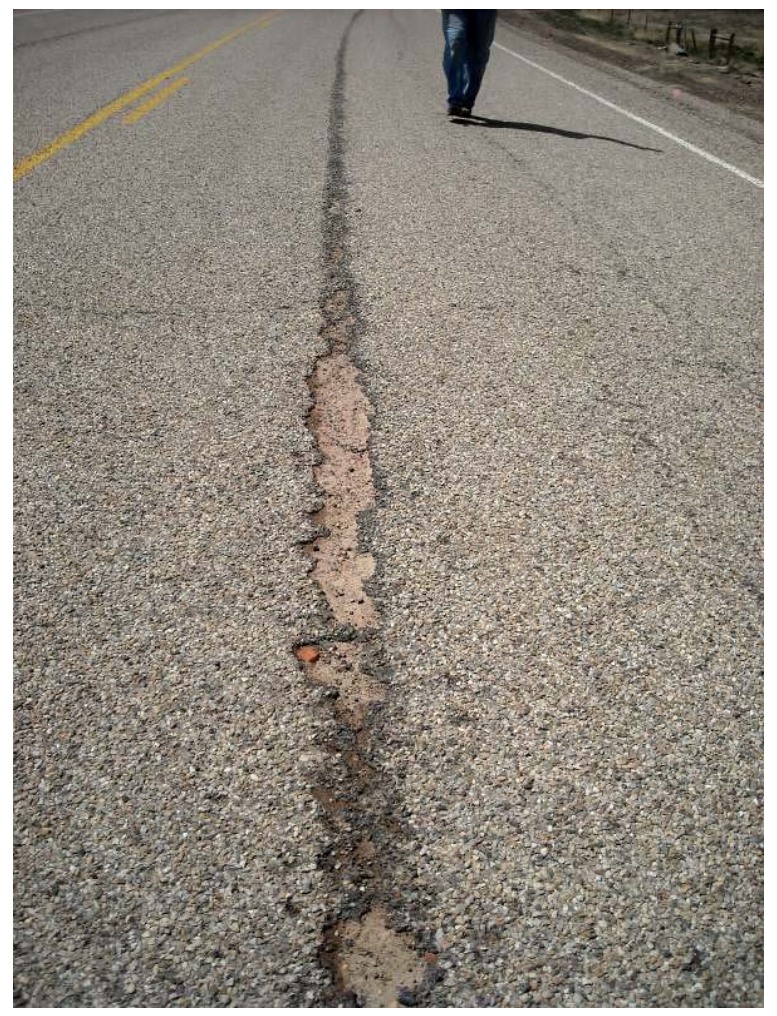

Figure 4.3 Pothole along chip seal joint.

down the centerline of the road corresponding with the CTB construction joint. In a few instances, cracking was also evident in the wheel paths. These longitudinal cracks were primarily low-severity. Detailed distress maps for each site are provided in Appendix B.

Rutting measurements are shown in Figure 4.4, and an example of rutting is shown in Figure 4.5. According to the LTPP Program guidelines, pavements with rut depths greater than 0.5 in. are considered failed, as water may pond in the wheel path and facilitate hydroplaning. Five stations exhibited rutting in excess of this limit. The average depth for all ruts was 0.2 in. The observed rutting may have occurred either during or after construction. During construction, as observed by the researchers, premature trafficking likely occurred at stations 1 through 7 in the outbound lane. After construction, rutting occurring in the pavement structure could be 


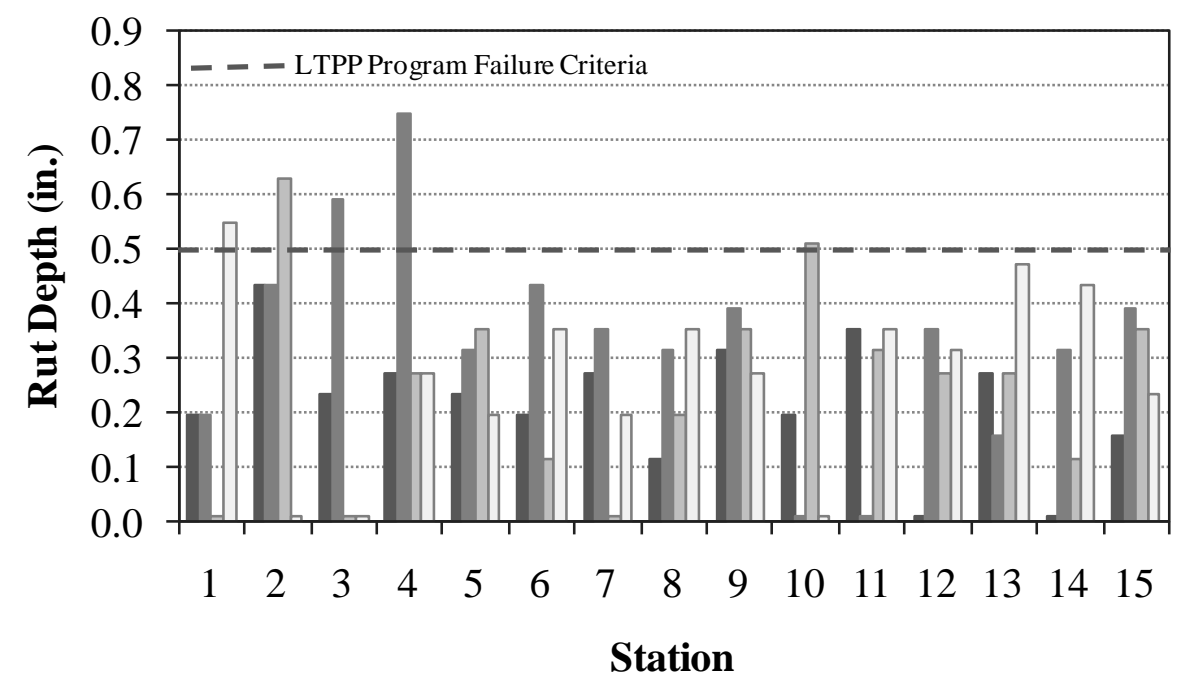

- Inbound Lane, Inner Wheel Path - Inbound Lane, Outer Wheel Path

$\square$ Outbound Lane, Inner Wheel Path $\square$ Outbound Lane, Outer Wheel Path

Figure 4.4 Nine-month CTB rutting.

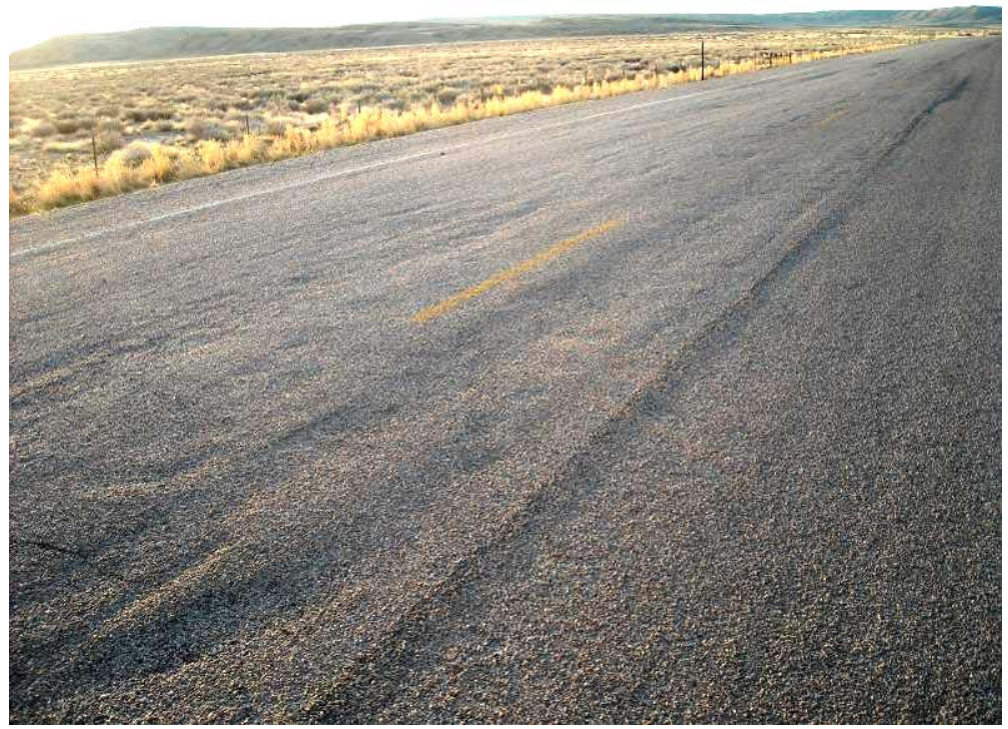

Figure 4.5 Rutting distress. 
attributable to an overall structural deficiency, caused by the absence of the HMA layer, and therefore inadequate protection of the soft, clayey subgrade beneath the CTB.

The IRI values measured during testing are shown in Figure 4.6. The rating criteria used for comparison in the figure are those adopted by the Utah Department of Transportation (UDOT) for asphalt roads (25). The average IRI values in and out of the wheel path were 155 and $158 \mathrm{in./mi}$, respectively. While these averages are in the fair ride category, six of the locations had ride qualities in the poor ride category. The UDOT criteria, however, are for paved roads and may be inappropriate for the analysis of a CTB surfaced with a chip seal. The IRI in the wheel path was not significantly higher than the IRI between the wheel paths, where the resulting $p$-value was 0.6064 . Therefore, the pavement roughness was not likely caused by trafficking but probably resulted from construction or climatic factors. Whether this degree of roughness could have been avoided or not with an HMA surface course is uncertain.

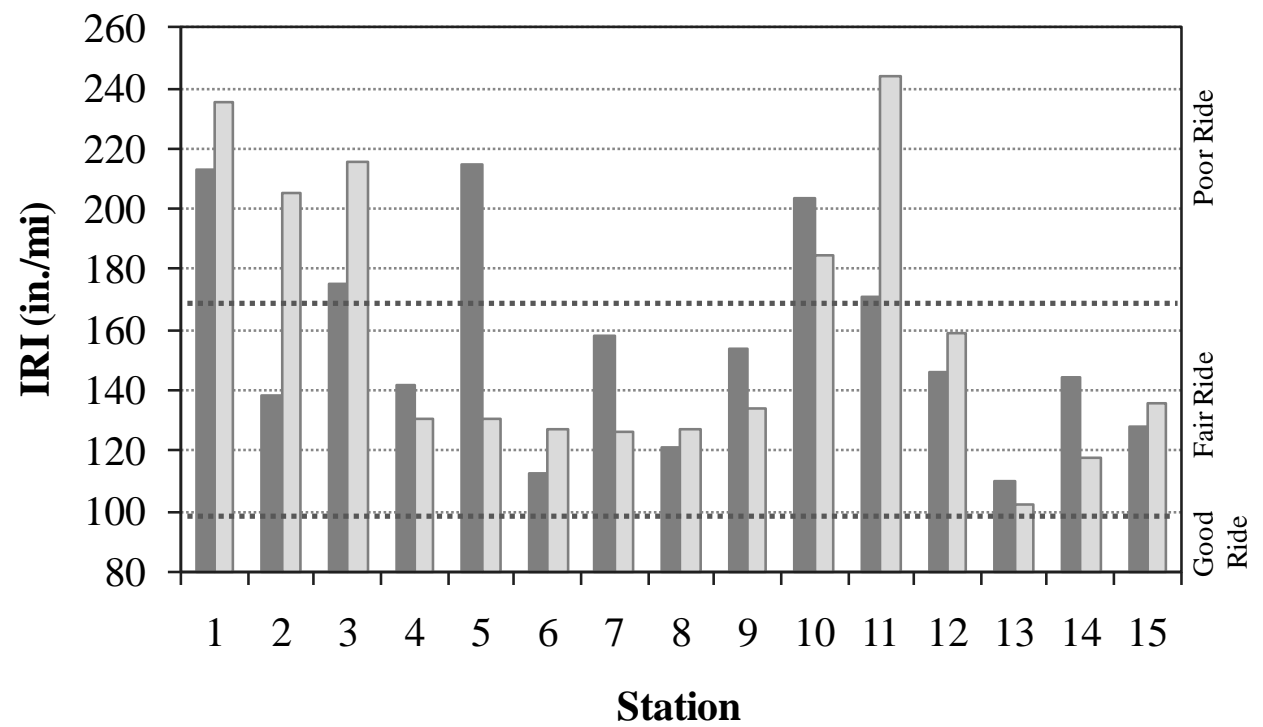

In Wheel Path $\quad \square$ Between Wheel Paths

Figure 4.6 Nine-month CTB roughness. 
The average SSG stiffness values measured during testing are shown in Figure 4.7. The average stiffnesses in the wheel path and between the wheel paths were 226 and 244 kips/in., respectively. These averages are not significantly different from the average CTB stiffness before microcracking but are well above the average stiffness after microcracking. The stiffness in the wheel path was significantly lower than the stiffness between the wheel paths, where the p-value was 0.0395 . According to the SSG test results, 9 months of trafficking was sufficient to cause a significant decrease in CTB stiffness in the wheel paths as compared to that between the wheel paths.

The average PFWD moduli measured during testing are shown in Figure 4.8. The average moduli in the wheel path and between the wheel paths were 469 and $705 \mathrm{ksi}$, respectively. These values are well above the average CTB moduli before and after microcracking. The CTB modulus in the wheel path was significantly lower than the

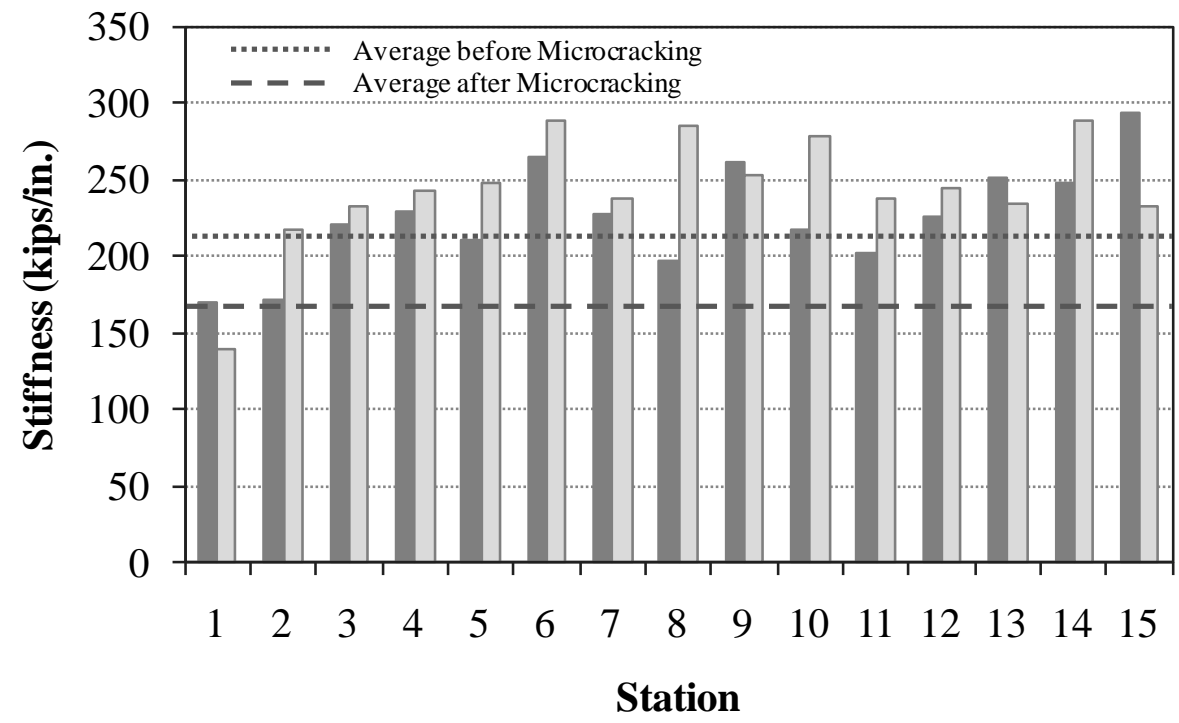

घn Wheel Path $\square$ Between Wheel Paths

Figure 4.7 Nine-month CTB stiffness (SSG). 


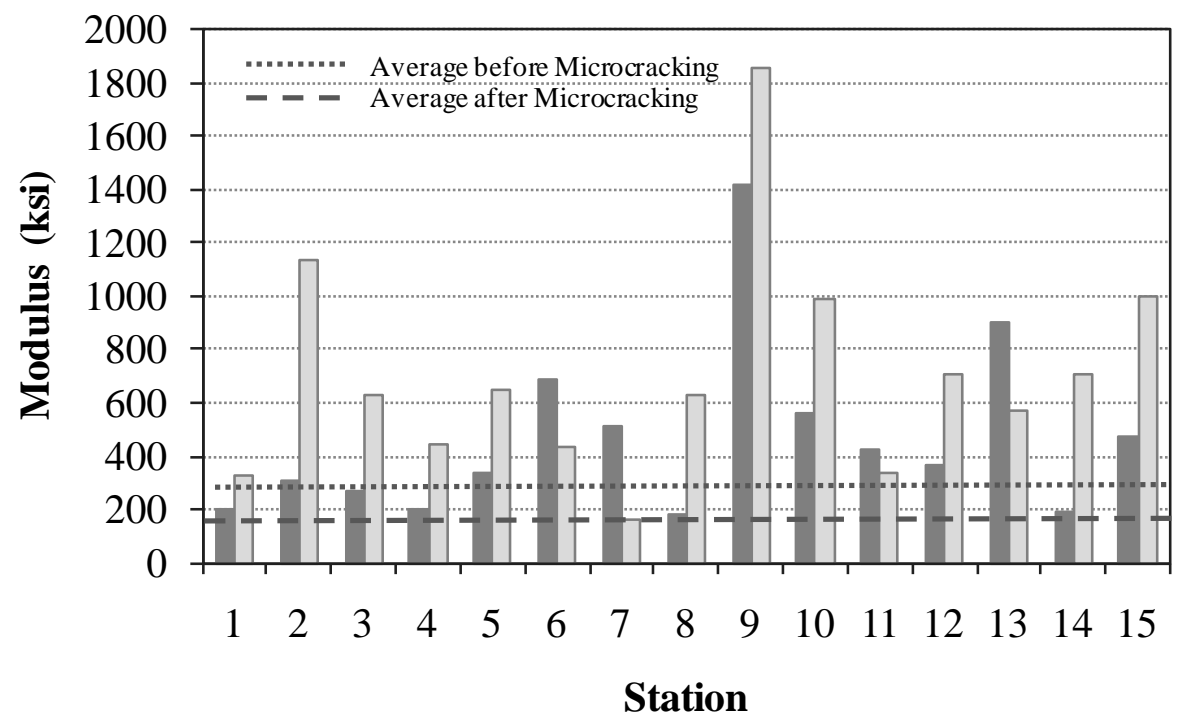

In Wheel Path $\quad \square$ Between Wheel Paths

Figure 4.8 Nine-month CTB modulus (PFWD).

modulus between the wheel paths, where the $p$-value was 0.0099 . According to the PFWD test results, 9 months of trafficking caused a significant decrease in CTB modulus. Though trafficking had a detrimental effect on modulus that may have been avoided if an HMA surface had been placed, the likelihood of continuing reductions in modulus with future trafficking in the wheel paths is unknown.

The UCS values of cores from in and between the wheel paths are shown in Figure 4.9. Certain cores from in and between wheel paths at locations 1, 5, 7, 12, and 14 could not be extracted intact and were therefore not tested. The average UCS values of the specimens from in the wheel path and between the wheel paths were 587 and 483 psi, respectively. These averages are not statistically different than the average 6-week UCS value of the field-compacted specimens, which represented a theoretical non-microcracked condition. Also, the UCS values of the cores in the wheel path were not significantly lower than the values between the wheel 


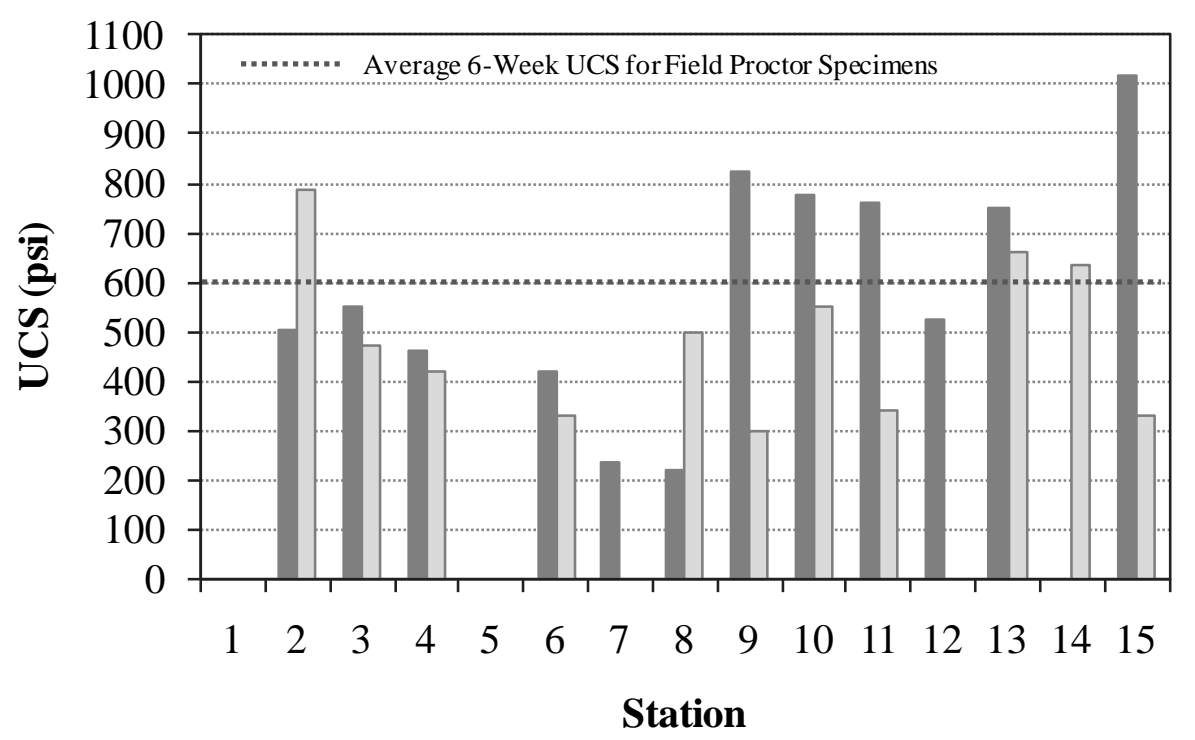

口In Wheel Path $\quad \square$ Between Wheel Paths

Figure 4.9 Nine-month CTB UCS.

paths, where the $p$-value was 0.9187 . That is, insufficient evidence exists to suggest that trafficking caused reductions in UCS.

\subsection{Summary}

The average 3-day CTB stiffnesses before and after microcracking were 212 and 166 kips/in., respectively. The corresponding average 3-day moduli were 211 and 133 ksi, respectively. The average decreases in stiffness and modulus were computed to be 22 and 37 percent, respectively. The average 7-day UCS value for the two sites was nearly $400 \mathrm{psi}$. The average 6-week UCS value was nearly 600 psi. These values represent a hypothetical situation in which the CTB was never microcracked and are typical of values at the upper end of the acceptable range for CTB layers. 
After 9 months of service, the average transverse crack spacing within a given lane was roughly $50 \mathrm{ft}$, a comparatively low frequency of shrinkage cracking. Significant joint failure of the chip seal was evident at over half of the test stations. The importance of the role of the chip seal as a wearing course is made evident by these failures since the exposed CTB often exhibited material loss. In two instances, long 1-in.-deep potholes had developed. Five stations exhibited rutting in excess of $0.5 \mathrm{in}$., and the average depth for all ruts was $0.2 \mathrm{in.}$ The average ride qualities in and between the wheel paths were in the fair ride category, and six of the locations had ride qualities in the poor ride category. The IRI in the wheel path was not significantly higher than the IRI between the wheel paths; therefore, the pavement roughness was not likely caused by trafficking.

Structural testing performed after 9 months of service indicated that the CTB stiffness and modulus were greater than the values measured after microcracking at the time of construction. However, trafficking over the 9-month period had caused statistically significant reductions in these properties, where the average stiffnesses in the wheel path and between the wheel paths were 226 and 244 kips/in., respectively. The average corresponding moduli in the wheel path and between the wheel paths were 469 and 705 ksi, respectively. The average UCS of the cores tested at 9 months was not significantly different than the average UCS of the fieldcompacted specimens tested at 6 weeks, and insufficient evidence exists to suggest that 9 months of trafficking caused reductions in UCS. At 9 months, the average UCS values of the specimens from in the wheel path and between the wheel paths were 587 and 483 psi, respectively. 


\section{CONCLUSION}

\subsection{Summary}

The objective of this research was to analyze the performance of CTB as the primary structural layer of a pavement constructed through the FDR process and subjected to low-volume truck traffic in an extreme freeze-thaw climate. Performance was evaluated in terms of both strength and deformation characteristics at the time of construction and at 9 months. The results of this research address the viability of recommending such a pavement for construction, which would be a low-cost alternative to standard flexible pavements.

The subject of this research was a coal mine access road in Wyoming. The original pavement was reconstructed through FDR in conjunction with cement stabilization, microcracked after 3 days of moist curing, and surfaced with a single chip seal. At the time of construction, strength characteristics were assessed in terms of stiffness, modulus, and compressive strength. After 9 months of service, the same strength characteristics were assessed, and deformation characteristics were also assessed in terms of surface distress and roughness. Many of the 9-month CTB properties were measured both in the wheel path and between the wheel paths to capture the effects of trafficking on different CTB performance indicators. To determine whether the results obtained in the wheel path for a given test were significantly worse than those obtained between the wheel paths, a one-tailed, paired $t$-test was conducted in each case. 


\subsection{Findings}

The CTB properties at the time of construction were consistent with design expectations. The average 3-day CTB stiffnesses before and after microcracking were 212 and 166 kips/in., respectively. The corresponding average 3-day moduli were 211 and $133 \mathrm{ksi}$, respectively. The average 7-day and 6-week UCS values were approximately 400 and 600 psi, respectively; these strengths are typical of values at the upper end of the acceptable range for CTB layers.

After 9 months of service, the average transverse crack spacing of the CTB layer within a given lane was roughly $50 \mathrm{ft}$, a comparatively low frequency of shrinkage cracking. Significant joint failure of the chip seal was evident at over half of the test stations. This was caused by poor chip seal construction practices and not a deficiency in the CTB layer. Nonetheless, the importance of the role of the chip seal as a wearing course is made evident by these failures since the exposed CTB often exhibited material loss. In two instances, long 1-in.-deep potholes had developed. The average depth of rutting was only 0.2 in., but five of the 15 test stations exhibited rut depths exceeding 0.5 in., attributable to either premature trafficking of the CTB layer or an overall structural deficiency.

The average ride qualities in and out of the wheel path were in the fair ride category; however, six of the locations had ride qualities in the poor ride category. The IRI in the wheel path was not significantly higher than the IRI between the wheel paths; therefore, the pavement roughness was not likely caused by trafficking but probably resulted from construction or climatic factors.

Structural testing performed after 9 months of service indicated that the CTB stiffness and modulus were greater than the values measured after microcracking at the time of construction, indicating continued strength gain. Trafficking over the 9-month period had caused 
significantly lower stiffnesses measured in the wheel paths than between the wheel paths, which were 226 and 244 kips/in., respectively. The corresponding moduli in and between the wheel paths were 469 and 705 ksi. Though trafficking had a detrimental effect on both of these properties that may have been avoided if an HMA surface had been placed, the likelihood of continuing reductions in stiffness and modulus with future trafficking in the wheel paths is

unknown. The average UCS of the cores tested at 9 months was not significantly different than the average UCS of the field-compacted specimens tested at 6 weeks, and insufficient evidence exists to suggest that trafficking caused reductions in UCS.

\subsection{Recommendations}

As similar pavement designs have been applied successfully and as the economic benefits could potentially be very high, minor design alterations to this pavement design warrant investigation for use in freeze-thaw climates. In particular, improved performance may be achieved through the use of a thicker CTB layer and/or a higher cement content. A higher content might inhibit CTB erosion, rutting, and weakening, although the susceptibility of the layer to shrinkage cracking might increase. In addition, the ride quality may be improved through careful finishing of the CTB surface during construction. Finally, the application of a double chip seal or equivalent could better prevent water ingress and degradation of the CTB surface under trafficking. 


\section{REFERENCES}

1. Guthrie, W. S., A. V. Brown, and D. L. Eggett. Cement Stabilization of Aggregate Base Material Blended with Reclaimed Asphalt Pavement. In Transportation Research Record: Journal of the Transportation Research Board, No. 2026, Transportation Research Board of the National Academies, Washington, DC, 2007, pp. 47-53.

2. Halsted, G. E. Long-Term Performance of Failed Flexible Pavements Stabilized with Cement. In Proceedings of the Twelfth AASHTO-TRB Maintenance Management Conference, Annapolis, MD, 2009, pp. 101-115.

3. Steyn, W. J. vdM., M. De Beer, and A. T. Visser. Thin Asphalt and Double Seal Rehabilitated Lightly Cemented Pavements: Evaluation of Structural Behavior and Life Cycle Costs. In Proceedings of the $8^{\text {th }}$ International Conference on Asphalt Pavements, Seattle, Washington, August, 1997.

4. De Beer, M. Aspects of the Design and Behavior of Road Structures Incorporating Lightly Cementitious Layers. Ph.D. dissertation. Department of Civil Engineering, University of Pretoria, Pretoria, South Africa, February 1990.

5. Taha, R., A. Al-Harthy, K. Al-Shamsi, and M. Al-Zubeidi. Cement Stabilization of Reclaimed Asphalt Pavement Aggregate for Road Bases and Subbases. In Journal of Materials in Civil Engineering, Vol. 14, No. 3, May/June 2002, pp. 239-245.

6. Scullion, T., S. Guthrie, and S. Sebesta. Field Performance and Design Recommendations for Full Depth Recycling in Texas. Report 4182-1. Texas Transportation Institute, Texas A\&M University System, College Station, TX, March 2003.

7. Syed, I. M. and T. Scullion. In-Place Engineering Properties of Recycled and Stabilized Pavement Layers. Report 3903-S. Texas Transportation Institute, Texas A\&M University System, College Station, TX, May 2000.

8. Kennedy, J. Demonstration Project Report on the Use of Fly Ash Base. Internal Report. Texas Department of Transportation, Austin, TX, 2000.

9. Hope, C. A., B. T. Wilson, and W. S. Guthrie. Comparison of Dry Powder and Slurry Application Techniques for Cement Stabilization of Aggregate Base Materials. In Transportation Research Board 90th Annual Meeting Compendium of Papers, Transportation Research Board of the National Academies, Washington, D.C., January 2011. 
10. Yuan, D., S. Nazarian, L. R. Hoyos, and A. J. Puppla. Evaluation and Mix Design of Cement-Treated Base Materials with High RAP Content. In Transportation Research Board 90th Annual Meeting Compendium of Papers, Washington, DC, 2011.

11. Guthrie, W. S., and M. A. Rogers. Variability in Construction of Cement-Treated Base Layers. In Transportation Research Record: Journal of the Transportation Research Board, No. 2186, Transportation Research Board of the National Academies, Washington, DC, 2010, pp. 78-89.

12. Adaska, W., and D. Luhr. Control of Reflective Cracking in Cement Stabilized Pavements. Proceedings of the 5th International RILEM Conference, Limoges, France, May 2004, pp. 309-316.

13. George, K. P. Mechanism of Shrinkage Cracking of Soil-Cement Bases. In Highway Research Record, No. 442, HRB, National Research Council, Washington, DC, 1973, pp. 110.

14. Sebesta, S. Use of Microcracking to Reduce Shrinkage Cracking in Cement Treated Bases. In Transportation Research Record: Journal of the Transportation Research Board, No 1936, Transportation Research Board of the National Academies, Washington, D.C., 2005, pp. 3-11.

15. Scullion, T. Field Investigation: Precracking of Soil-Cement Bases to Reduce Reflection Cracking. In Transportation Research Record: Journal of the Transportation Research Board, No. 1787, Transportation Research Board of the National Academies, Washington DC, 2002, pp. 22-30.

16. Little, D. N., T. Scullion, P. B. V. S. Kota, and J. Bhuiyan. Guidelines for Mixture Design of Stabilized Bases and Subgrades. Publication FHWA/TX-45/1287-3 F. Texas Department of Transportation, Austin, TX, October 1995.

17. Scullion, T., S. Sebesta, J. P. Harris, and I. Syed. A Balanced Approach to Selecting the Optimal Cement Content for Soil-Cement Bases. Report 404611-1. Texas Transportation Institute, Texas A\&M University System, College Station, TX, 2000.

18. Shirazi, H. Field and Laboratory Evaluation of the Use of Lime Fly Ash to Replace Soil Cement as a Base Course. In Transportation Research Record: Journal of the Transportation Research Board, No 1652, Transportation Research Board of the National Academies, Washington, DC, 1999, pp. 270-275.

19. Guthrie, W. S., S. Sebesta, and T. Scullion. Design Considerations for Cement Stabilization of Aggregate Base Materials. Report 4920-1. Texas Transportation Institute, Texas A\&M University System, College Station, TX, 2001.

20. Halsted, G. E., D. Luhr, and W. S. Adaska. Guide to Cement-Treated Base (CTB). Publication EB236. Portland Cement Association, Skokie, IL, 2006. 
21. George, K. P. Soil Stabilization Field Trial: Interim Report I. Publication FHWA/MXDOT-RD-01-133. Mississippi Department of Transportation, Research Division, Jackson, MS, April 2001.

http://www.gomdot.com/Divisions/Highways/Resources/Research/pdf/Reports/InterimFinal/ SS133Interim1.pdf. Accessed November 15, 2010.

22. Web Climate Services. NOAA Satellite and Information Service, National Climatic Data Center, U. S. Department of Commerce, Asheville, NC.

http://www.ncdc.noaa.gov/oa/climate/stationlocator.html. Accessed April 28, 2010.

23. Climatic Data for Frost Protected Shallow Foundations. NOAA Satellite and Information Service, National Climatic Data Center, U. S. Department of Commerce, Asheville, NC. http://www.ncdc.noaa.gov/oa/fpsf/fpsfpublications.html. Accessed July 19, 2010.

24. BAKFAA with LEAF, Documents and Downloads Page. Airport Technology, Research and Development Branch, Federal Aviation Administration, Washington, DC. http://www.airporttech.tc.faa.gov/naptf/download/index1.asp. Accessed July 21, 2010.

25. Pavement Preservation Manual—Part 4: Pavement Condition Modeling with dTIMS. Office of Asset Management, Utah Department of Transportation, Salt Lake City, UT, 2009. http://udot.utah.gov/main/f?p=100:pg:0:::1:T,V:120. Accessed November 15, 2010. 


\section{APPENDIX A: RAW DATA}

Table A.1 Three-Day SSG Data at Section A

\begin{tabular}{|c|c|c|c|c|c|c|c|c|}
\hline \multirow[b]{3}{*}{ Station } & \multicolumn{8}{|c|}{ Stiffness (kips/in.) } \\
\hline & \multicolumn{4}{|c|}{ Before Microcracking } & \multicolumn{4}{|c|}{ After Microcracking } \\
\hline & 1 & 2 & 3 & Average & 1 & 2 & 3 & Average \\
\hline 1 & - & - & - & - & 147.9 & 148.4 & 149.1 & 148.5 \\
\hline 2 & - & - & - & - & 148.5 & 172.3 & 162.1 & 161.0 \\
\hline 3 & - & - & - & - & 136.7 & 134.4 & 138.3 & 136.5 \\
\hline 4 & - & - & - & - & 140.1 & 139.4 & 138.4 & 139.3 \\
\hline 5 & - & - & - & - & 162.3 & 164.0 & 156.0 & 160.8 \\
\hline 6 & - & - & - & - & 167.7 & 184.6 & 171.9 & 174.7 \\
\hline 7 & - & - & - & - & 271.1 & 254.0 & 243.5 & 256.2 \\
\hline 8 & - & - & - & - & 185.9 & 178.4 & 177.0 & 180.4 \\
\hline 9 & - & - & - & - & 180.7 & 184.2 & 173.4 & 179.4 \\
\hline 10 & - & - & - & - & 164.5 & 188.0 & 182.6 & 178.4 \\
\hline Average & & & & - & & & & 171.5 \\
\hline St. Dev. & & & & - & & & & 34.0 \\
\hline
\end{tabular}


Table A.2 Three-Day SSG Data at Section B

\begin{tabular}{|c|c|c|c|c|c|c|c|c|}
\hline \multirow[b]{3}{*}{ Station } & \multicolumn{8}{|c|}{ Stiffness (kips/in.) } \\
\hline & \multicolumn{4}{|c|}{ Before Microcracking } & \multicolumn{4}{|c|}{ After Microcracking } \\
\hline & 1 & 2 & 3 & Average & 1 & 2 & 3 & Average \\
\hline 1 & - & - & - & - & 112.1 & 110.5 & 108.7 & 110.5 \\
\hline 2 & - & - & - & - & 105.9 & 117.7 & 107.1 & 110.2 \\
\hline 3 & - & - & - & - & 108.7 & 107.6 & 105.4 & 107.2 \\
\hline 4 & - & - & - & - & 207.2 & 195.5 & 206.0 & 202.9 \\
\hline 5 & - & - & - & - & 235.2 & 258.6 & 261.4 & 251.7 \\
\hline 6 & - & - & - & - & 211.6 & 206.8 & 225.8 & 214.8 \\
\hline 7 & - & - & - & - & 227.2 & 189.5 & 193.9 & 203.5 \\
\hline 8 & - & - & - & - & 157.4 & 183.6 & 195.3 & 178.8 \\
\hline 9 & - & - & - & - & 132.1 & 130.8 & 130.2 & 131.0 \\
\hline 10 & 192.6 & 193.3 & 171.7 & 185.9 & 170.0 & 201.9 & 186.2 & 186.0 \\
\hline Average & & & & 185.9 & & & & 169.7 \\
\hline St. Dev. & & & & - & & & & 51.4 \\
\hline
\end{tabular}

Table A.3 Three-Day SSG Data at Section C

\begin{tabular}{|c|c|c|c|c|c|c|c|c|}
\hline \multirow[b]{3}{*}{ Station } & \multicolumn{8}{|c|}{ Stiffness (kips/in.) } \\
\hline & \multicolumn{4}{|c|}{ Before Microcracking } & \multicolumn{4}{|c|}{ After Microcracking } \\
\hline & 1 & 2 & 3 & Average & 1 & 2 & 3 & Average \\
\hline 1 & 254.5 & 246.4 & 246.6 & 249.2 & 170.8 & 166.8 & 156.8 & 164.8 \\
\hline 2 & 220.5 & 247.0 & 215.5 & 227.7 & 167.2 & 175.5 & 155.7 & 166.1 \\
\hline 3 & 201.6 & 225.2 & 212.6 & 213.2 & 214.0 & 200.1 & 191.1 & 201.7 \\
\hline 4 & 215.7 & 212.7 & 203.6 & 210.7 & 200.8 & 186.1 & 205.6 & 197.5 \\
\hline 5 & 217.8 & 216.2 & 213.9 & 216.0 & 174.2 & 176.3 & 165.1 & 171.9 \\
\hline 6 & 204.5 & 199.9 & 218.2 & 207.6 & 130.1 & 136.6 & 146.8 & 137.8 \\
\hline 7 & 220.8 & 189.7 & 205.3 & 205.3 & 174.4 & 170.6 & 178.5 & 174.5 \\
\hline 8 & 162.5 & 187.9 & 179.3 & 176.6 & 163.8 & 161.7 & 152.3 & 159.3 \\
\hline 9 & 156.6 & 139.5 & 147.9 & 148.0 & 152.8 & 149.2 & 143.6 & 148.5 \\
\hline 10 & 140.2 & 141.0 & 152.9 & 144.7 & 138.4 & 130.5 & 123.0 & 130.6 \\
\hline Average & & & & 199.9 & & & & 165.3 \\
\hline St. Dev. & & & & 33.5 & & & & 23.0 \\
\hline
\end{tabular}


Table A.4 Three-Day SSG Data at Section D

\begin{tabular}{|c|c|c|c|c|c|c|c|c|}
\hline \multirow[b]{3}{*}{ Station } & \multicolumn{8}{|c|}{ Stiffness (kips/in.) } \\
\hline & \multicolumn{4}{|c|}{ Before Microcracking } & \multicolumn{4}{|c|}{ After Microcracking } \\
\hline & 1 & 2 & 3 & Average & 1 & 2 & 3 & Average \\
\hline 1 & 154.3 & 158.8 & 171.1 & 161.4 & 123.5 & 119.9 & 131.3 & 124.9 \\
\hline 2 & 228.1 & 206.9 & 207.8 & 214.3 & 169.7 & 167.7 & 172.5 & 170.0 \\
\hline 3 & 165.0 & 154.5 & 168.2 & 162.5 & 142.3 & 131.9 & 142.6 & 138.9 \\
\hline 4 & 212.4 & 211.3 & 208.7 & 210.8 & 160.6 & 164.3 & 167.5 & 164.1 \\
\hline 5 & 193.7 & 210.2 & 208.0 & 204.0 & 140.6 & 138.0 & 163.7 & 147.5 \\
\hline 6 & 183.8 & 174.2 & 162.3 & 173.4 & 146.0 & 114.1 & 146.8 & 135.6 \\
\hline 7 & 275.6 & 282.6 & 288.9 & 282.3 & 199.3 & 217.0 & 216.2 & 210.9 \\
\hline 8 & 148.3 & 148.3 & 145.8 & 147.5 & 113.7 & 105.4 & 109.7 & 109.6 \\
\hline 9 & 213.7 & 222.9 & 221.4 & 219.3 & 147.9 & 157.4 & 147.2 & 150.8 \\
\hline 10 & 257.5 & 260.2 & 271.7 & 263.1 & 212.9 & 208.8 & 205.7 & 209.1 \\
\hline Average & & & & 203.9 & & & & 156.1 \\
\hline St. Dev. & & & & 44.3 & & & & 33.4 \\
\hline
\end{tabular}

Table A.5 Three-Day SSG Data at Section E

\begin{tabular}{|c|c|c|c|c|c|c|c|c|}
\hline \multirow[b]{3}{*}{ Station } & \multicolumn{8}{|c|}{ Stiffness (kips/in.) } \\
\hline & \multicolumn{4}{|c|}{ Before Microcracking } & \multicolumn{4}{|c|}{ After Microcracking } \\
\hline & 1 & 2 & 3 & Average & 1 & 2 & 3 & Average \\
\hline 1 & 253.6 & 281.7 & 264.0 & 266.4 & 183.8 & 160.2 & 177.6 & 173.8 \\
\hline 2 & 265.4 & 263.1 & 255.3 & 261.2 & 195.5 & 195.3 & 206.4 & 199.1 \\
\hline 3 & 209.2 & 227.7 & 217.6 & 218.1 & 190.7 & 190.1 & 170.8 & 183.9 \\
\hline 4 & 287.1 & 284.0 & 289.4 & 286.8 & 205.2 & 195.8 & 194.4 & 198.5 \\
\hline 5 & 210.5 & 205.6 & 212.5 & 209.5 & 135.2 & 136.3 & 128.6 & 133.4 \\
\hline 6 & 159.5 & 157.2 & 164.6 & 160.4 & 133.9 & 135.6 & 139.1 & 136.2 \\
\hline 7 & 275.7 & 270.6 & 276.5 & 274.3 & 163.3 & 164.2 & 162.2 & 163.2 \\
\hline 8 & 218.3 & 238.1 & 209.6 & 222.0 & 167.3 & 171.6 & 174.5 & 171.1 \\
\hline 9 & 264.0 & 232.7 & 194.5 & 230.4 & 156.1 & 152.3 & 158.4 & 155.6 \\
\hline 10 & 212.4 & 233.5 & 224.3 & 223.4 & 192.5 & 198.1 & 189.9 & 193.5 \\
\hline 11 & 289.0 & 312.5 & 276.7 & 292.7 & 224.3 & 216.2 & 209.8 & 216.8 \\
\hline Average & & & & 240.5 & & & & 175.0 \\
\hline St. Dev. & & & & 39.7 & & & & 26.6 \\
\hline
\end{tabular}


Table A.6 Three-Day SSG Data at Section F

\begin{tabular}{|c|c|c|c|c|c|c|c|c|}
\hline \multirow[b]{3}{*}{ Station } & \multicolumn{8}{|c|}{ Stiffness (kips/in.) } \\
\hline & \multicolumn{4}{|c|}{ Before Microcracking } & \multicolumn{4}{|c|}{ After Microcracking } \\
\hline & 1 & 2 & 3 & Average & 1 & 2 & 3 & Average \\
\hline 1 & 154.2 & 153.3 & 152.1 & 153.2 & 100.5 & 101.1 & 105.9 & 102.5 \\
\hline 2 & 143.7 & 159.5 & 161.1 & 154.8 & 136.8 & 123.1 & 123.7 & 127.9 \\
\hline 3 & 230.6 & 229.1 & 245.8 & 235.2 & 209.2 & 188.4 & 197.8 & 198.5 \\
\hline 4 & 227.4 & 208.5 & 221.6 & 219.2 & 173.2 & 183.9 & 186.4 & 181.2 \\
\hline 5 & 264.0 & 246.1 & 246.8 & 252.3 & 214.4 & 198.5 & 208.6 & 207.2 \\
\hline 6 & 175.3 & 175.0 & 200.2 & 183.5 & 166.3 & 161.5 & 164.2 & 164.0 \\
\hline 7 & 181.2 & 180.5 & 171.9 & 177.9 & 139.2 & 140.5 & 136.1 & 138.6 \\
\hline 8 & 254.2 & 253.5 & 251.2 & 253.0 & 174.5 & 170.8 & 173.9 & 173.1 \\
\hline 9 & 183.5 & 184.0 & 178.8 & 182.1 & 148.6 & 131.7 & 141.2 & 140.5 \\
\hline 10 & 238.5 & 239.8 & 225.9 & 234.7 & 166.3 & 161.3 & 166.9 & 164.9 \\
\hline Average & & & & 204.6 & & & & 159.8 \\
\hline St. Dev. & & & & 38.7 & & & & 32.6 \\
\hline
\end{tabular}

Table A.7 Three-Day PFWD Data at Section A

\begin{tabular}{|c|c|c|c|c|c|c|c|c|}
\hline \multirow[b]{4}{*}{ Station } & \multicolumn{4}{|c|}{ Before Microcracking } & \multicolumn{4}{|c|}{ After Microcracking } \\
\hline & \multirow[b]{3}{*}{ Load (lbf) } & \multirow{2}{*}{\multicolumn{3}{|c|}{$\frac{\text { Sensor Deflection (mils) }}{\text { Offset (in.) }}$}} & \multirow[b]{3}{*}{ Load (lbf) } & \multirow{2}{*}{\multicolumn{3}{|c|}{$\frac{\text { Sensor Deflection (mils) }}{\text { Offset (in.) }}$}} \\
\hline & & & & & & & & \\
\hline & & 0 & 12 & 24 & & 0 & 12 & 24 \\
\hline 1 & 3830 & 21.70 & 10.37 & 4.51 & 3923 & 21.62 & 10.30 & 4.25 \\
\hline 2 & 3848 & 13.28 & 7.88 & 4.34 & 3901 & 16.35 & 8.36 & 4.40 \\
\hline 3 & 3841 & 15.17 & 8.36 & 3.90 & 3944 & 15.56 & 8.61 & 4.03 \\
\hline 4 & 3886 & 11.03 & 6.62 & 3.75 & 3925 & 14.21 & 7.19 & 3.87 \\
\hline 5 & 3916 & 11.50 & 7.05 & 3.72 & 3930 & 12.93 & 7.72 & 3.87 \\
\hline 6 & 3339 & 8.17 & 5.32 & 3.25 & 3958 & 11.31 & 7.15 & 3.82 \\
\hline 7 & 3980 & 5.68 & 3.97 & 2.75 & 3940 & 6.70 & 4.16 & 2.75 \\
\hline 8 & 3954 & 10.20 & 6.32 & 3.73 & 3911 & 11.40 & 6.03 & 3.89 \\
\hline 9 & 3957 & 8.88 & 5.50 & 3.07 & 3816 & 10.11 & 5.89 & 3.22 \\
\hline 10 & 3986 & 13.04 & 8.24 & 4.88 & 3715 & 14.20 & 9.71 & 5.00 \\
\hline
\end{tabular}


Table A.8 Three-Day PFWD Data at Section B

\begin{tabular}{|c|c|c|c|c|c|c|c|c|}
\hline \multirow[b]{4}{*}{ Station } & \multicolumn{4}{|c|}{ Before Microcracking } & \multicolumn{4}{|c|}{ After Microcracking } \\
\hline & \multirow[b]{3}{*}{ Load (lbf) } & \multicolumn{3}{|c|}{ Sensor Deflection (mils) } & \multicolumn{4}{|c|}{ Sensor Deflection (mils) } \\
\hline & & \multicolumn{3}{|c|}{ Offset (in.) } & \multirow[b]{2}{*}{ Load (lbf) } & \multicolumn{3}{|c|}{ Offset (in.) } \\
\hline & & 0 & 12 & 24 & & 0 & 12 & 24 \\
\hline 1 & - & - & - & - & 3922 & 16.93 & 8.07 & 3.40 \\
\hline 2 & 3745 & 32.16 & 12.88 & 3.42 & 3805 & 34.67 & 15.03 & 3.34 \\
\hline 3 & 3884 & 23.58 & 9.06 & 2.93 & 3815 & 24.83 & 8.96 & 2.74 \\
\hline 4 & 3948 & 6.07 & 3.46 & 1.60 & 3957 & 9.32 & 5.05 & 1.87 \\
\hline 5 & 3177 & 8.30 & 4.68 & 2.46 & 3388 & 9.34 & 5.47 & 2.63 \\
\hline 6 & 3984 & 13.79 & 8.01 & 4.43 & 3360 & 15.77 & 9.17 & 4.37 \\
\hline 7 & 3617 & 9.79 & 5.68 & 3.05 & 3949 & 17.40 & 7.72 & 3.56 \\
\hline 8 & 3816 & 17.03 & 7.67 & 3.36 & 3906 & 21.71 & 7.36 & 3.75 \\
\hline 9 & 3351 & 19.44 & 6.78 & 2.98 & 3823 & 32.60 & 11.68 & 4.06 \\
\hline 10 & 3235 & 9.02 & 4.63 & 2.16 & 3914 & 11.66 & 6.16 & 2.83 \\
\hline
\end{tabular}

Table A.9 Three-Day PFWD Data at Section C

\begin{tabular}{|c|c|c|c|c|c|c|c|c|}
\hline \multirow[b]{4}{*}{ Station } & \multicolumn{4}{|c|}{ Before Microcracking } & \multicolumn{4}{|c|}{ After Microcracking } \\
\hline & \multirow[b]{3}{*}{ Load (lbf) } & \multirow{2}{*}{\multicolumn{3}{|c|}{$\frac{\text { Sensor Deflection (mils) }}{\text { Offset (in.) }}$}} & \multirow[b]{3}{*}{ Load (lbf) } & \multirow{2}{*}{\multicolumn{3}{|c|}{$\frac{\text { Sensor Deflection (mils) }}{\text { Offset (in.) }}$}} \\
\hline & & & & & & & & \\
\hline & & 0 & 12 & 24 & & 0 & 12 & 24 \\
\hline 1 & 3875 & 7.95 & 5.38 & 3.31 & 3855 & 10.48 & 6.04 & 3.56 \\
\hline 2 & 3719 & 33.45 & 22.92 & 9.60 & 3627 & 31.35 & 21.06 & 8.01 \\
\hline 3 & 3850 & 16.73 & 8.45 & 3.78 & 3680 & 19.68 & 9.30 & 3.78 \\
\hline 4 & 3873 & 5.07 & 3.28 & 1.94 & 3854 & 6.70 & 3.57 & 1.94 \\
\hline 5 & 3864 & 15.00 & 9.36 & 4.43 & 3775 & 17.23 & 8.86 & 4.29 \\
\hline 6 & 3926 & 9.74 & 6.41 & 3.69 & 3728 & 10.51 & 6.85 & 3.89 \\
\hline 7 & 3871 & 10.42 & 5.88 & 3.20 & 3654 & 13.47 & 6.38 & 3.33 \\
\hline 8 & 3900 & 10.52 & 6.05 & 3.23 & 3782 & 10.74 & 5.94 & 3.08 \\
\hline 9 & 3803 & 11.55 & 6.78 & 3.34 & 3766 & 11.98 & 6.75 & 3.22 \\
\hline 10 & 2961 & 9.44 & 5.12 & 2.54 & 3799 & 13.56 & 7.28 & 3.17 \\
\hline
\end{tabular}


Table A.10 Three-Day PFWD Data at Section D

\begin{tabular}{|c|c|c|c|c|c|c|c|c|}
\hline \multirow[b]{4}{*}{ Station } & \multicolumn{4}{|c|}{ Before Microcracking } & \multicolumn{4}{|c|}{ After Microcracking } \\
\hline & \multirow[b]{3}{*}{ Load (lbf) } & \multirow{2}{*}{\multicolumn{3}{|c|}{$\frac{\text { Sensor Deflection (mils) }}{\text { Offset (in.) }}$}} & \multirow[b]{3}{*}{ Load (lbf) } & \multirow{2}{*}{\multicolumn{3}{|c|}{$\frac{\text { Sensor Deflection (mils) }}{\text { Offset (in.) }}$}} \\
\hline & & & & & & & & \\
\hline & & 0 & 12 & 24 & & 0 & 12 & 24 \\
\hline 1 & 3430 & 12.95 & 7.39 & 4.03 & 3734 & 16.97 & 8.60 & 4.50 \\
\hline 2 & 3913 & 10.18 & 6.71 & 3.82 & 3695 & 14.70 & 8.73 & 4.29 \\
\hline 3 & 3858 & 24.49 & 8.78 & 4.14 & 3740 & 27.62 & 9.51 & 4.31 \\
\hline 4 & 3338 & 10.50 & 6.34 & 3.58 & 3761 & 17.14 & 7.88 & 4.27 \\
\hline 5 & 3732 & 13.26 & 7.45 & 4.04 & 3728 & 16.00 & 8.12 & 4.06 \\
\hline 6 & 2682 & 7.93 & 4.35 & 2.66 & 3662 & 14.49 & 7.36 & 4.42 \\
\hline 7 & 3944 & 7.72 & 5.78 & 3.59 & 3765 & 11.54 & 7.86 & 4.13 \\
\hline 8 & 3842 & 19.80 & 9.28 & 4.68 & 3779 & 23.45 & 11.76 & 5.41 \\
\hline 9 & 3842 & 9.77 & 5.89 & 3.79 & 3770 & 13.39 & 7.40 & 4.34 \\
\hline 10 & 3845 & 10.59 & 7.12 & 4.30 & 3812 & 15.14 & 10.33 & 5.52 \\
\hline
\end{tabular}

Table A.11 Three-Day PFWD Data at Section E

\begin{tabular}{|c|c|c|c|c|c|c|c|c|}
\hline \multirow[b]{4}{*}{ Station } & \multicolumn{4}{|c|}{ Before Microcracking } & \multicolumn{4}{|c|}{ After Microcracking } \\
\hline & \multirow[b]{3}{*}{ Load (lbf) } & \multirow{2}{*}{\multicolumn{3}{|c|}{$\frac{\text { Sensor Deflection (mils) }}{\text { Offset (in.) }}$}} & \multirow[b]{3}{*}{ Load (lbf) } & \multirow{2}{*}{\multicolumn{3}{|c|}{$\frac{\text { Sensor Deflection (mils) }}{\text { Offset (in.) }}$}} \\
\hline & & & & & & & & \\
\hline & & 0 & 12 & 24 & & 0 & 12 & 24 \\
\hline 1 & 3661 & 10.45 & 6.81 & 4.05 & 3571 & 15.53 & 8.59 & 4.28 \\
\hline 2 & 3355 & 6.56 & 4.46 & 2.77 & 3773 & 8.46 & 5.76 & 3.47 \\
\hline 3 & 3694 & 9.24 & 6.18 & 3.45 & 3735 & 15.99 & 7.84 & 3.63 \\
\hline 4 & 3685 & 7.54 & 5.14 & 3.24 & 3745 & 9.75 & 6.33 & 3.62 \\
\hline 5 & 3249 & 12.42 & 7.11 & 3.83 & 3741 & 20.95 & 10.39 & 4.74 \\
\hline 6 & 3559 & 17.24 & 6.97 & 3.48 & 3582 & 22.36 & 6.99 & 3.43 \\
\hline 7 & 3704 & 9.68 & 5.40 & 3.34 & 3659 & 9.13 & 5.03 & 2.98 \\
\hline 8 & 3633 & 13.06 & 6.42 & 3.87 & 3611 & 13.09 & 7.20 & 4.28 \\
\hline 9 & 3589 & 13.48 & 8.23 & 4.56 & 3590 & 19.83 & 10.97 & 4.62 \\
\hline 10 & 3641 & 10.67 & 6.82 & 4.10 & 3707 & 18.57 & 9.49 & 4.68 \\
\hline 11 & 3814 & 12.26 & 7.73 & 4.13 & 3748 & 18.47 & 10.69 & 4.90 \\
\hline
\end{tabular}


Table A.12 Three-Day PFWD Data at Section F

\begin{tabular}{|c|c|c|c|c|c|c|c|c|}
\hline \multirow[b]{4}{*}{ Station } & \multicolumn{4}{|c|}{ Before Microcracking } & \multicolumn{4}{|c|}{ After Microcracking } \\
\hline & \multirow[b]{3}{*}{ Load (lbf) } & \multirow{2}{*}{\multicolumn{3}{|c|}{$\begin{array}{l}\text { Sensor Deflection (mils) } \\
\text { Offset (in.) }\end{array}$}} & \multirow[b]{3}{*}{ Load (lbf) } & \multirow{2}{*}{\multicolumn{3}{|c|}{$\frac{\text { Sensor Deflection (mils) }}{\text { Offset (in.) }}$}} \\
\hline & & & & & & & & \\
\hline & & 0 & 12 & 24 & & 0 & 12 & 24 \\
\hline 1 & 3682 & 20.00 & 6.98 & 3.40 & 3786 & 27.85 & 9.46 & 3.80 \\
\hline 2 & 3738 & 14.11 & 8.38 & 4.61 & 3743 & 17.73 & 11.91 & 5.73 \\
\hline 3 & 3666 & 8.25 & 4.94 & 3.09 & 3848 & 12.62 & 7.24 & 3.75 \\
\hline 4 & 3674 & 4.72 & 2.63 & 1.52 & 3539 & 5.88 & 3.19 & 1.61 \\
\hline 5 & 3687 & 10.08 & 6.16 & 3.89 & 3799 & 15.15 & 9.07 & 4.89 \\
\hline 6 & 3685 & 28.64 & 19.56 & 10.76 & 3357 & 32.28 & 21.97 & 11.43 \\
\hline 7 & 3671 & 19.22 & 6.57 & 2.53 & 3840 & 24.44 & 10.42 & 3.84 \\
\hline 8 & 3716 & 6.32 & 4.11 & 2.30 & 3893 & 10.11 & 6.36 & 3.06 \\
\hline 9 & 3820 & 11.69 & 6.04 & 3.28 & 3819 & 16.68 & 6.95 & 3.35 \\
\hline 10 & 3725 & 7.45 & 4.95 & 2.69 & 3858 & 8.70 & 5.61 & 3.11 \\
\hline
\end{tabular}

Table A.13 Inputs for 3-Day Modulus Backcalculations

\begin{tabular}{lc}
\hline Parameter & Value \\
\hline Plate Radius (in.) & 3.9 \\
CTB & \\
$\quad$ Modulus (ksi) & 500,000 \\
$\quad$ Poisson's Ratio & 0.15 \\
Interface Parameter & 1.0 \\
$\quad$ Thickness (in.) & 7.0 \\
Subbase-Subgrade & \\
$\quad$ Modulus (ksi) & 11,000 \\
$\quad$ Poisson's Ratio & 0.35 \\
Interface Parameter & 1.0 \\
\hline
\end{tabular}


Table A.14 Seven-Day UCS Data for Field-Compacted Specimens

\begin{tabular}{llccc}
\hline Location & Specimen & UCS (psi) & Moisture Content (\%) & Dry Density (pcf) \\
\hline 1 & 1 & 325 & 7.6 & 120.5 \\
& 2 & 355 & 7.6 & 118.2 \\
& 3 & 349 & 7.4 & 120.1 \\
\hline 2 & 1 & 466 & 8.7 & 116.5 \\
& 2 & 537 & 7.6 & 118.9 \\
& 3 & 456 & 8.3 & 118.2 \\
\hline
\end{tabular}

Table A.15 Six-Week UCS Data for Field-Compacted Specimens

\begin{tabular}{llccc}
\hline Location & Specimen & UCS (psi) & Moisture Content (\%) & Dry Density (pcf) \\
\hline 1 & 1 & 454 & 6.6 & 120.1 \\
& 2 & 392 & 7.2 & 118.4 \\
& 3 & 435 & 7.0 & 119.8 \\
\hline 2 & 1 & 831 & 7.0 & 119.6 \\
& 2 & 890 & 6.6 & 119.3 \\
\hline
\end{tabular}

Table A.16 Nine-Month SSG Data

\begin{tabular}{|c|c|c|c|c|c|c|}
\hline \multirow[b]{3}{*}{ Station } & \multicolumn{6}{|c|}{ Stiffness (kips/in.) } \\
\hline & \multicolumn{3}{|c|}{ In Wheel Path } & \multicolumn{3}{|c|}{ Between Wheel Paths } \\
\hline & 1 & 2 & 3 & 1 & 2 & 3 \\
\hline 1 & 173.0 & 161.3 & 173.8 & 140.8 & 143.8 & 135.7 \\
\hline 2 & 38.1 & 127.8 & 169.6 & 209.3 & 210.5 & 231.9 \\
\hline 3 & 37.0 & 235.9 & 215.7 & 189.8 & 253.8 & 255.9 \\
\hline 4 & 38.1 & 230.9 & 238.8 & 214.3 & 257.5 & 256.4 \\
\hline 5 & 41.8 & 208.0 & 186.8 & 255.2 & 229.0 & 256.9 \\
\hline 6 & 46.0 & 272.0 & 260.2 & 286.3 & 294.4 & 283.7 \\
\hline 7 & 39.0 & 227.1 & 233.1 & 215.4 & 231.6 & 267.2 \\
\hline 8 & 35.4 & 197.5 & 192.5 & 282.1 & 286.1 & 165.5 \\
\hline 9 & 50.3 & 242.3 & 254.2 & 260.3 & 225.9 & 270.1 \\
\hline 10 & 38.8 & 224.4 & 203.7 & 289.2 & 238.3 & 304.5 \\
\hline 11 & 37.1 & 203.5 & 188.3 & 225.2 & 256.8 & 230.4 \\
\hline 12 & 38.9 & 227.0 & 226.7 & 239.4 & 232.1 & 261.1 \\
\hline 13 & 48.9 & 223.7 & 247.9 & 263.0 & 190.8 & 250.2 \\
\hline 14 & 42.7 & 243.8 & 253.4 & 296.2 & 277.7 & 292.6 \\
\hline 15 & 49.8 & 287.4 & 307.0 & 249.9 & 201.5 & 244.3 \\
\hline
\end{tabular}


Table A.17 Nine-Month PFWD Data

\begin{tabular}{|c|c|c|c|c|c|c|c|c|c|}
\hline \multirow[b]{4}{*}{ Station } & \multicolumn{5}{|c|}{ In Wheel Path } & \multicolumn{4}{|c|}{ Between Wheel Paths } \\
\hline & \multirow{3}{*}{$\begin{array}{c}\text { CTB } \\
\text { Thickness (in.) }\end{array}$} & \multirow[b]{3}{*}{ Load (lbf) } & \multicolumn{3}{|c|}{ Sensor Deflection (mils) } & \multirow[b]{3}{*}{ Load (lbf) } & \multirow{2}{*}{\multicolumn{3}{|c|}{$\begin{array}{l}\text { Sensor Deflection (mils) } \\
\text { Offset (in.) }\end{array}$}} \\
\hline & & & Offset & & & & & & \\
\hline & & & 0 & 12 & 24 & & 0 & 12 & 24 \\
\hline 1 & 7.00 & 3894 & 11.66 & 6.74 & 4.18 & 3859 & 16.35 & 8.36 & 4.40 \\
\hline 2 & 6.88 & 3894 & 7.72 & 4.56 & 2.77 & 3996 & 4.26 & 3.45 & 2.33 \\
\hline 3 & 6.69 & 3873 & 9.46 & 6.04 & 3.39 & 3570 & 5.66 & 4.23 & 2.71 \\
\hline 4 & 6.13 & 3236 & 8.54 & 4.92 & 2.53 & 3778 & 6.92 & 4.86 & 2.83 \\
\hline 5 & 7.63 & 3916 & 8.76 & 6.11 & 3.34 & 3935 & 6.05 & 4.92 & 2.58 \\
\hline 6 & 7.88 & 3358 & 5.86 & 4.94 & 3.05 & 4048 & 6.68 & 4.36 & 2.55 \\
\hline 7 & 7.00 & 3850 & 7.84 & 6.48 & 3.60 & 3916 & 11.60 & 6.12 & 3.42 \\
\hline 8 & 7.06 & 3833 & 11.65 & 6.72 & 3.67 & 3929 & 6.60 & 5.08 & 3.23 \\
\hline 9 & 7.19 & 3889 & 4.96 & 4.35 & 3.38 & 3935 & 3.60 & 3.13 & 2.37 \\
\hline 10 & 6.56 & 3866 & 7.66 & 5.75 & 3.92 & 3957 & 5.63 & 4.75 & 3.30 \\
\hline 11 & 8.00 & 3935 & 8.14 & 5.23 & 3.88 & 4005 & 9.43 & 6.57 & 3.85 \\
\hline 12 & 7.75 & 3538 & 9.42 & 6.91 & 4.49 & 3908 & 7.30 & 6.16 & 4.02 \\
\hline 13 & 7.13 & 3957 & 7.04 & 6.18 & 4.48 & 3611 & 7.17 & 5.32 & 3.83 \\
\hline 14 & 7.38 & 3876 & 12.79 & 7.60 & 4.82 & 3941 & 7.11 & 5.58 & 3.99 \\
\hline 15 & 7.38 & 3938 & 6.49 & 5.62 & 4.24 & 3945 & 8.97 & 6.72 & 4.53 \\
\hline
\end{tabular}

Table A.18 Inputs for 9-Month Modulus Backcalculations

\begin{tabular}{lc}
\hline Parameter & Value \\
\hline Plate Radius (in.) & 3.9 \\
CTB & \\
$\quad$ Modulus (ksi) & 800,000 \\
Poisson's Ratio & 0.15 \\
$\quad$ Interface Parameter & 1.0 \\
Subbase-Subgrade & \\
$\quad$ Modulus (ksi) & 11,250 \\
Poisson's Ratio & 0.35 \\
Interface Parameter & 1.0 \\
\hline
\end{tabular}


Table A.19 Nine-Month Core Properties in the Wheel Path

\begin{tabular}{lccccc}
\hline Station & UCS (psi) & CTB Depth (in.) & Moisture Content (\%) & Dry Density (pcf) & RAP Content (\%) \\
\hline 1 & - & - & - & - & 59 \\
2 & 503 & 6.6 & 12.6 & 112.8 & 32 \\
3 & 549 & 6.4 & 11.2 & 112.9 & 48 \\
4 & 461 & 6.4 & 12.3 & 110.5 & 54 \\
5 & - & - & 13.6 & 106.4 & 55 \\
6 & 421 & 8.1 & 9.3 & 113.7 & 60 \\
7 & 238 & 7.0 & 9.7 & 108.7 & 72 \\
8 & 221 & 6.3 & 8.6 & 108.9 & 80 \\
9 & 825 & 7.4 & 11.0 & 115.0 & 44 \\
10 & 774 & 5.5 & 10.9 & 114.6 & 50 \\
11 & 760 & 8.4 & 12.3 & 111.9 & 44 \\
12 & 525 & 7.8 & 13.1 & 110.9 & 30 \\
13 & 749 & 7.4 & 10.1 & 113.5 & 55 \\
14 & - & 7.0 & 11.8 & 109.5 & 69 \\
15 & 1017 & 8.3 & 8.7 & 117.7 & 71 \\
\hline
\end{tabular}

Table A.20 Nine-Month Core Properties between the Wheel Paths

\begin{tabular}{lccccc}
\hline Station & UCS (psi) & CTB Depth (in.) & Moisture Content (\%) & Dry Density (pcf) & RAP Content (\%) \\
\hline 1 & - & - & - & - & 46 \\
2 & 784 & 7.1 & 10.3 & 115.4 & 40 \\
3 & 470 & 7.0 & 10.6 & 114.2 & 60 \\
4 & 419 & 5.9 & 12.6 & 112.2 & 45 \\
5 & 357 & 7.6 & 11.2 & 111.1 & 52 \\
6 & 331 & 7.6 & 9.5 & 113.8 & 68 \\
7 & - & - & 11.3 & 108.1 & 70 \\
8 & 500 & 7.9 & 8.1 & 116.2 & 70 \\
9 & 298 & 7.0 & 12.9 & 111.2 & 35 \\
10 & 550 & 7.6 & 10.1 & 116.2 & 54 \\
11 & 339 & 7.6 & 11.3 & 110.9 & 45 \\
12 & 465 & - & 14.1 & 110.7 & 25 \\
13 & 660 & 6.9 & 9.3 & 113.5 & 54 \\
14 & 633 & 7.8 & 9.0 & 115.1 & 69 \\
15 & 331 & 6.5 & 10.6 & 109.4 & 62 \\
\hline
\end{tabular}


APPENDIX B: DISTRESS SURVEYS 


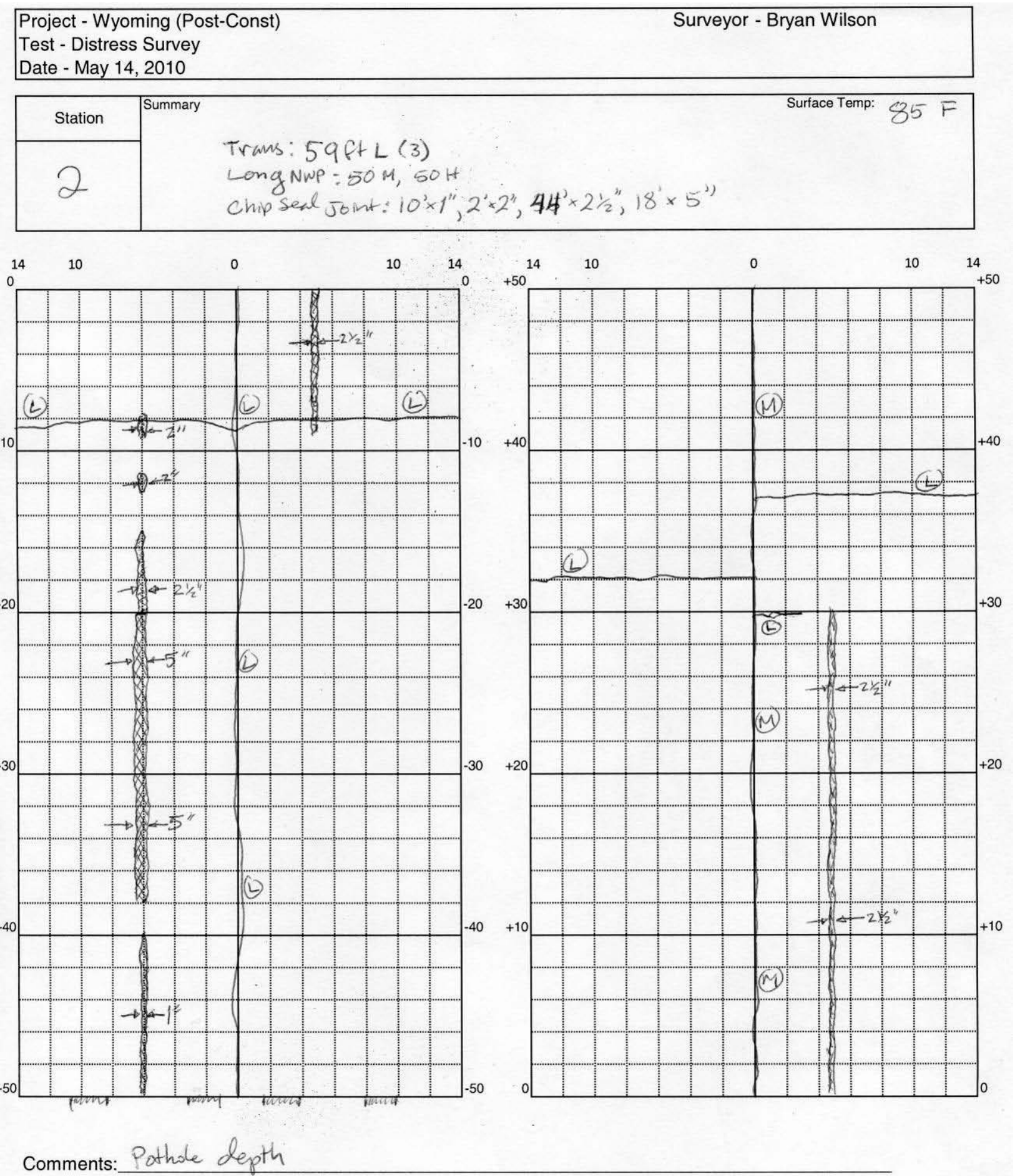

Figure B.2 Nine-month distress survey of station 2. 
Project - Wyoming (Post-Const)

Surveyor - Bryan Wilson

Test - Distress Survey

Date - May 14, 2010

\begin{tabular}{|c|c|c|}
\hline Station & Summary & Surface Temp: $75 \mathrm{~F}$ \\
\hline 3 & $\begin{array}{l}\text { Lony: } 85 \mathrm{ft} L \text { Long WP: } 52 \mathrm{ft} L \\
\left.\text { Chip Seal Joint: } 5^{\prime} \times 1^{\prime \prime}, 20^{\prime} \times 1^{\prime \prime}\right)^{\prime \prime}, 4^{\prime} \times 3^{\prime \prime}, 7^{\prime} \times 4^{\prime \prime}\end{array}$ & \\
\hline
\end{tabular}

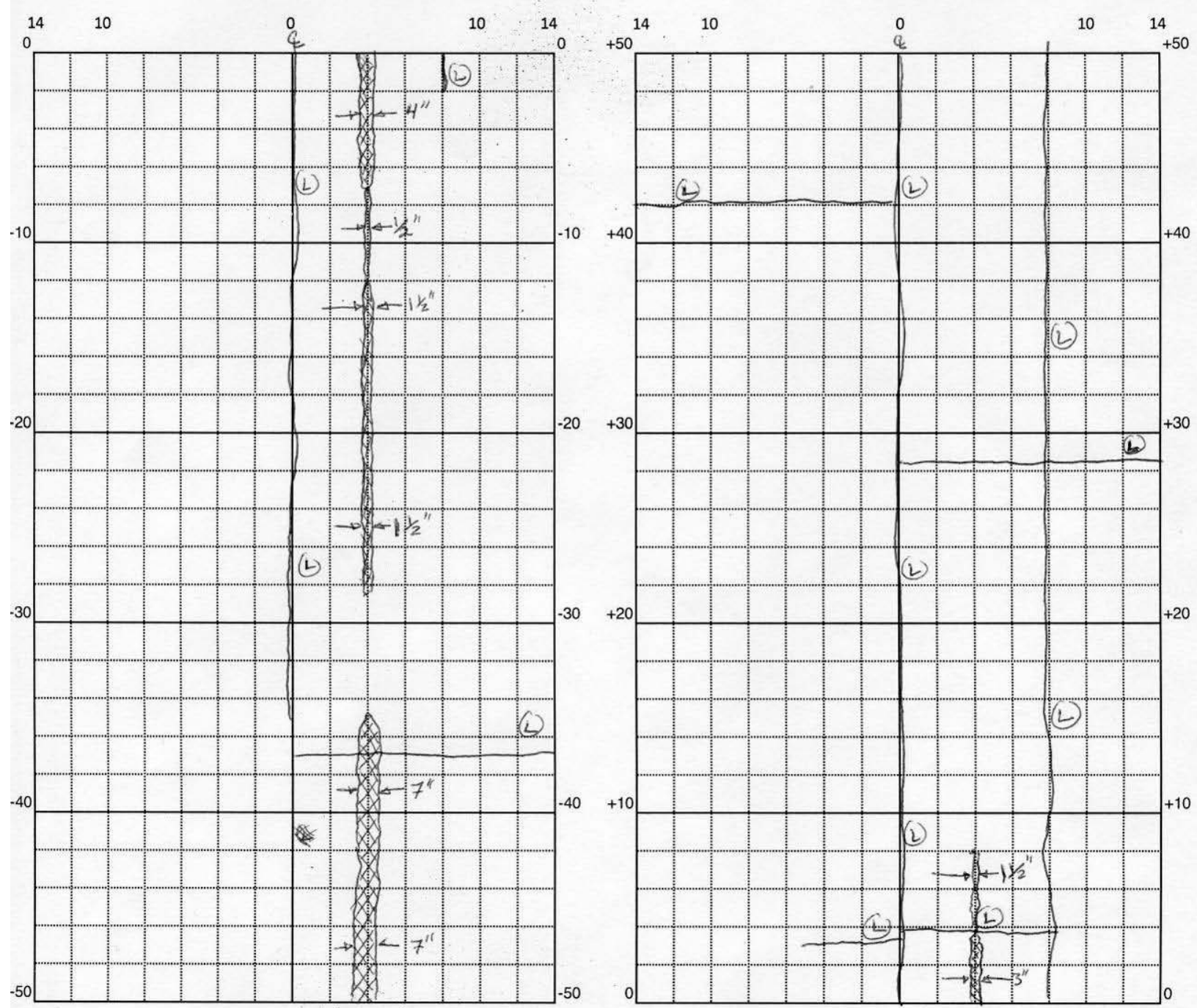

Comments: Longitudinal crack on mbound lane is an edge of rutting, not construction joint

Figure B.3 Nine-month distress survey of station 3. 
Project - Wyoming (Post-Const)

Surveyor - Bryan Wilson

Test - Distress Survey

Date - May $1 \not \$, 2010$

\begin{tabular}{|c|c|c|}
\hline Station & Summary & Surface Temp: $65 \mathrm{~F}$ \\
\hline 2 & $\begin{array}{l}\text { Long NwP: } 3 \text { ft L } \\
\text { chip seal Jont: } 11^{\prime} \times 2^{\prime \prime}, 53^{\prime} \times 3^{\prime \prime}, 11^{\prime} \times 41^{\prime \prime}, 13^{\prime \prime} \times 5^{\prime \prime}\end{array}$ & \\
\hline
\end{tabular}

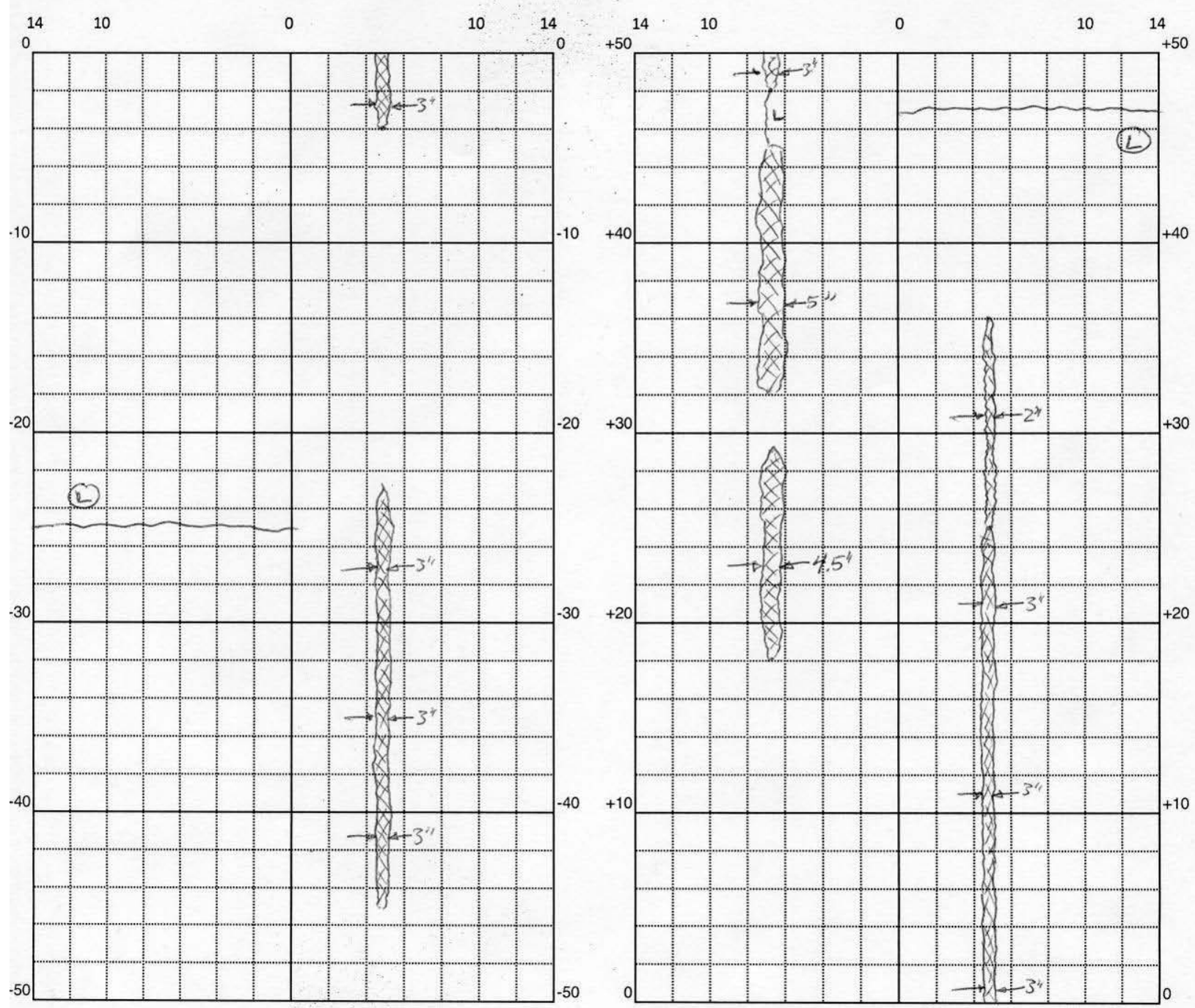

Comments.

Figure B.4 Nine-month distress survey of station 4. 
Project - Wyoming (Post-Const)

Surveyor - Bryan Wilson

Test - Distress Survey

Date - May 14, 2010

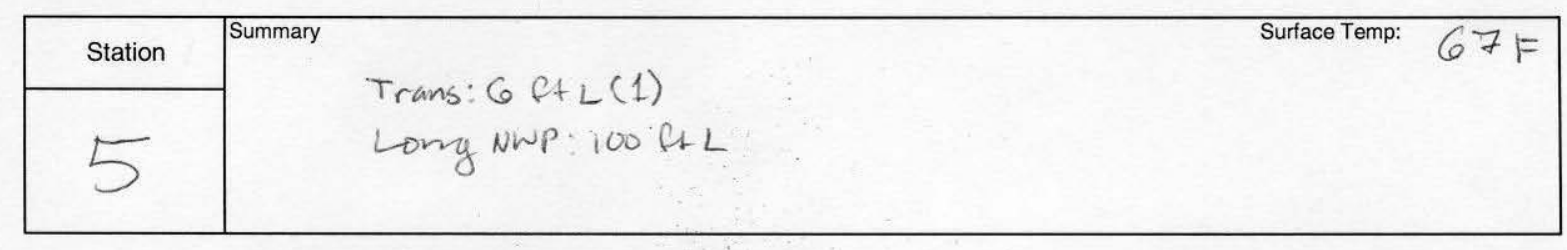
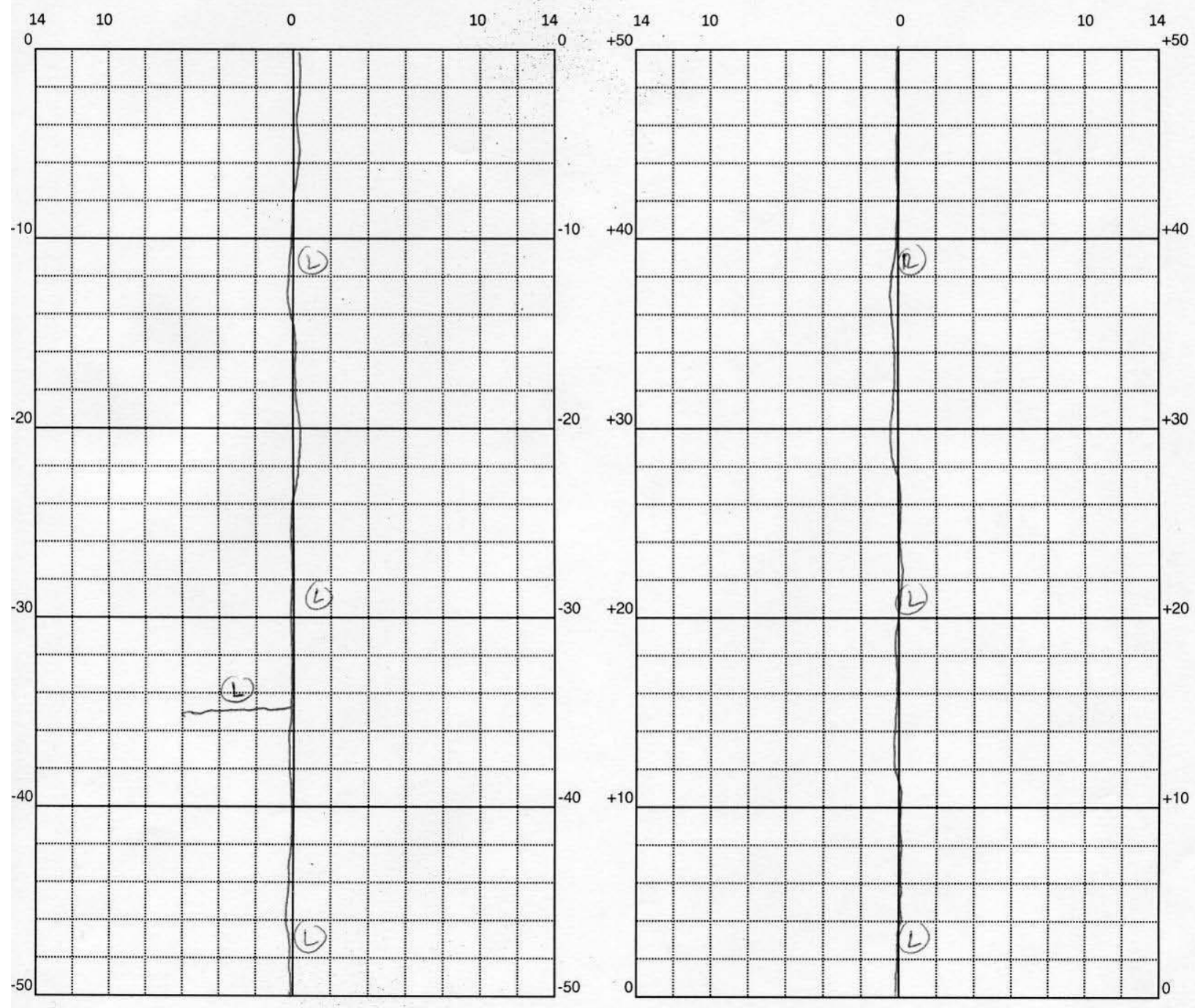

Comments:

Figure B.5 Nine-month distress survey of station 5 . 
Project - Wyoming (Post-Const)

Surveyor - Bryan Wilson

Test - Distress Survey

Date - May 14, 2010

\begin{tabular}{|c|c|c|}
\hline Station & Summary & Surface Temp: \\
\hline 6 & Long NWP $=35 \mathrm{ft} L, 65 \mathrm{~A} \mathrm{M}$ & \\
\hline
\end{tabular}

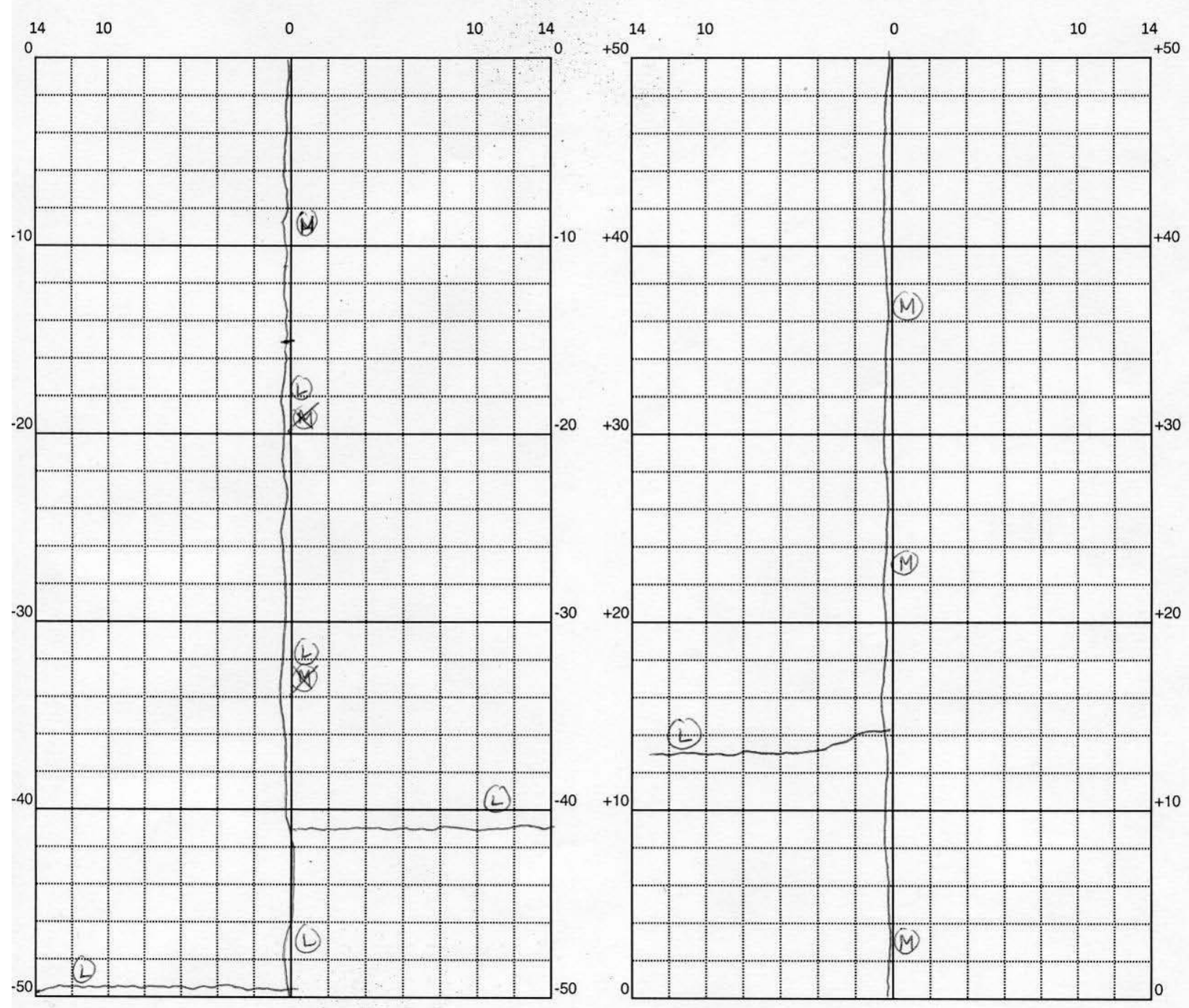

Comments:

Figure B.6 Nine-month distress survey of station 6. 
Project - Wyoming (Post-Const)

Surveyor - Bryan Wilson

Test - Distress Survey

Date - May 14, 2010

\begin{tabular}{|c|c|c|c|}
\hline Station & \multirow[t]{2}{*}{ Summary } & Surface Temp: & $52 F$ \\
\hline & & $\begin{array}{l}\text { Trans: } 4 \mathrm{ft} L(1) \\
\text { Lony NWP: } 117 \mathrm{~L}, 15 \mathrm{ft} M \\
\text { chip Seal Joint: } 5^{\prime} \times 1^{\prime \prime}, 25^{\prime} \times 1^{\prime \prime}, 11^{\prime} \times 1^{\prime \prime} 2^{\prime \prime}, 5^{\prime} \times 2^{\prime \prime}, 7^{\prime} \times 3^{\prime \prime}, 15^{\prime \prime} \times 4^{\prime \prime}\end{array}$ & \\
\hline
\end{tabular}
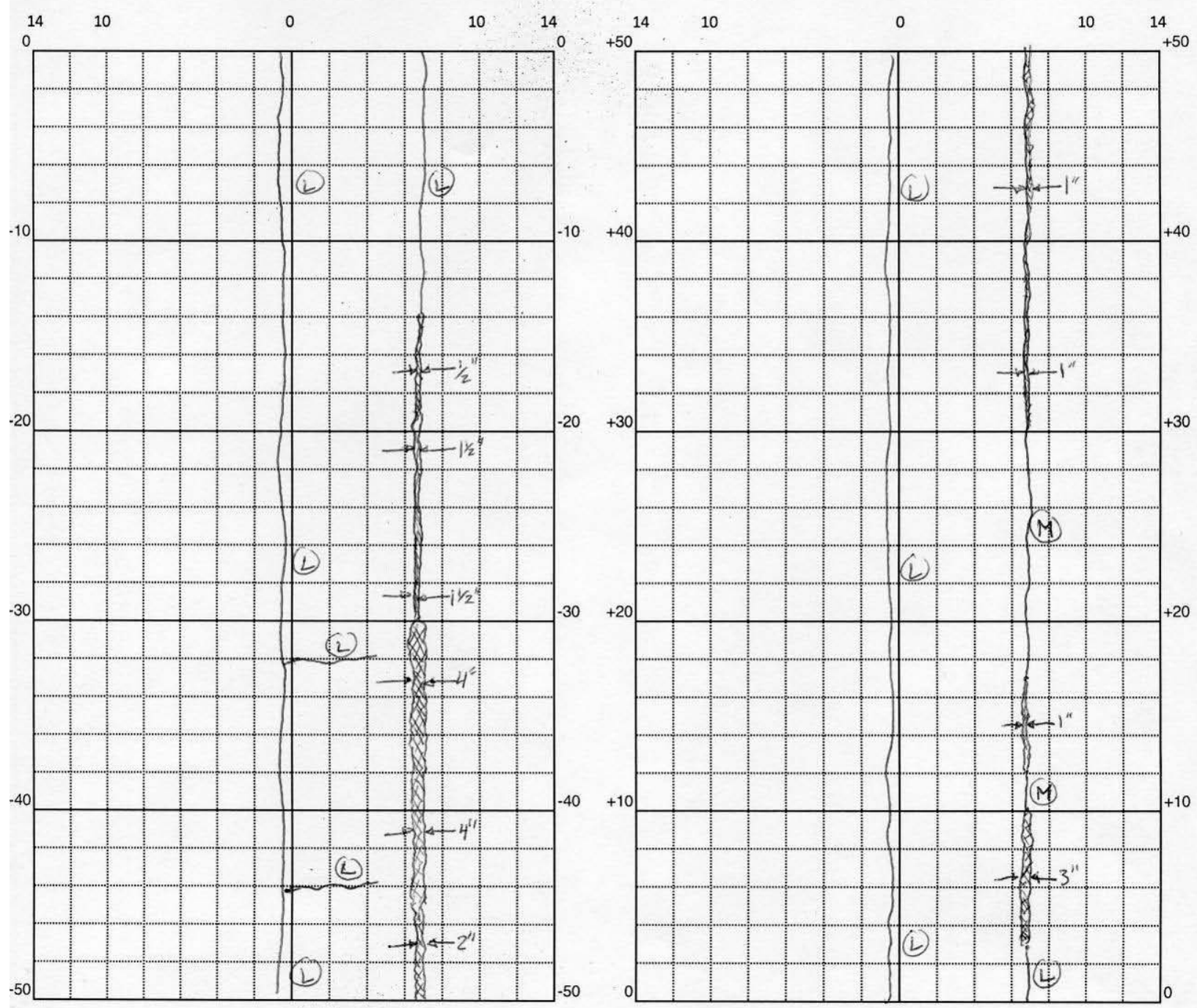

Comments:

Figure B.7 Nine-month distress survey of station 7 . 


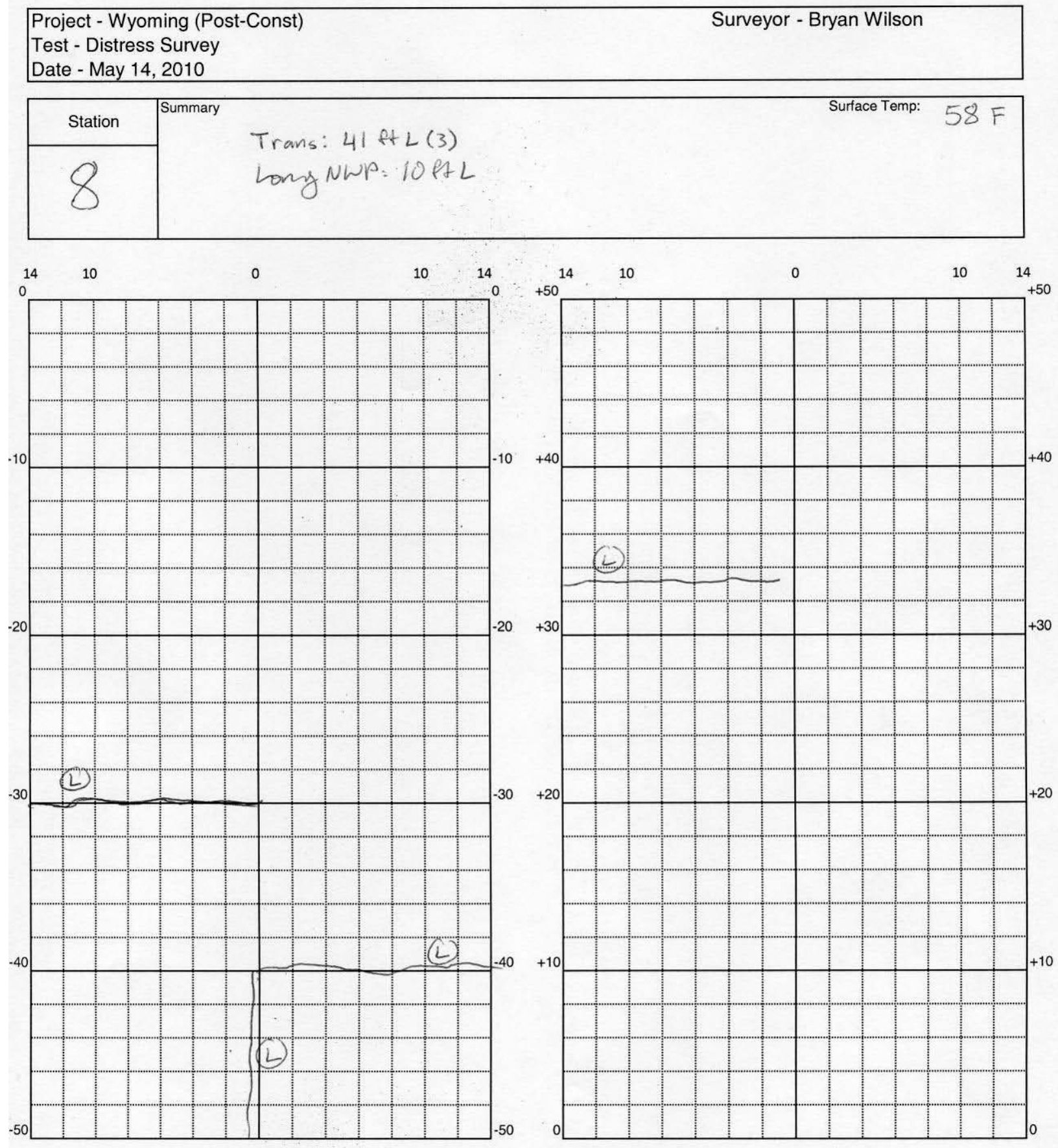

Comments:

Figure B.8 Nine-month distress survey of station 8. 
Project - Wyoming (Post-Const)

Surveyor - Bryan Wilson

Test - Distress Survey

Date - May 13, 2010

\begin{tabular}{|c|c|}
\hline Station & Summary \\
\cline { 1 - 2 } & Trans: $76 \mathrm{ft} L(5)$ \\
& Lony NWP: $100 \mathrm{Pt} \mathrm{L}$ \\
\hline
\end{tabular}
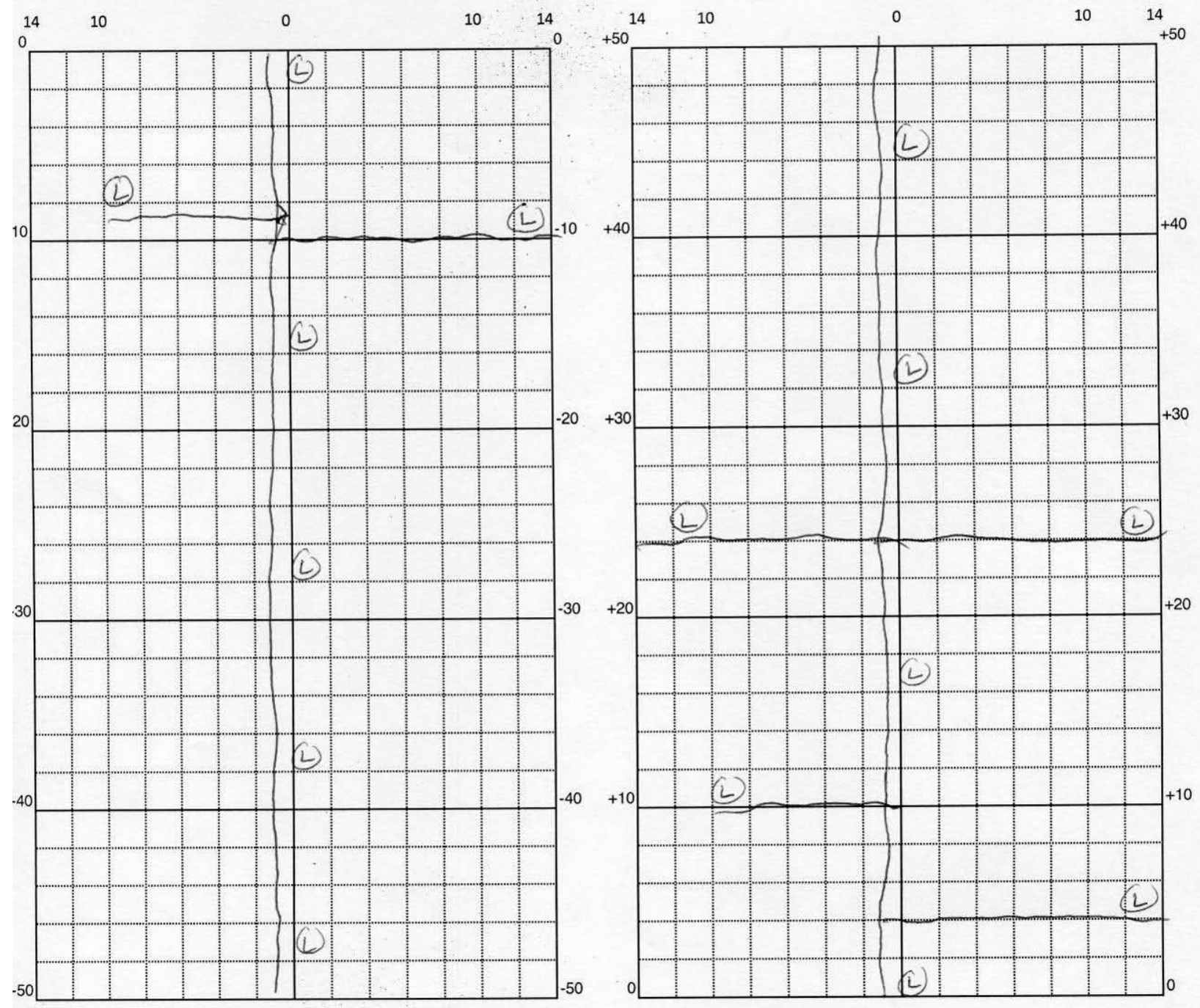

Comments:

Figure B.9 Nine-month distress survey of station 9. 
Project - Wyoming (Post-Const)

Surveyor - Bryan Wilson

Test - Distress Survey

Date - May 13, 2010

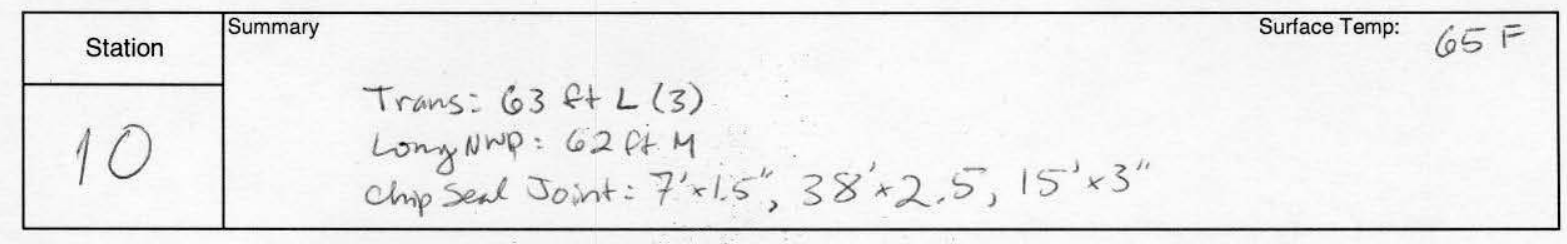
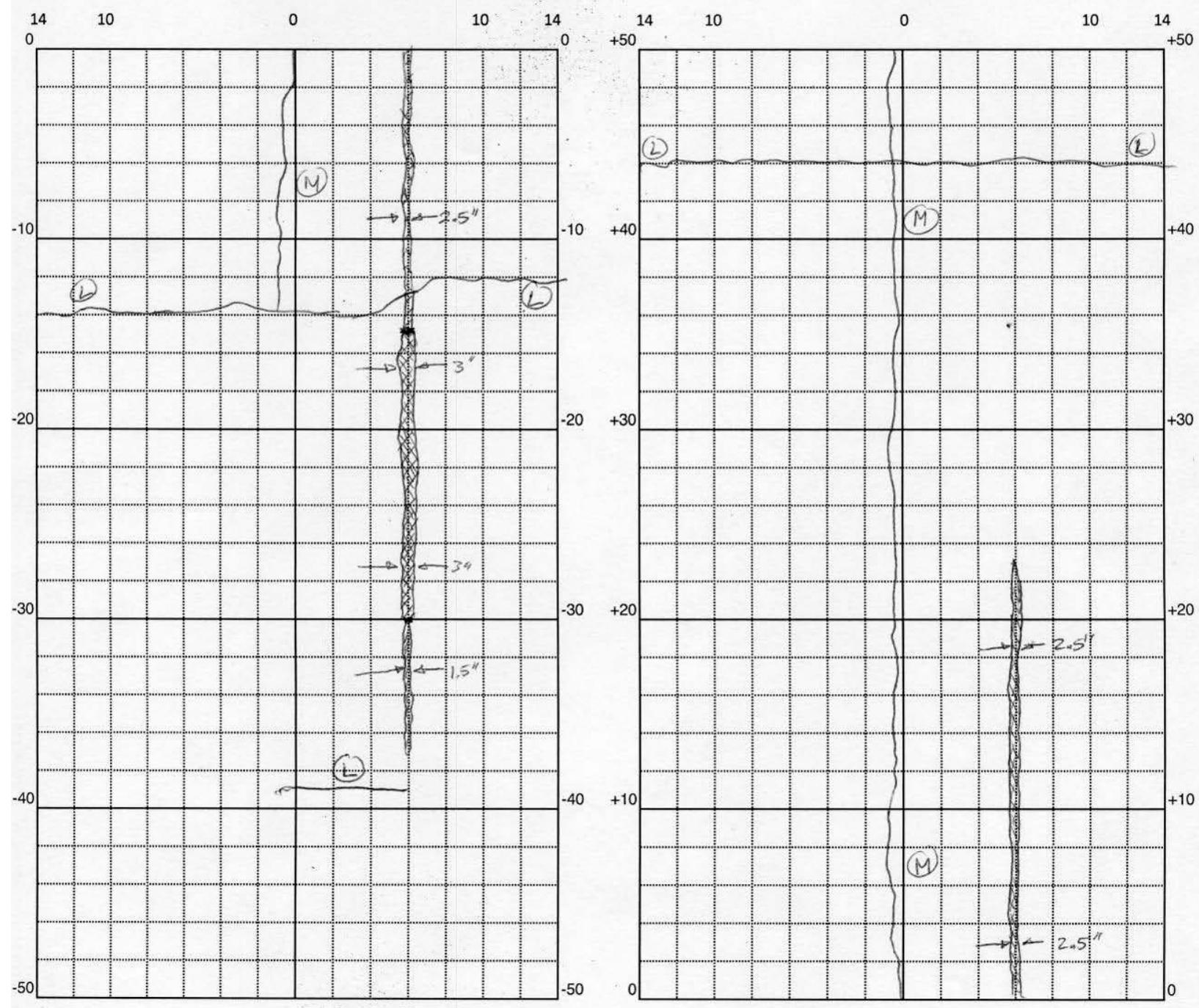

Comments:

Figure B.10 Nine-month distress survey of station 10. 
Project - Wyoming (Post-Const)

Surveyor - Bryan Wilson

Test - Distress Survey

Date - May 13, 2010

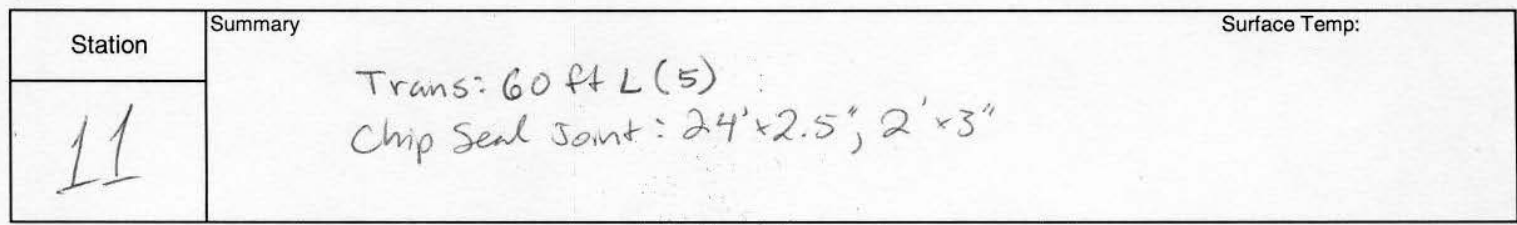
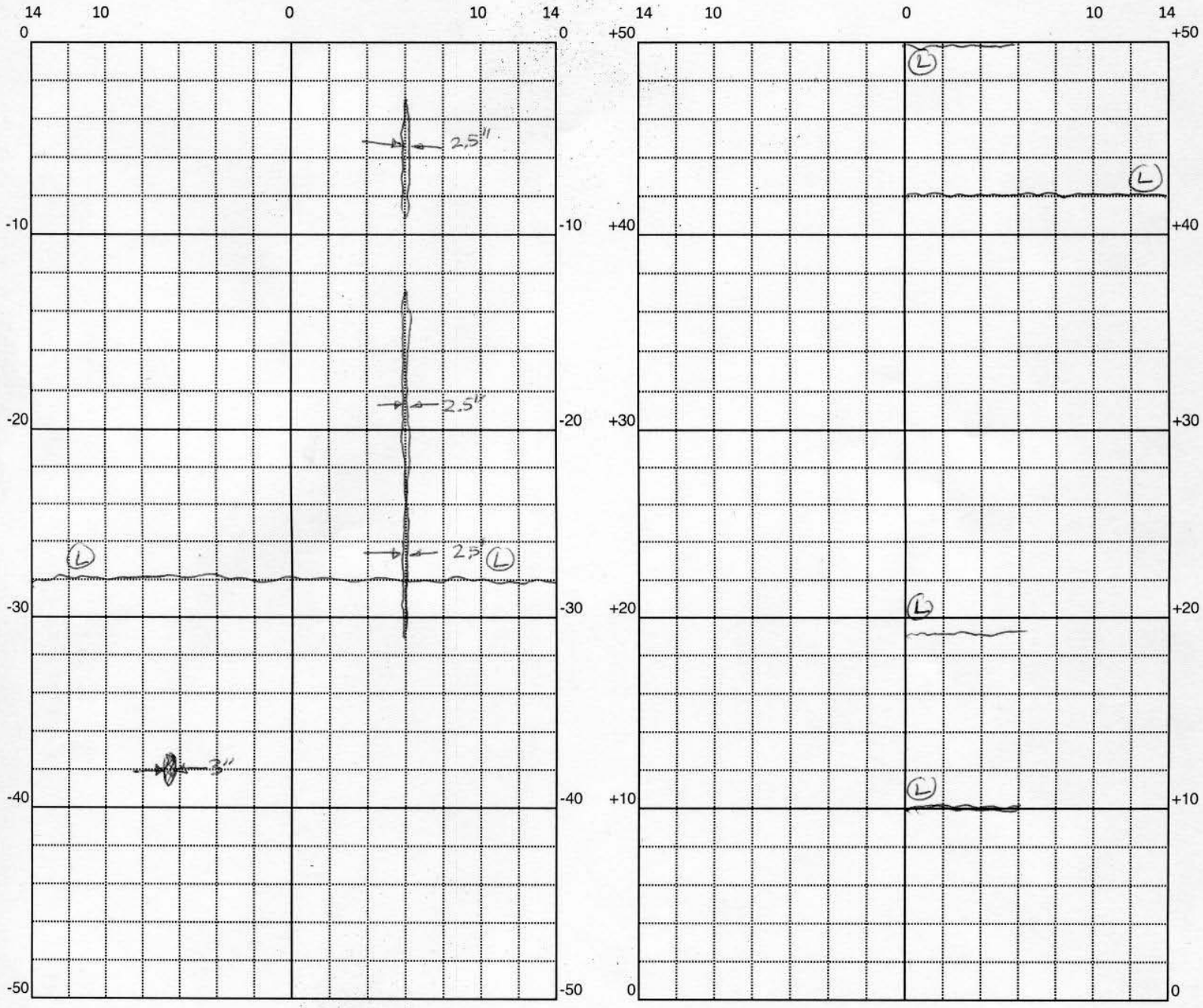

Comments:

Figure B.11 Nine-month distress survey of station 11. 
Project - Wyoming (Post-Const)

Surveyor - Bryan Wilson

Test - Distress Survey

Date - May 13, 2010

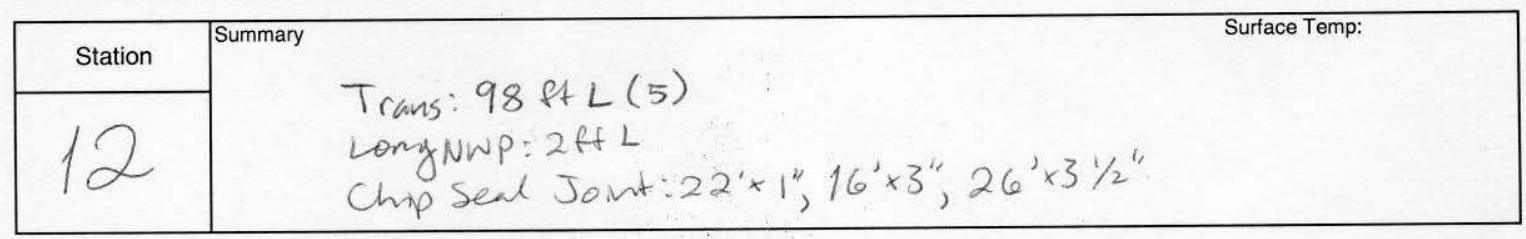
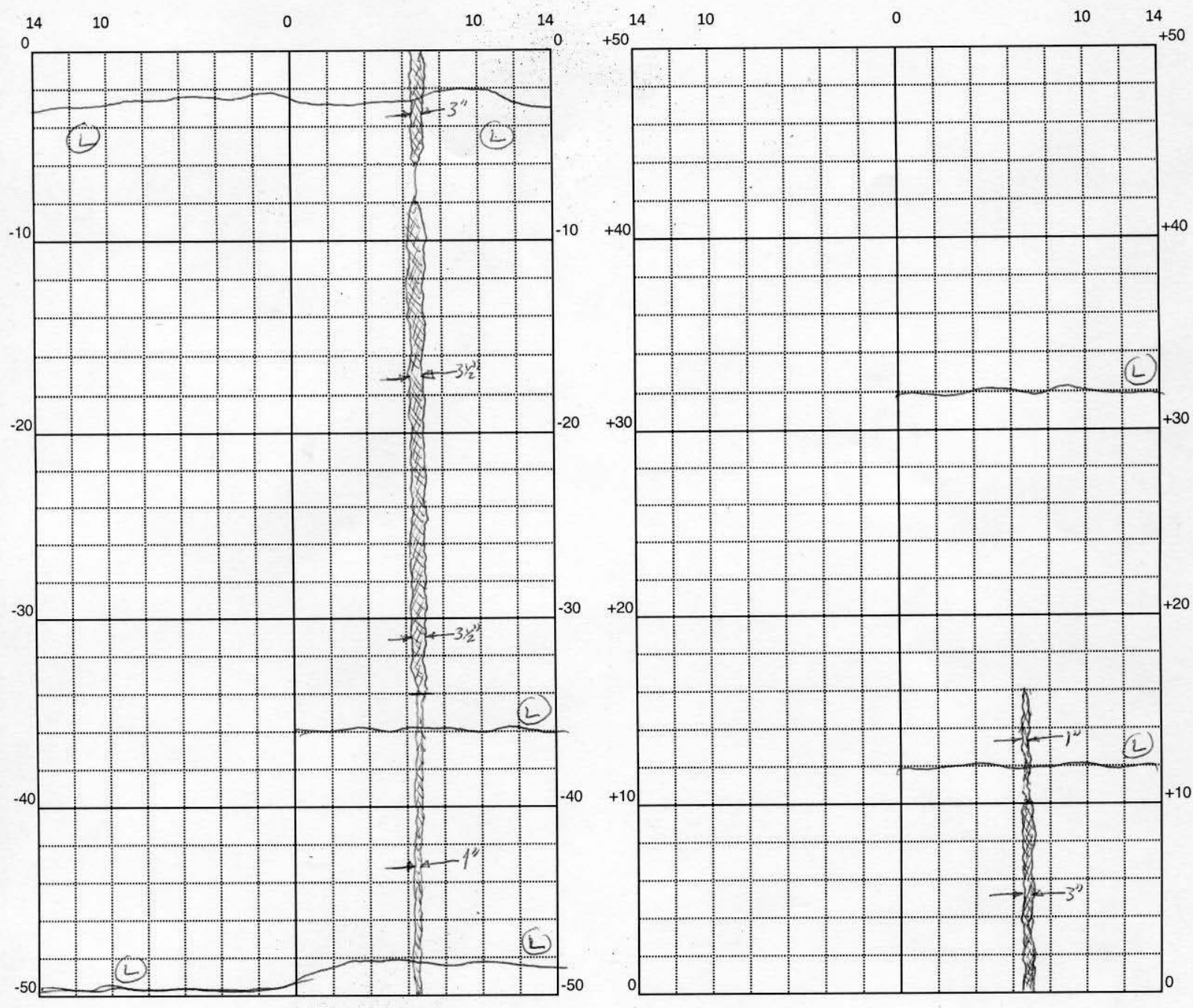

Comments:

Figure B.12 Nine-month distress survey of station 12. 


\begin{tabular}{|lc|}
\hline Project - Wyoming (Post-Const) & Surveyor - Bryan Wilson \\
Test - Distress Survey & \\
Date - May 13, 2010 & \\
\hline
\end{tabular}

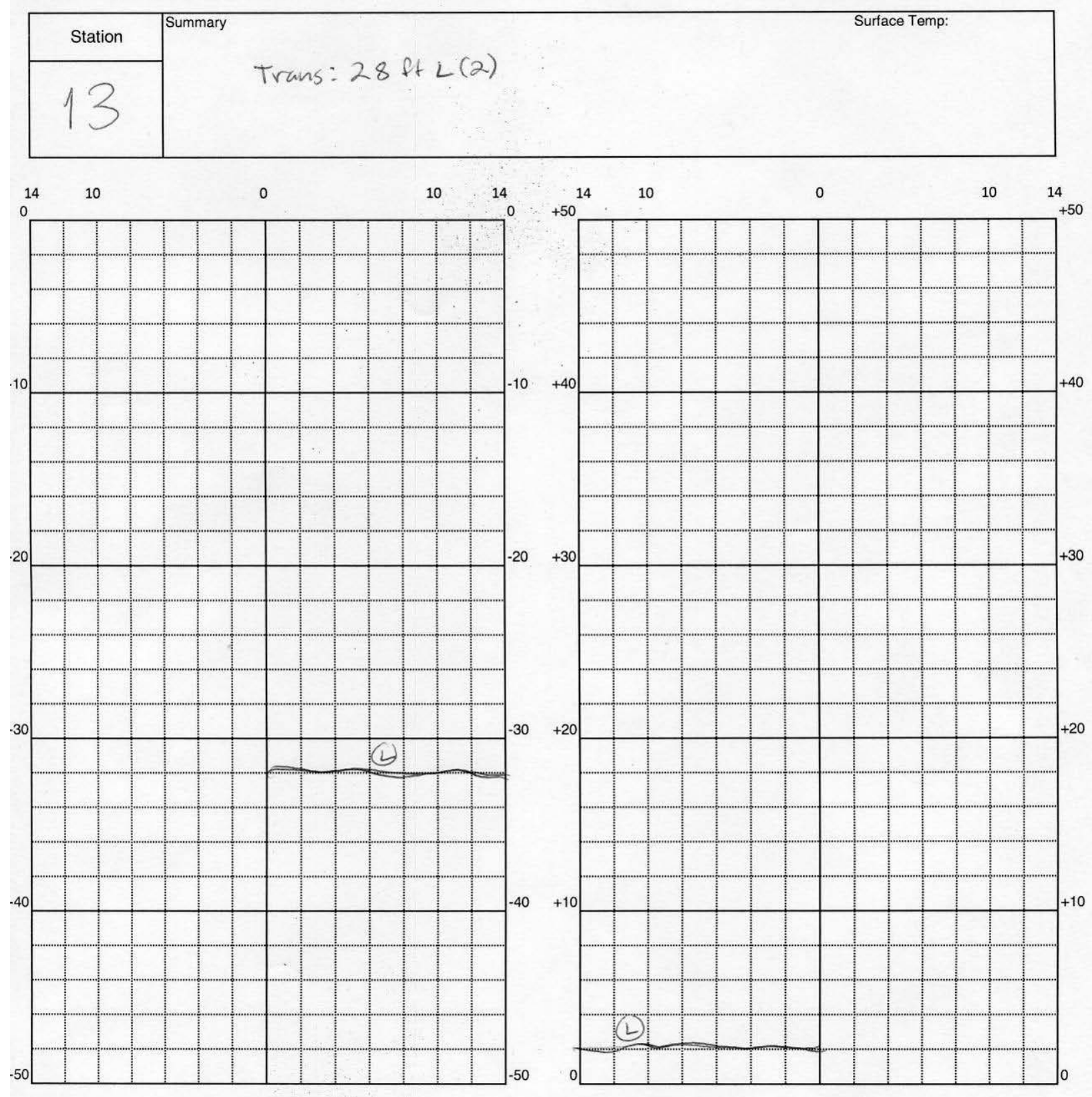

Comments:

Figure B.13 Nine-month distress survey of station 13. 


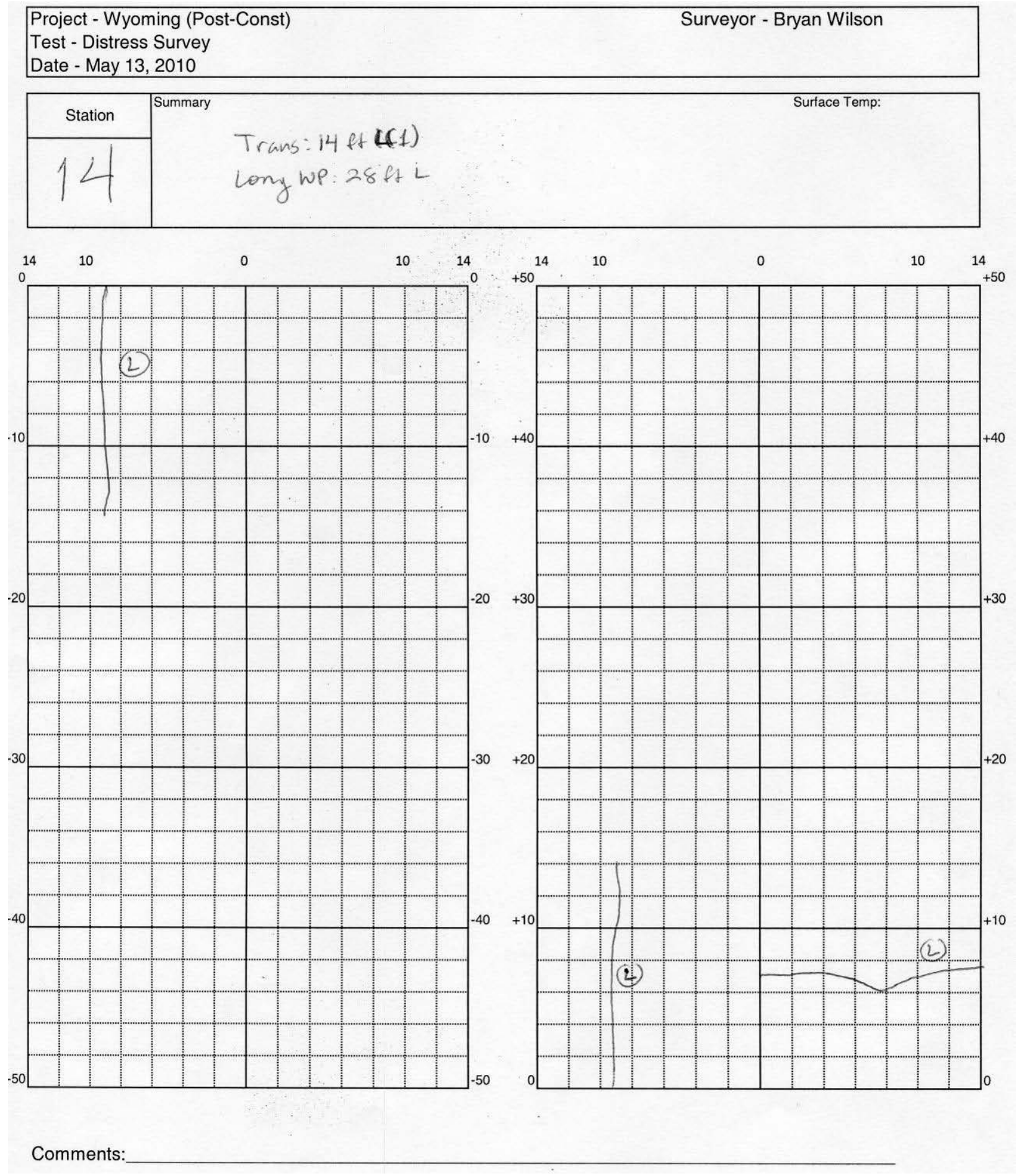

Figure B.14 Nine-month distress survey of station 14. 
Project - Wyoming (Post-Const)

Surveyor - Bryan Wilson

Test - Distress Survey

Date - May 13, 2010

\begin{tabular}{|c|l|l|}
\hline Station & Summary & Surface Temp: \\
\cline { 1 - 2 } 15 & Trans: $17 \mathrm{ft} L(1)$ \\
& Lony NWP: $100 \mathrm{ft} L$ \\
& Lony WP: $32 \mathrm{PA} L$ \\
\hline
\end{tabular}

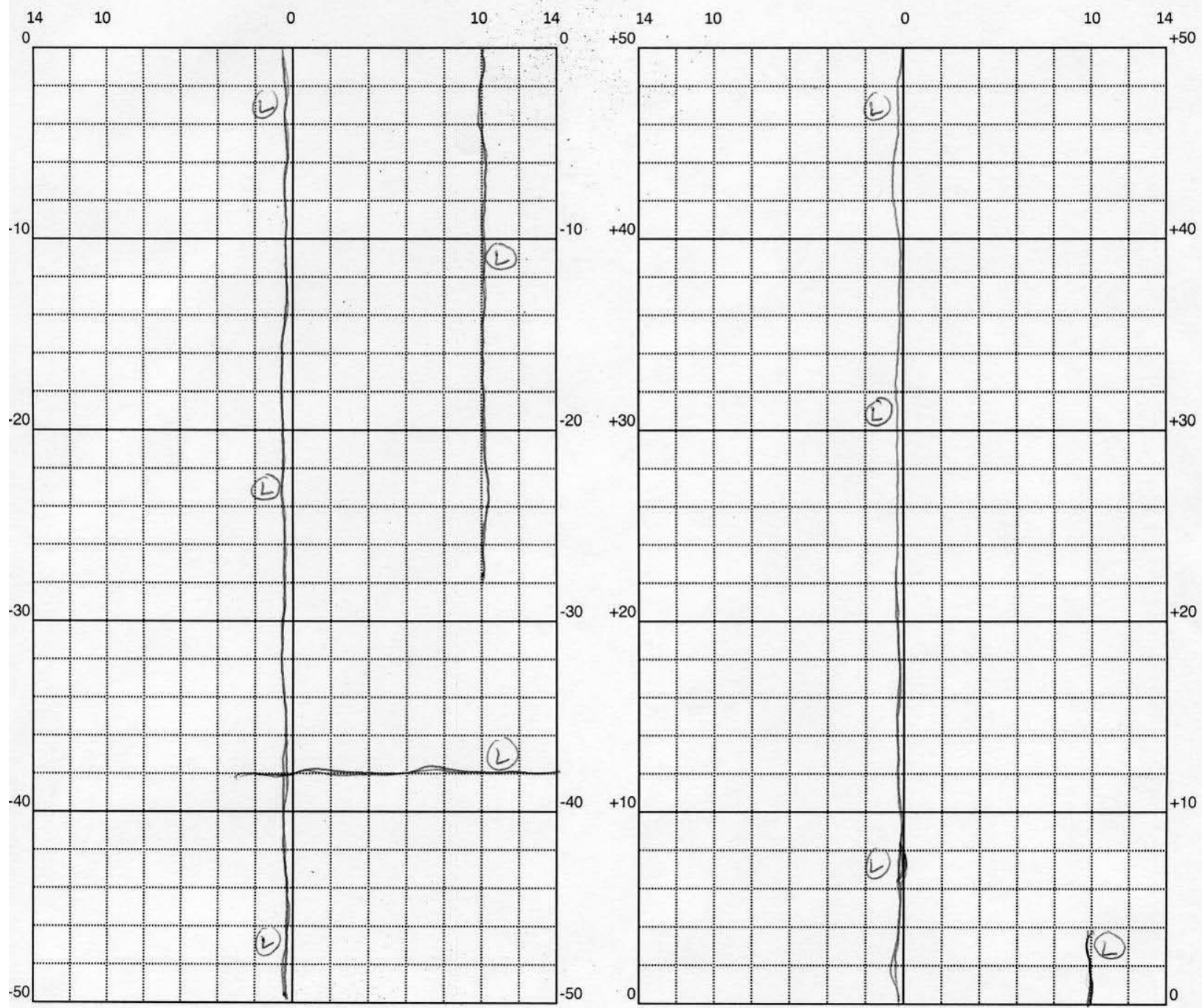

Comments:

Figure B.15 Nine-month distress survey of station 15. 